\title{
Regression Analysis of Fracture Toughness for Secondary Osteons Located In Human Cortical Bone
}

\author{
A Thesis \\ Presented to \\ The Faculty of California Polytechnic State University, \\ San Luis Obispo
}

\author{
In Partial Fulfillment \\ Of the Requirements for the Degree \\ Master of Science in Biomedical Engineering
}

By

Chase Alexander Fetzer

September 2009 
(C)2009

Chase Alexander Fetzer

ALL RIGHTS RESERVED 


\section{COMMITTEE MEMBERSHIP}

TITLE: $\quad$ Regression Analysis of Fracture Toughness for Secondary Osteons Located In Human Cortical Bone
AUTHOR:
Chase Alexander Fetzer

DATE SUBMITTED: $\quad$ September 2009

COMMITTEE CHAIR: Dr. Lanny Griffin

COMMITTEE MEMBER: Dr. Scott Hazelwood

COMMITTEE MEMBER: Dr. Daniel Walsh 


\author{
ABSTRACT \\ Regression Analysis of Fracture Toughness for Secondary Osteons Located \\ In Human Cortical Bone
}

Chase Alexander Fetzer

An experiment was carried out in order to locate and quantify osteon types within a sample of cortical bone taken from a human tibia. This was done using a microscopecamera assembly and the BioQuant computer software. The results of this were correlated with a previous experiment's results on fracture toughness so that an analysis could be run on the data in order to determine the factors that most affect the value of fracture toughness of this cortical bone. Results were examined closely and the analysis repeated until the author was satisfied that the best possible model for fracture toughness had been achieved. A combination of usable parameters included: region, porosity, volume fraction of lightfield osteons, volume fraction of hooped osteons, volume fraction of dark osteons, volume fraction of alternating osteons, volume fraction total, density, average diameter total, average diameter of hooped osteons, average diameter of lightfield osteons, average diameter of darkfield osteons and average diameter of alternating osteons. This model explains the parameters that most affect fracture toughness by using a regression analysis, which also provides a regression equation to show exactly how much each specific parameter affects the fracture toughness value. 
Keywords: Osteon, Fracture Toughness, Strain, Regression Analysis

\section{ACKNOWLEDGMENTS}

I would like to thank Dr. Lanny Griffin for supplying the necessary materials to conduct this study as well as support and guidance while completing the project and writing the thesis itself. 


\section{TABLE OF CONTENTS}

Page

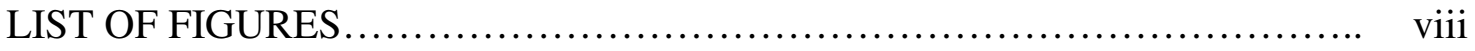

\section{CHAPTER}

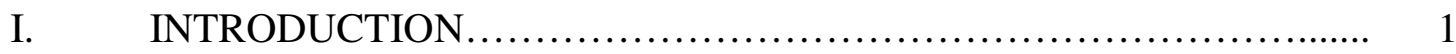

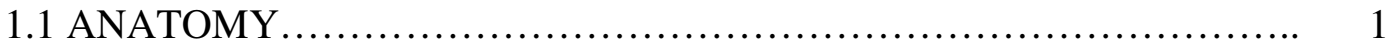

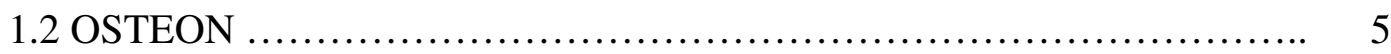

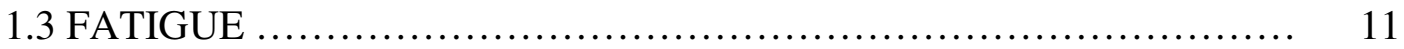

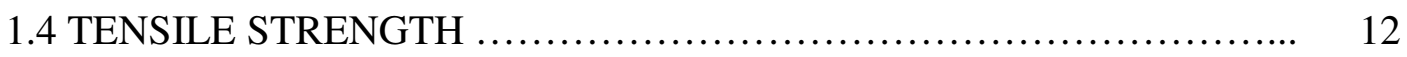

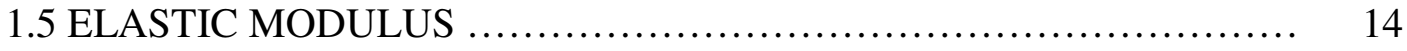

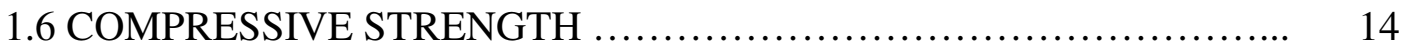

1.7 BENDING PROPERTIES .................................... 15

1.8 FRACTURE TOUGHNESS ....................................... 17

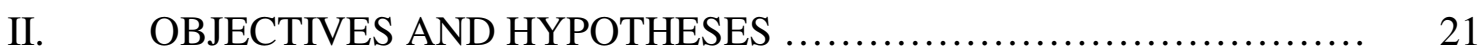

III. METHODS AND MATERIALS ............................... 22

3.1 BIOQUANT ................................................... 22

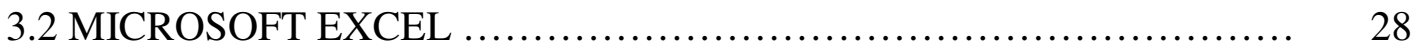

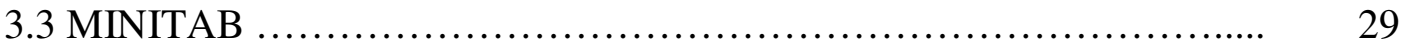

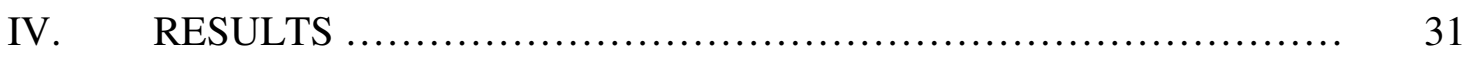

4.1 BIOQUANT / MICROSOFT EXCEL ............................. 31 
4.2 MINITAB ANALYSIS .......................................... 33

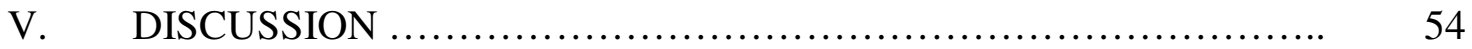

VI. LIMITATIONS ..................................................... 59

VII. CONCLUSIONS .................................................. 60

APPENDIX A. BIOQUANT DATA TABLES ............................... 61

APPENDIX B. CALCULATIONS ........................................ 88

LITERATURE CITED ................................................. 91 


\section{List of Figures}

Figure 1.1 Diagram of important features of both cortical and cancellous bone. (Page 3)

Figure 1.2 Diagram of the important exterior and interior features of a long bone. (Page 4)

Figure 1.3 Osteon types as categorized by Ascenzi and Bonucci in 1965. (Page 9)

Figure 1.4 Diagram of stages of hooped osteons as seen in equine metacarpi depicted by Martin et al. (1996) (Page 10)

Figure 3.1 Olympus (Tokyo, Japan) microscope used in accordance with polarized light, in order to determine osteons types within each bone chip. (Page 25)

Figure 3.2 View of the keyboard and monitor set-up with BioQuant open on screen. (Page 26)

Figure 3.3 Screen shot of BioQuant in mid-tracing of a topo. Notice how each osteon type has its own color scheme, as does porosity. (Page27)

Figure 4.1 Scatterplot of Porosity versus Density. This graph was generated in order to ensure that the two parameters were inversely related. It appears that they are in fact, inversely proportional, so our data is valid. (Page 35)

Figure 4.2 Chart of Mean for Volume Fraction Total versus Region. This is a depiction of how concentrated each area was with osteons of any type. (Page 36)

Figure 4.3 Chart of mean for Volume Fraction of Hooped Osteons versus Region. This shows the concentration of Hooped osteons in the posterior and anterior regions and the lack in the lateral and medial regions. (Page 37)

Figure 4.4 Chart of Mean for Volume Fraction of Dark osteons versus Region. This shows the concentration of Darkfield osteons in the anterior region of bone and the decreasing value as it reaches the posterior region. (Page 38)

Figure 4.5 Chart of mean for Volume Fraction of Light osteons versus Region. This shows the opposite trend than that of darkfield osteons. Concentration is highest in the posterior region and decreases back to the anterior region. (Page 39)

Figure 4.6 Chart of Mean for Volume Fraction of Alternating Osteons versus Region. The concentration of alternating osteons is fairly constant throughout all regions of bone. (Page 40)

Figure 4.7 Chart of Mean for Average Total Diameter versus Region. There is a fairly constant value for diameter throughout each region. Values range from 175 - 225 microns. (Page 42)

Figure 4.8 Chart of Mean for Average Diameter of Hooped Osteons versus Region. There is no apparent trend in regions; however hooped osteons are smaller on average then most other osteons. Values range from $115-137$ microns. (Page 43)

Figure 4.9 Chart of Mean for Average Diameter of Dark Osteons versus Region. There is no apparent trend from region to region; however dark osteons 
were on average of a larger size than hooped osteons. Values ranged from $200-240$ microns. (Page 44)

Figure 4.10 Chart of Mean for Diameter of Light Osteons versus Region. Lightfield osteons appeared to be largest in the posterior region, and smallest in the medial region. Values ranged from $190-275$ microns. Lightfield osteons reached the largest observed diameters of all the osteons measured.

(Page 45)

Figure 4.11 Chart of Mean for Average Diameter of Alternating Osteons versus Region. Alternating osteons were of a typical size with other osteons measured and had no apparent trends. Values ranged from $175-225$ microns.Region (Page 46)

Figure 4.12 Chart of Mean for Porosity versus Region. This chart shows the larger concentrations of porosity in the anterior and lateral regions. In the medial and finally the posterior regions, the porosity reaches its lows, implying that densities are highest in the posterior region. Values range from $9-23$ $\%$ porosity. (Page 47 )

Figure 4.13 Chart of Mean for Density versus Region. Generated in order to determine if certain regions are denser than others. This chart depicts that posterior region is densest and anterior and lateral regions are least dense. (Page 48)

Figure 4.14 Main Effects Plot for Fracture Toughness versus Region. The fracture toughness is highest in the anterior region, decreases through the lateral to the medial region, and then spikes back up in the posterior region. (Page 49)

Figure 4.15 Main Effects Plot for Porosity versus Region. Porosity is highest in the anterior region and decreases steadily through the lateral and medial region and is lowest in the posterior region. (Page 50) 


\section{Introduction}

\subsection{Anatomy}

Bone is the framework for most living creatures and is of the utmost importance within those living organisms. In order to fully understand the nature of bone, there are wide varieties of properties to consider: structural, mechanical, and biological to name a few. Focused on in this paper are the micromechanical properties of human cortical bone; and its underlying structures. In order to be able to calculate Volume Fracture Characterization, it is first necessary to discuss the anatomy and function of bone and bone tissue to understand where the data is derived from.

Bone is classed as a connective tissue, as it is composed of cells and their products which form an organic matrix that is then mineralized. Bone in general is denoted as either cortical or cancellous dependant on its form, density and porosity. (22) Compact/cortical bone has a density greater than $0.7 \mathrm{~kg} / \mathrm{m}^{3}$, where trabecular/cancellous bone is classified as having a density less than $0.7 \mathrm{~kg} / \mathrm{m}^{3}$.

While in principle the porosity of bone can vary continuously from zero to 100 per cent, in fact most bone tissues are of either very low or very high porosity, with little bone of intermediate porosity. Trabecular/cancellous bone is porous bone found in the cuboidal bone, the flat bones, and the ends of long bones; its porosity is $75 \%-95 \%$. Compact/cortical bone is the dense bone found in shafts of long bones and forming a cortex around vertebral bones and other spongy bones. Its porosity is 5\%-10\%. (24-26)

It is a very unique structure in regards to the fact that it can and is remodeling itself constantly. Remodeling produces secondary osteons and is the primary process of skeletal renewal and functional adaptation in mature bone. (16) 
There are three principal cell types within bone: osteoblasts, osteoclasts, and osteocytes. Osteoblasts secrete the organic matrix of collagen and other proteins, forming bone. Osteoclasts secrete acids to demineralise bone and enzymes to digest the organic matrix. Osteocytes are less active, but function more as a mechanosensor within the matrix. In compact bone, osteoclasts form a cutting cone which resorbs bone as it is passed through a specific area. Following behind those are osteoblasts which lay down new osteoid and close the opened space.(36) This process takes about 2-3 months to complete and can occur inside the bone tissue or on its surfaces. (24)

The team of osteoclasts and -blasts is known as a basic multicellular unit (BMU). The size of the osteoclast cutting cone determines the size of any osteon that is formed in its wake. (33) The osteoblast size has no effect on the size of an osteon, they determine only to what extent and how quickly the tunnel caused by an osteoclast will be filled in.

As seen in Figure 1.1, compact/cortical bone accounts for the majority of area and mass within any bone. Located within the cortical bone are three main spaces that account for its porosity. Haversian canals are approximately aligned to the long axis of the bone, contain capillaries and nerves, and are about 50 micrometeres in diameter. Volkmann's canals run transversely from Haversian canal to Haversian canal in order to connect them. They also run to the outer edge of bones and contain blood vessels and nerves. Resorption cavities are the temporary spaces created by osteoclasts in the initial stage of remodeling. Resorption cavities are about 200 micrometeres in diameter. (25) In any given transverse cut of cortical bone, there are an enormous amount of osteons viewable. Osteons, also referred to as haversian systems, are circumferentially lamellar cylinders oriented parallel to the long axis of the bone. Each osteon is made up of 
lamellae that are stacked, layer upon layer. Surrounding each osteon is a cement line interface, keeping each osteon separate from others. In humans, osteons range in diameter from 150 to 350 micrometers. (33)

\section{Compact Bone \& Spongy (Cancellous Bone)}

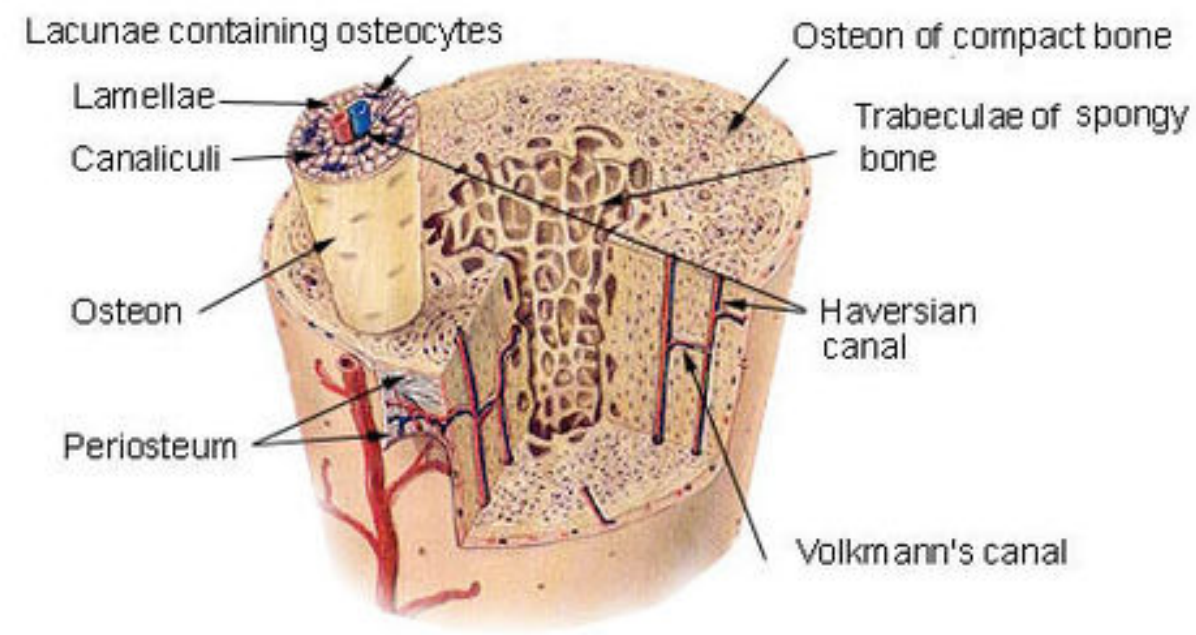

Figure 1.1 Diagram of important features of both cortical and cancellous bone.

The bone used in this study is a human tibia. As seen in Figure 1.2, the human tibia is a long bone consisting of both cortical and cancellous bone tissue. The epiphysis consists of mostly cancellous bone; conversely, the diaphysis is typically mostly cortical tissue. Cortical bone is where all the specimens for this study are taken from. Currey (1964) reported that the structure of cortical bone is similar to fiber reinforced composites, where osteons and interstitial bone serve as fibers and the matrix respectively. (18) 


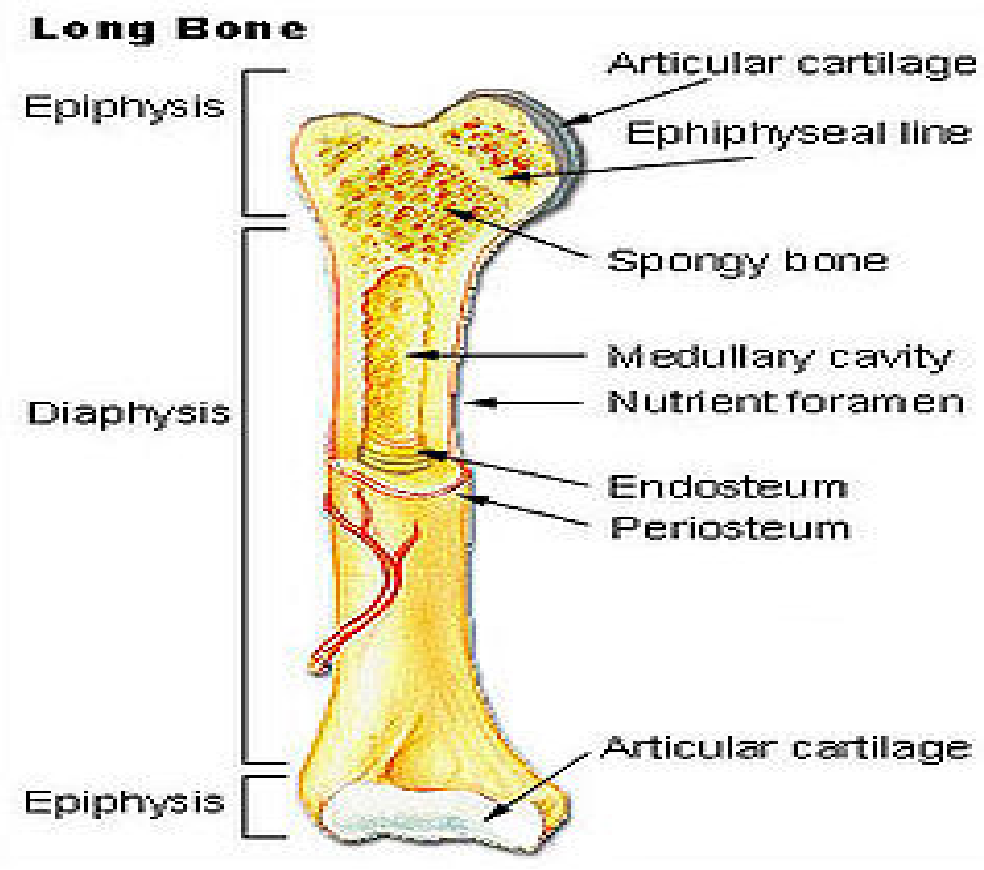

Figure 1.2 Diagram of the important exterior and interior features of a long bone.

According to Schaffler and Jepsen bone is a complex material microstructurally, comprised principally of the fibrous protein type 1 collagen embedded in a mineral matrix. The matrix consists of hydroxyapatite crystals around the size of 50 nanometers. Bone is most commonly formed in layers, or lamellae, in which collagen fiber orientation in each successive layer appears to be at 90 degrees to the previous layer, making bone into a cross-ply laminate like plywood. Each of the layers is approximately 2-5 micrometers in width. In long bones, such as the one used in this study, the tissue is made of large sheets of lamellar bone organized in concentric rings around the entire bone, like tree rings. Lamellar bone can also be organized into smaller tubes of concentric layers of bone, known as osteons or Haversian systems. $(22,37)$ 


\subsection{Osteon}

For the purpose of this study, the focus is not on bones as a whole, but more on the smaller structures present in human cortical bone, i.e. osteons. When each human is born, their cortical bone contains only primary osteons. As these osteons within the bone are subjected to stresses and strains, they are remodeled into what is called secondary osteons (hereafter referred to simply as osteons.)

The lamellar structure of secondary osteons has been an open question for years. The osteon is composed of a central Haversian canal hosting a blood vessel and is surrounded by alternating mineralized collagen lamellae. Although the osteon has been the focus of numerous studies over decades, the detailed anatomy of osteonic lamellae is still a matter of dispute. (21) One thing we can be certain of is that secondary osteons are separated from the rest of the matrix by a cement line. This cement line is a stiff substance, which gives it some vulnerability. As is discussed later in this report, microcracks present in bone typically propagate throughout the cement line, commonly avoiding penetrating osteons themselves. $(30,32,38)$

Prendergast and Huiskes (1996) reported that within osteonal cortical bone, lamellar layers create secondary osteons by surrounding the Haversian canal cylindrically. An incoherent tissue known as interstitial bone fill the space between the osteons. An osteon consists of 10-30 concentric lamellae, each having a thickness of 3-7 microns, surrounding the Haversian canal whose diameter is $30-50$ microns. There is a thin amorphous interface between osteon and interstitial bone, known as the cement line, whose material properties are yet to be fully established. (34) 
Ascenzi et al. (2002) suggested that there are two main theories of lamellar structure, both specifically focused on the so-called alternate osteon. One attributes the differences between the two lamellar types to the orientation of the main elementary components of bone tissue: collagen fibrils and carbonated apatite crystallites. (10) Giraud-Guille (1906) had a theory in conjunction with this belief. He suggested that the differences observed in successive lamellae by polarizing light examination were due to a change in orientation of bundles with a spiral arrangement alternately clockwise and counterclockwise, varying from 0 to 90 degrees within each osteonal axis. $(19,20)$

In contrast to this first theory, there is another idea presented by Marotti (1996) that attributes the lamellar differences in alternate osteons as dependent on the relative densities of the elementary components. That is, the composition of successive lamellae is supposed to alternate mainly between relative predominance of collagen and cementing substance. (23)

Ziv et al. (1996) suggested that adjacent lamellae have roughly the same structure, but their layers are aligned in different orientations with transitional regions between the neighboring lamellae in which the orientation of the collagen and its associated mineral changes rapidly but smoothly over a few microns. (41)

Each osteon is in some stage of calcification. This can be determined by the amount of apatite present in each osteon. The more apatite present in the osteon, the tougher it is. However, the more apatite the osteon contains, the more brittle it becomes. Osteons containing the least amount of apatite are those at the initial stage of calcification; and those having the maximum amount of apatite are sometimes referred to as "fully calcified osteons." This latter statement is not completely true however; 
interosteonic lamellae are the only kind of bone which can properly be considered fully calcified. (8)

When osteons are viewed under polarized light, different orientations of fiber bundles are apparent. These types have been investigated and studied by many scientists and engineers in the past. We are able to look at lamellar bone under a polarizing microscope because of a phenomenon known as birefringence, defined as the capacity of some fibrous structures to interact with polarized light. When a section of bone is transilluminated with polarized light and viewed through a polarizing filter oriented perpendicular to the vibration plane of this incident light, the section appears dark, expect where collagen fibers are parallel to the plan of the section. These collagen fibers rotate the light's plane of polarization so it is no longer perpendicular to the viewing polarizing filter. Therefore, the light is not blocked and reaches the viewer's eyes. Thus, in a bone section observed in a polarizing microscope, transversely oriented fibers are bright and longitudinally oriented fibers are dark. (26) It seems noteworthy to mention that a thickness of 500 microns is a critical limit, because beyond it the bone section is no longer sufficiently transparent for examination under the polarizing microscope. (Bone transparency can be increased to some extent by soaking the section in bromoform. (3-8)

Among the earliest to investigate the identifying and cataloging of osteons were Ascenzi and Bonucci $(1965,1964)$ who discovered and classed three distinct types using a polarizing microscope and the theory of birefringence. In the first type, the fibers had a marked longitudinal spiral course with the pitch of the spiral changing so slightly that the angle of the fibers in one lamella was practically the same as that of the fibers of the next lamella. Under polarized light, osteons of this type appeared uniformly bright, hence 
why they are termed as "bright-field osteons". In the second type, the fibers in one lamella formed an angle of nearly 90 degrees with the fibers of the next one (fibers ran alternately). Under polarized light these osteons revealed an alternating pattern of dark and bright lamellae, and were therefore called alternating osteons. In the third and final type noted by Ascenzi and Bonucci, the fibers have a marked longitudinal spiral course with the pitch of the spiral changing so slightly that the angle of the fibers in one lamella was practically the same as that of the fibers of the next. Under the polarizing microscope the osteons belonging to this type appear homogeneously dark in cross section, although frequently they are bordered by a bright lamella. These three types as designated by Ascenzi and Bonucci are seen in Figure 1.3.

Ascenzi and Bonucci were not the only ones to type osteons based on polarized orientation however; Martin et al. (1996) and later Skedros et al. (2008) typed osteons in a horse's metacarpus into six distinct categories. They are as follows: M5 - category O osteon with dark interior and strongly birefringent peripheral lamellae; M4 - category OI, similar to $\mathrm{O}$ but the birefringent ring is incomplete; M3 - category OW, similar to O but the birefringent ring is weak; 2 - category OWI, a combination of OI and OW; 1 category $\mathrm{D}$, birefringent lamellae are distributed throughout the wall of the osteon; 0 category $\mathrm{N}$, a dark osteon with no birefringent lamellae. The images of these classifications can be seen in Figure 4. The purpose of this typing scheme is to take into account a separate type of osteon that is predominant in bone of horses and other animals: the hooped osteon. Hooped osteons are not as prevalent in the bone of humans, although they are present. Hooped osteons appear dark with a "hoop" of bright lamellae around the outside. As is seen in Figure 1.4, osteon types are not always "cut and dry" so to 
speak. $(26,39)$ Very rarely, when examining a histological sample of bone, does an osteon appear clearly as one type. Commonly you must denote the osteon type that the sample most resembles. Examples will be discussed later in "Methods and Materials" as well as in "Results".
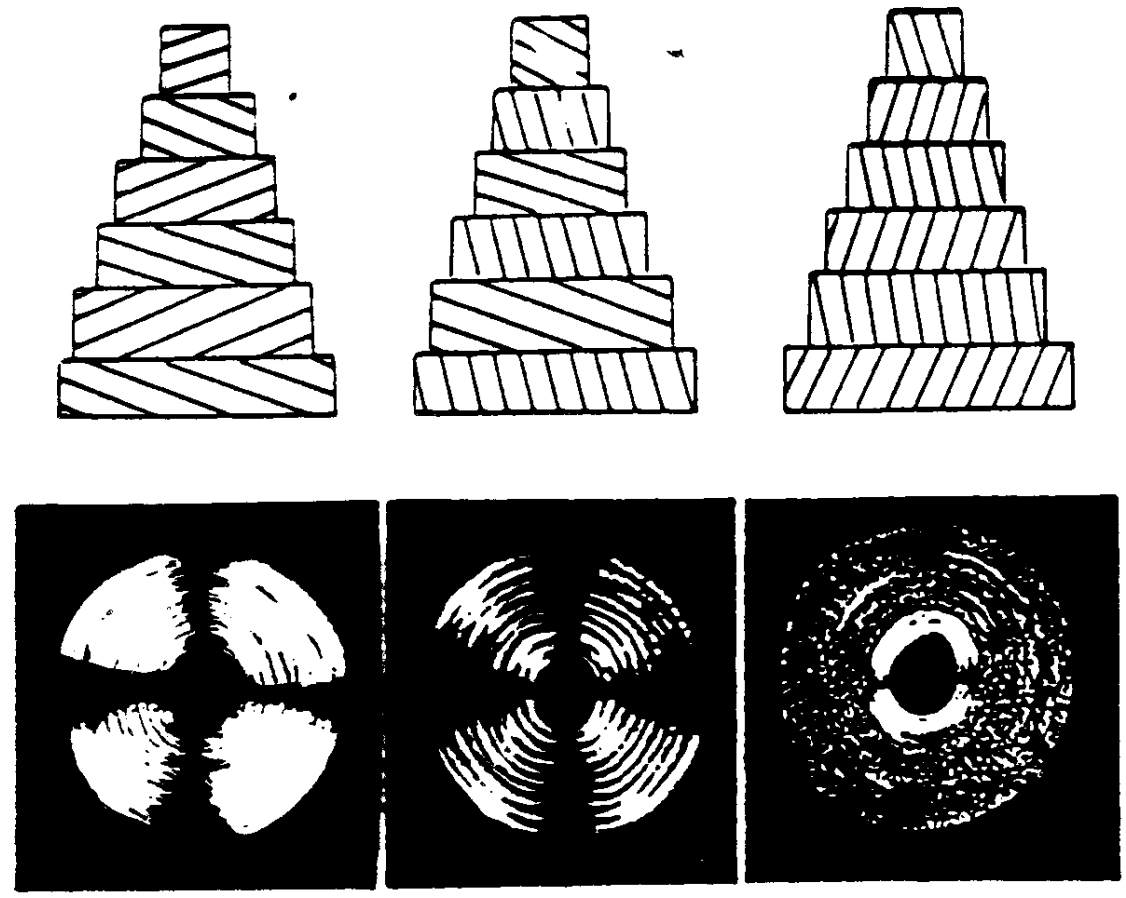

a

b

C

Figure 1.3 Osteon types as categorized by Ascenzi and Bonucci in 1965.

Not all studies performed have been only to type and identify osteon orientations; there have been countless studies over the last 50 years to determine and investigate separate properties of osteonal bone, such as tensile strength, compressive strength, elastic modulus, shear stress, fatigue and properties of microcrack propagation. The mechanical properties of osteonal bone are affected by a number of factors, including 
age, porosity, mineralization, sex, collagen fiber orientation, rate of resorption and remodeling. These properties of bone will each be discussed briefly in the following sections.
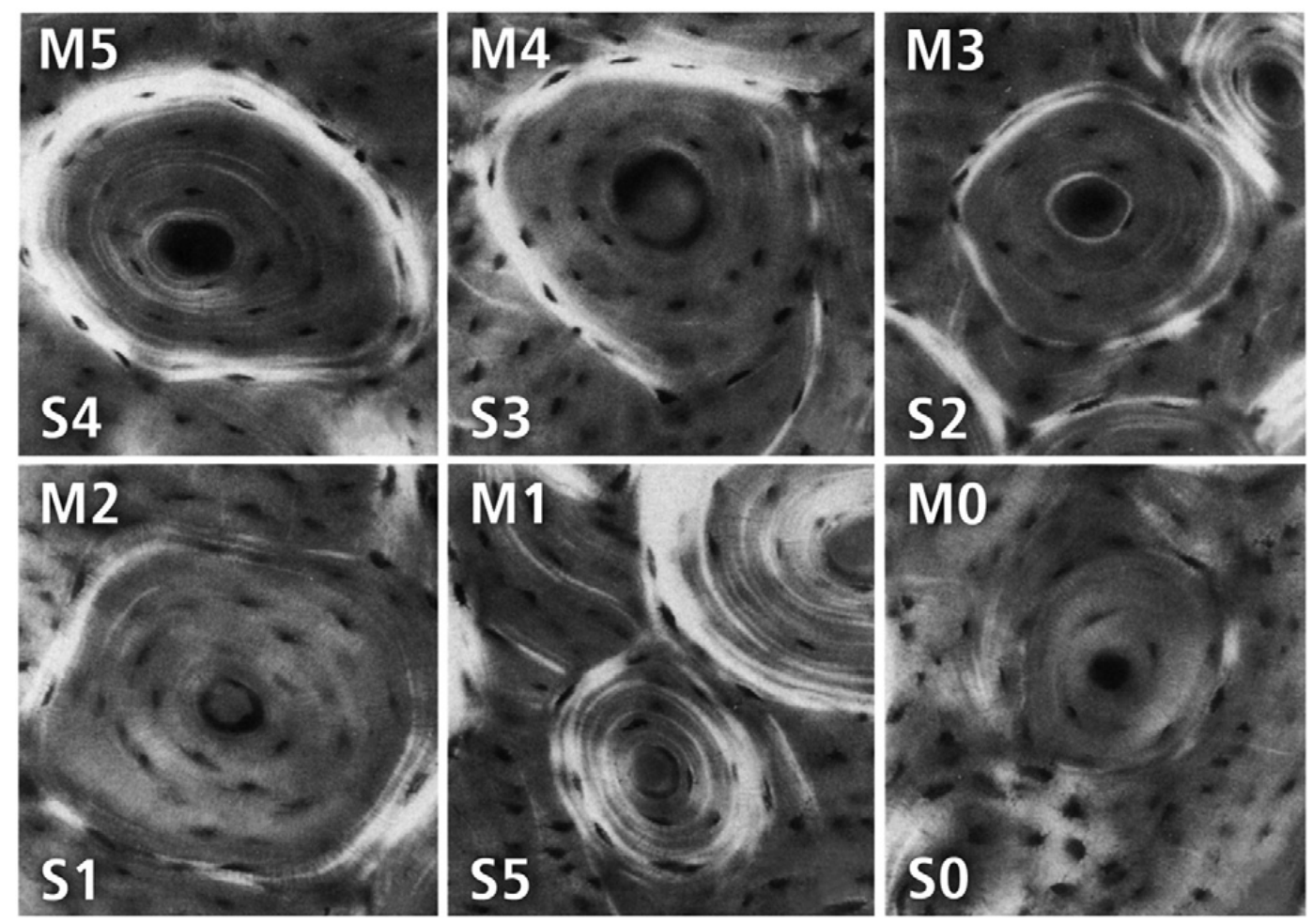

Figure 1.4 Diagram of stages of hooped osteons as seen in equine metacarpi depicted by Martin et al. (1996)

Before entering into the mechanical properties of osteons, it is worth mentioning that a study was performed by A. Ascenzi and A Benvenuti (1977) providing evidence that osteonic lamellae is in a state of initial stress and strain. A study was carried out by the aforementioned investigators to isolate and dissect osteons in order to determine if details on this initial stress could be noted. They discovered that when approximately cylindrical samples are set free in saline solution, they show a tendency to twist. This 
effect is magnified in lamellae whose diameters are largest with respect to height. All of their data indicated that a lamellar sample whose fiber bundles and crystallites are transversally oriented is a structure which reveals a state of initial stress when it is isolated from an osteon. (4)

Not only is the structure important when dealing with osteonal bone, but mechanical properties of such is crucial in understanding the tissue and its properties. Mechanical properties of bone are determined by a multiplicity of material and structural properties such as tissue mineralization, collagen cross links, size and composition of mineral crystals, anisotropy, heterogeneity, and micro-architectural features. (21)

\subsection{Fatigue}

Cyclic loading of bone, as in all materials, leads to failure incrementally through a process known as fatigue. In bone, this incremental failure process corresponds to the accumulation of microstructural level failures or microdamage. Mechanically, the accumulation of microdamage is correlated to loss of material stiffness, or modulus reduction. At a normal strain magnitude the fatigue life to failure for compact bone is extremely long - in the order of $10^{7}$ load cycles which corresponds to approximately 5 10 years of use in life. However significant amounts of fatigue damage occur throughout the loading history; damage which must be repaired in order not to lead to fatigue failure of skeletal elements. Types of fatigue include: elastic deformation, where the bone is strained but returns to its original form, and plastic deformation where the applied load causes the material to yield resulting in permanent deformation or damage. (22) Fatigue damage itself is directly responsible for bone remodeling; damage caused by repetitive 
stresses stimulates bone adaptation. Thus, fatigue damage has both mechanical and biological consequences. (37)

An example of a typical fatigue test performed on bone was carried out by Boyce et al. (1998). In order to determine how stress type influences fatigue damage in bone, they used the non-uniform strain field produced by four-point bending fatigue tests of human compact bone samples. The samples were cyclically loaded to a single level of stiffness degradation and then they measured microdamage type in each principal stress region. In tension, compression and along the neutral axis all resulted in different types of fatigue damage. It is necessary to observe the nature of fatigue damage in bone so that it may be studied further and assessed in the future. (15)

\subsection{Tensile Strength}

Like all mechanical properties of bone, numerous studies have been performed on the tensile strength of osteonal bone. Before discussing the actual tests performed to determine tensile strength, it is worth explaining a device that was used by multiple groups in order to dissect individual osteons from a histologic sample of bone. It was designed by Ascenzi and Bonucci in 1965; it is called a Mannesman drill. The specially designed device consisted of a very thin and accurately sharpened steel needle eccentrically inserted on a dentist's drill. When the drill was turning, the tip of the needle described a circle having a diameter of about $180-200$ microns which is the average diameter of an osteon. If the rotating axis of the needle coincided with the axis of an osteon and this osteon was perpendicularly oriented with respect to the surfaces of a bone 
section, the tip of the needle itself cut just inside its limits (an osteon sample has the shape of a cylinder with walls of uniform thickness). (8)

Results from all tests that involve isolated osteons with a marked longitudinal arrangement of fiber bundles in successive lamellae show that the tensile curve approximates a straight line. These results have been reported by many noted investigators such as Wertheim (1847), Marique (1945), and Evans and Lebow (1951).

An interesting point to make is the difference in most mechanical properties when samples are wet as opposed to dry. For example, Ascenzi and Bonucci (1965) reported that the influence of moisture on the tensile properties of osteons is indicated by the difference in the shape of the stress-strain curves from wet and dry samples. In wet samples having a marked longitudinal arrangement of the fiber bundles in successive lamellae, the curve shows an elastic range like that of the dry osteon. But, as the samples elongate further toward the breaking point, the proportionality between stress and strain ends at a proportional limit about half the breaking stress. (6-8)

The Ultimate Tensile Strength or UTS is the maximum possible tensile strength that can be achieved with a given sample. J.C. Linden et al. (2001) reported UTS of 130 +/- $14 \mathrm{MPa}$ for Haversian bone and UTS of $161+/-11 \mathrm{MPa}$ for primary bone. An important item to note is that a higher of concentration of osteons per area will lower the tensile strength of a given sample. The same study showed that an area of bone with larger and fewer osteons yielded tensile strengths of $15.60-17.08 \mathrm{~kg} / \mathrm{mm}^{2}$; conversely a section with smaller and numerous osteons yielded tensile strengths of 8.42-12.04 $\mathrm{kg} / \mathrm{mm}^{2}$. Tensile specimens with predominately transverse osteon populations deformed more than specimens with longitudinal type osteons prior to fracture. (23) 


\subsection{Elastic Modulus}

Nanoindentation has become the method of choice for direct assessment of tissue mechanical properties e.g. hardness and elastic modulus. However, two inherent limitations are associated with this destructive indentation technique: (1) the lateral dimension of the indenter tip is several microns, therefore it is difficult to probe very thin or adjacent lamellae, and (2) the spot-measurement does not provide structural information. (21) There is no significant difference between the modulus of elasticity of dry, fully calcified osteons and the modulus of elasticity of dry osteons at the initial stage of calcification. There is a very close correspondence between the modulus of elasticity of osteons with the lowest and highest degrees of calcification. In the former, the modulus of elasticity is $10,500+/-3,500 \mathrm{~kg} / \mathrm{cm}^{2}$ and in the latter $14,800+/-6,200 \mathrm{~kg} / \mathrm{cm}^{2}$

. The modulus of elasticity of bright-field osteons is $94,905+/-16,670 \mathrm{~kg} / \mathrm{cm}^{2}$ and that of alternating osteons is $75,404+/-16,349 \mathrm{~kg} / \mathrm{cm}^{2} \cdot(36,43)$

\subsection{Compressive Strength}

Compressive strengths of osteonal bone are less investigated than the tensile strength or other mechanical properties, but they it is still an important field of study. Queries of this type were carried out by noted scientists such as Rauber (1876), Calabrisi and Smith, Dempster and Liddicoat (1952); however again we turn to Ascenzi and Bonucci (1965), who carried out compression tests on osteon samples of the bright-field, dark-field and alternating types. As a preliminary, they decided that when comparing the compressive behavior of samples of macroscopic size and of single osteons, it appeared 
advisable to consider first fully calcified osteons, because they are the most representative units in compact bone; the ultimate compressive strength of osteons at the initial stage of calcification is significantly lower than that of fully calcified ones. Their ultimate compressive strength recorded ranged from a minimum of $11.20+/-1.03$ $\mathrm{kg} / \mathrm{mm}^{2}$ for dark-field osteons to a maximum of $16.70+/-1.19 \mathrm{~kg} / \mathrm{mm}^{2}$ for bright-field osteons. Results from previous investigators seemed to support these results; therefore, we can conclude that the compressive strengths in bright-field osteons are higher in comparison to that of dark-field osteons. (7) It also appears that age has no effect on the ability of an osteon to withstand compressive stresses. (16) Shear failure was observed in all three types of osteons when stressed to their breaking point. One last noteworthy item is that Ascenzi and Bonucci (1967) reported that the ratio between ultimate tensile strength and ultimate compressive strength of fresh human bone is 0.73 . As regards to isolated osteons, this value was 0.70 for calcified alternating osteons and 1.04 for fully calcified dark-field osteons. (6)

\subsection{Bending Properties}

Compressive and shearing stresses are the close cousins of bending stress, and all are affected by the cross-sectional area of the specimen. None of them however, does this uniformly so it is hard to use the magnitude of these calculations to contribute to the whole figure of bending property. As a result, bending has generally been considered an unreliable way of investigating the mechanical properties of a material. (3) Despite this, over the last hundred years or so, experimental investigations on the properties of the 
whole bone structures in a bending loading investigation have been performed by several authors: Knese et al. (1956), Motoshima Stevens and Ray (1962), Mather (1968), Azang et al. (1972) and Olivo (1937) among others. Each of these investigators partly discovered the need to study the mechanism of bone fractures which are often produced by bending stresses, and was partly undertaken to explore the relationship between the macroscopic and the microscopic mechanical properties of bone. (5)

Results from this most recent study showed that osteons whose fibers have a marked longitudinal spiral course in successive lamellae show conspicuous deformation before fracture occurs. On the other hand, alternate osteons show relatively little deformation before fracture occurs. Obviously, the orientation of osteon's lamellae has a huge effect on how durable a structure is when subject to bending stress. In an alternating osteon, each additional layer of lamellae adds additional durability to the osteon as a whole. Also, fractures produced by bending differ substantially according to the type of lamellar structure. In osteons having a marked longitudinal spiral course in successive lamellae the fractures normally occur on the tension side of the unit, while the compression side appears free of discontinuities. In alternating osteons, fractures may appear throughout the structure and include traveling cracks. $(14,15,17)$

It was determined that the bending mechanical properties are dependant on the diameter of the canal tested. The larger the canal that is being tested, the smaller the Ultimate Bending Load. As an example, when the canal tested was 40 microns the UBL was 2.61; when the canal was 50 microns in diameter, the mean UBL was 2.48. Significant measurements collected while investigating bending properties are Ultimate Bending Load, Ultimate Bending Deformation and Modulus of Rupture. In order to 
calculate these properties the elastic modulus is very necessary, as in most mechanical properties. (3)

\subsection{Fracture Toughness}

There have been countless studies performed not only on the fracture toughness of bone, but also the propagation of microcracks and resistance to crack growth. A study was performed by Norman et al. (1996) on microcracks in human cortical bone, and how the tissue of bone resists crack propagation. They hypothesized that human bone has a tendency to form microdamage in tension as opposed to shear regions. Regardless of this however, it is not likely that the shear fracture toughness of human bone is less than its tensile fracture toughness. Previous investigations have shown the shear toughness of fibrous composite materials and found that shear toughness is approximately 2 to 10 times greater than tensile toughness for toughened and brittle matrix composites. Osteonal bone behaves much like a composite laminate in fatigue but demonstrates superb resistance to crack growth. Although human bone is weak in shear, materials with low shear strength often have good fatigue and impact properties because greater displacement is possible along shear planes prior to failure. (31-32)

Corondan and Haworth (1986) and Alto and Pope (1979) showed that crack propagation in bone is inhibited by increased numbers of osteons and by larger osteons. Increased fiber (osteon) discontinuity increases toughness in three point bending, suggesting that a history of active Haversian remodeling may not reduce bone toughness although remodeling reduces bone strength. Osteons only provide great toughness for a

given strength. $(1,17)$ Barth et al. (1992) demonstrated fewer osteons per unit area, and 
larger osteons with larger Haversian canals in the cortex of the medial femoral neck of patients who sustained a femoral neck fracture than in the same location in age matched controls who did not sustain a femoral neck fracture. (13)

Ural and Vashishth (2006) reported that longitudinal fracture studies demonstrated that fracture resistance of cortical bone increases with crack propagation and both the initiation and propagation toughness decline with age. Bone is an anisotropic material and demonstrates different fracture behaviors in the transverse and longitudinal directions. When investigating fracture properties of bone, data is gathered using $\mathrm{K}_{\mathrm{C}}$, the critical fracture toughness and $\mathrm{G}_{\mathrm{C}}$, the strain energy release rate. When inspecting longitudinal crack propagation in human cortical bone, the tissue exhibited increasing fracture toughness with crack extension, also known as rising R-curve behavior. This was attributed to crack-tip damage and crake wake debonding mechanisms. (41)

In regards to fracture mechanisms that function in order to prevent fractures from propagating, Behiri and Bonfield (1989) reported that fracture mechanisms in fiber reinforced composites include fiber pull-out, fiber bridging, fiber/matrix debonding, fiber failure and matrix cracking. These mechanisms have been also observed in cortical bone in the form of osteon pull-out, microcracking in the interstitial bone, osteon failure, and osteon/interstitial bone debonding at cement lines. (14)

Norman and Wang (1997) found that the majority of the microcracks were located in the bone matrix and the cement line. The occurrence of $87 \%$ of the microcracks in interstitial bone and interstitial bone intersecting with osteonal cement lines. A low percentage of cracks were found to be located in the cement lines (11\%) and penetrating 
osteons $(2 \%)$. These findings indicate that, although osteonal structure and cement lines alter the crackpath and provide crack arresting features, the penetration of osteons by cracks is also a viable fracture mechanisms. (32) Ural and Vashishth (2007) concluded that their studies indicated that a crack exceeding a critical length will cause transverse failure. They also predicted that when a crack approaches an osteon at a 90 degree angle in human bone it will penetrate an osteon. However, conditions including oblique cracks and osteons, as well as the phase angle alterations in the crack wake, may increase the probability of crack arrest over osteonal penetration. (41)

Najafi et al. (2007) reported that secondary osteons in cortical bone could reduce stiffness and strength compared to primary cortical bone. However, osteons could help stop microcrack propagation. The cement line's weak interface, on the other hand, will result in osteon separation from interstitial bone. This tends to deviate or stop microcrack propagation, and thereby increase bone toughness. In the model explored consisting of two osteons under tensile loading, the crack propagation is found to follow a trajectory between the two osteons. The crack behaves as if it preferred not to enter an osteon. Multi-osteonal models show that microcrack growth slowed and eventually approached a complete halt when distances between osteons were small. (29) Other experimental results suggest that microcracks stop once they enter a high osteon density bone tissue, a point directly related to bone toughness. (33) Based on this, Najafi et al. (2007) concluded that osteons behave as a barrier to microcrack growth. Short cracks are therefore encountered more frequently than long cracks in bone tissue. (39)

In summary, all these studies offered evidence that ultimate compressive strength and modulus of elasticity in compression are greatest for osteons whose fiber bundles are 
transversally oriented in successive lamellae, while the ultimate tensile strength and the modulus of elasticity in tension are greatest for osteons whose fiber bundles have a marked longitudinal arrangement. The fracture properties of cortical bone and osteons themselves were focused on heavily throughout this report because that is what the study is focused on: the fracture toughness of osteonal bone and what affects it. 


\section{Objectives and Hypotheses}

The objectives of this study were as follows:

- Quantify the microstructure of human cortical bone using polarized light.

- Correlate microstructure results with fracture toughness data.

- Determine microstructural factors that most affect $\mathrm{K}_{\mathrm{C}}$, or the fracture toughness.

This study was performed in order to closely investigate and determine the microstructure of cortical bone from a human tibia. Using polarized light viewed from a microscope/camera assembly, individual osteons within the chips of cortical will be classified based on type and the properties of which will be measured. This data will be matched up with fracture toughness data from a previous experiment. Analyses will then be run on this final data in order to determine what factors most affect the fracture toughness of human cortical bone, whether it is the volume fraction of a certain type of osteon, or perhaps the diameter measurements of a specific type, or possibly a combination of multiple elements. Hypotheses for the results of this study include:

- Differences in osteonal bone microstructure will exist due to region.

- The Volume Fracture of osteons will influence $\mathrm{K}_{\mathrm{C}}$, the fracture toughness.

- Specific osteon type(s) will affect the fracture toughness as well.

Based on the data gathered, it is conjectured that differences will be exhibited within regions of the cortical bone: Anterior, Lateral, Medial and Posterior. Fracture toughness is not constant throughout the bone, and there must be microstructural differences that affect the value of it, such as volume fraction or porosity. 


\section{Methods and Materials}

\subsection{BioQuant}

The osteon, when fully formed, is an irregularly cylindrical and branching structure a few millimeters in length and usually oriented in the long axis of the bone. A cross section, no thicker than 500 microns from the diaphysis usually contains the straight non-branching portions of many osteons. The material used in this study was obtained from tibia bones of human subjects the ages of whom are unknown. So far as is known, no pathological bones were included in the material. Cross sections of tibial shafts cut transversely were used in this experiment. In preparation of the slides, every precaution was taken to avoid heating the material. Eight slides were prepared with 2 to 4 chips of bone each making for a total of 28 chips of bone. The slides are labeled as B9N2 _ _ . The two underscores designate the orientation of the cut of the bone. The former underscore denotes whether the cut is anterior, A; posterior, P; lateral, L; or medial, M. The latter underscore simply denotes the order of the chips as they are taken from the bone; $1,2,3,4$. There were numerous other slides prepared from the same tibia bone, but unfortunately they could not be used because of the cut orientation; all of the chips in this category were cut longitudinally downward along the length of the bone. Because of this, the view of the chip was lengthwise down an osteon instead of the cross-section view that was needed.

Each slide was inserted into an Olympus (Japan) U-AN360P U-TAD microscope with a polarizing filter. Connected to this microscope is a camera that projects the focused image onto a computer monitor. The slides were viewed with a 10x projection, in combination with a $4 \mathrm{x}$ natural magnification of the attached microscope camera. In 
combination with the previously mentioned equipment, the computer software BioQuant BQ Nova Prime 6.70.10 Beta was utilized. The first objective of this program is to show a live-time view of what is seen on the microscope, with the ability to freeze any image at any time.

Once a slide is loaded onto the microscope stand, it is aligned vertically, making sure that the whole viewing is occupied with part of the bone chip. For each chip of bone two topos were recorded (topos will be explained shortly). Once the chip is aligned in its appropriate spot, BioQuant was used in order to measure and record the total area of the viewable space. Total area was just one of the arrays available and used in BioQuant. The total area is measured automatically by the software at the user's direction. Once the total area is measured, it is possible to alter the filter so that the viewed light alternated from polarized to natural. This is done in order to use the Porosity array and measure: the spaces at the center of the osteon, the Haversian canals, and the Volkmann's canals. The porosity and osteon tracings are all done manually. This is done slowly so that the measurements can be accurate and the recorded values will positively reflect the size seen of osteons.

After that measurement is taken, osteons are then located and identified as what type they are. Arrays available and used on BioQuant were Hooped Edge, Hooped Central, Dark Edge, Dark Central, Light Edge, Light Central, Alternating Edge, Alternating Central, Porosity and Total Area. Each array can be selected or deselected depending on what you want to measure. For example, if only half of a bright-field osteon is seen in the viewing window because it is on the edge, then that would be traced while the Light Edge array was selected. Each separate array had its own color scheme 
so that it would make for easier viewing. The BioQuant program records the areas of each osteon traced and records the amounts of samples traced.

Special care was taken to only include completely modeled osteons. Because bone is constantly being modeled and remodeled, there were older osteons that had been partially covered by new osteons remodeled in their place. In a case like this, only the new, complete osteon was recorded. Once every osteon was traced and recorded for one viewing window, this was considered a complete topo. Once a topo was complete, the viewing slide was moved downward so that a second topo could be recorded on the same chip of bone. The result of this method yields eight topos per microscope slide that contains four chips of bone, and four topos on a slide that contains two chips of bone. In addition to measuring the area of each recorded osteon, the program also calculates the porosity and volume fraction characterization.

The data from each topo was recorded in a laboratory notebook, and then transferred to a computer so it could be viewable in this report. In order to see the orientation of bone chips in each histological sample, the data for each area, and the calculations performed by BioQuant at the user's request, see Appendix A. For pictures of the microscope setup and BioQuant program in action, see Figures 3.1, 3.2, 3.3. 


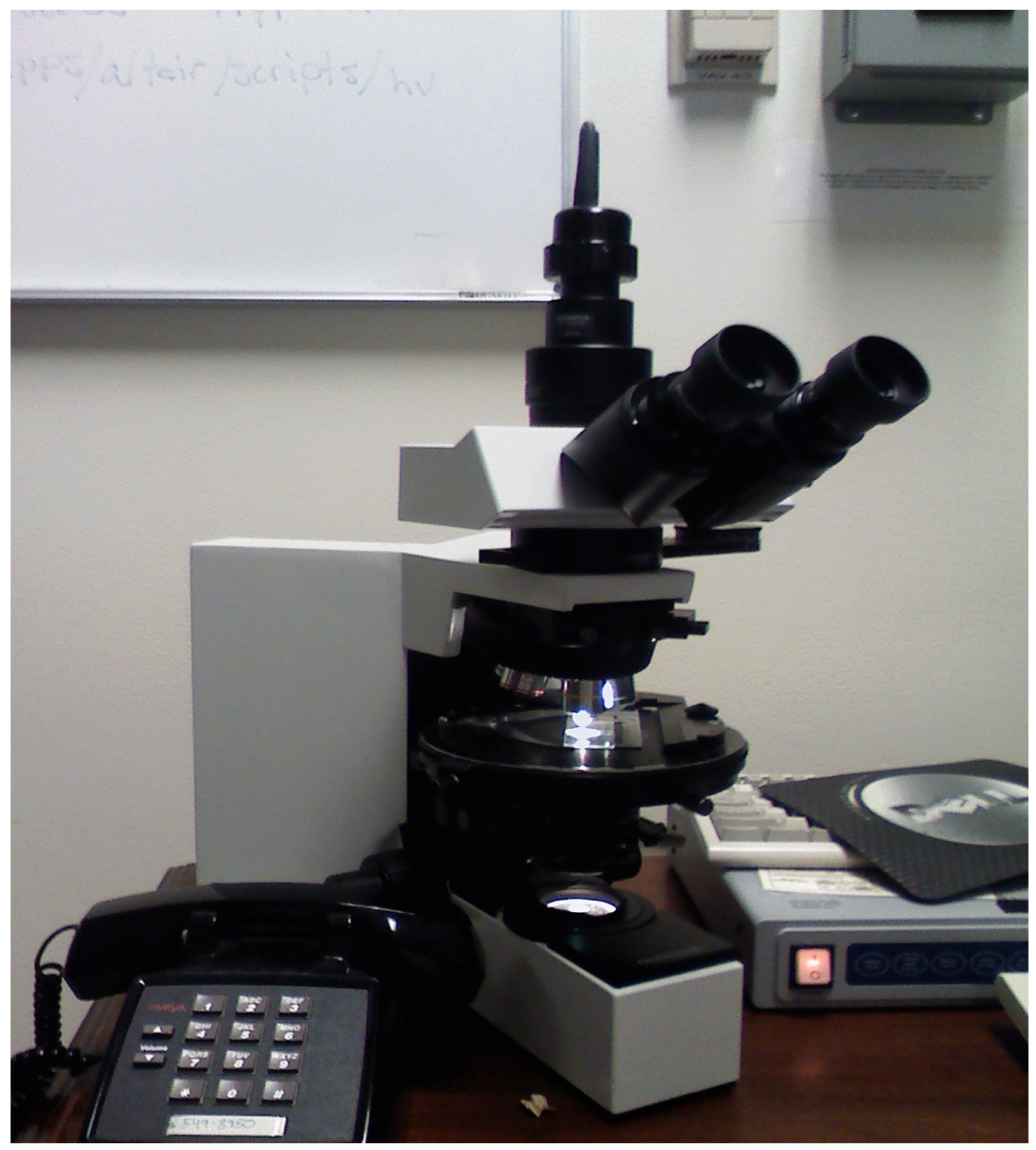

Figure 3.1 Olympus (Tokyo, Japan) microscope used in accordance with polarized light, in order to determine osteons types within each bone chip. 


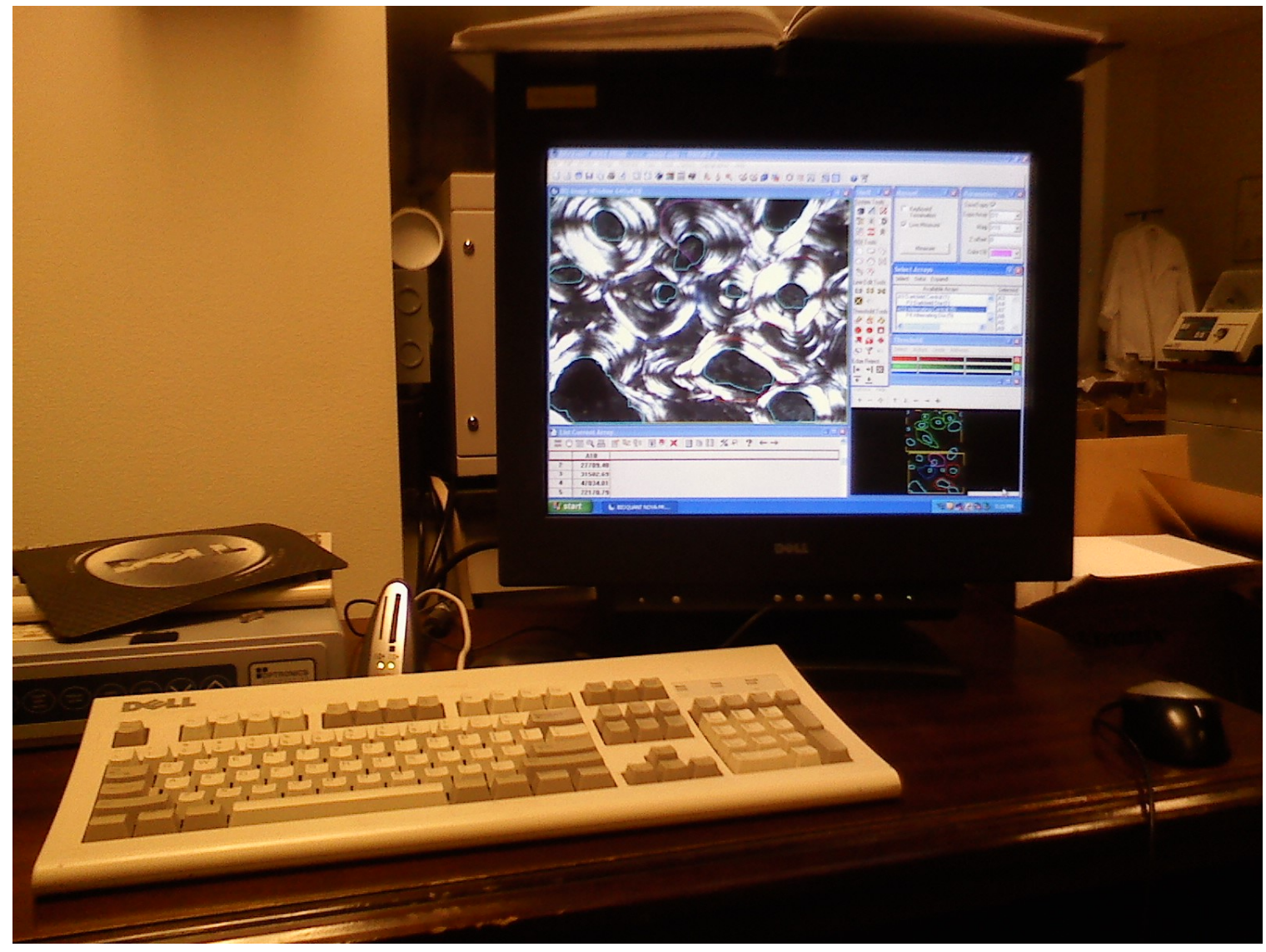

Figure 3.2 View of the keyboard and monitor set-up with BioQuant open on screen. 


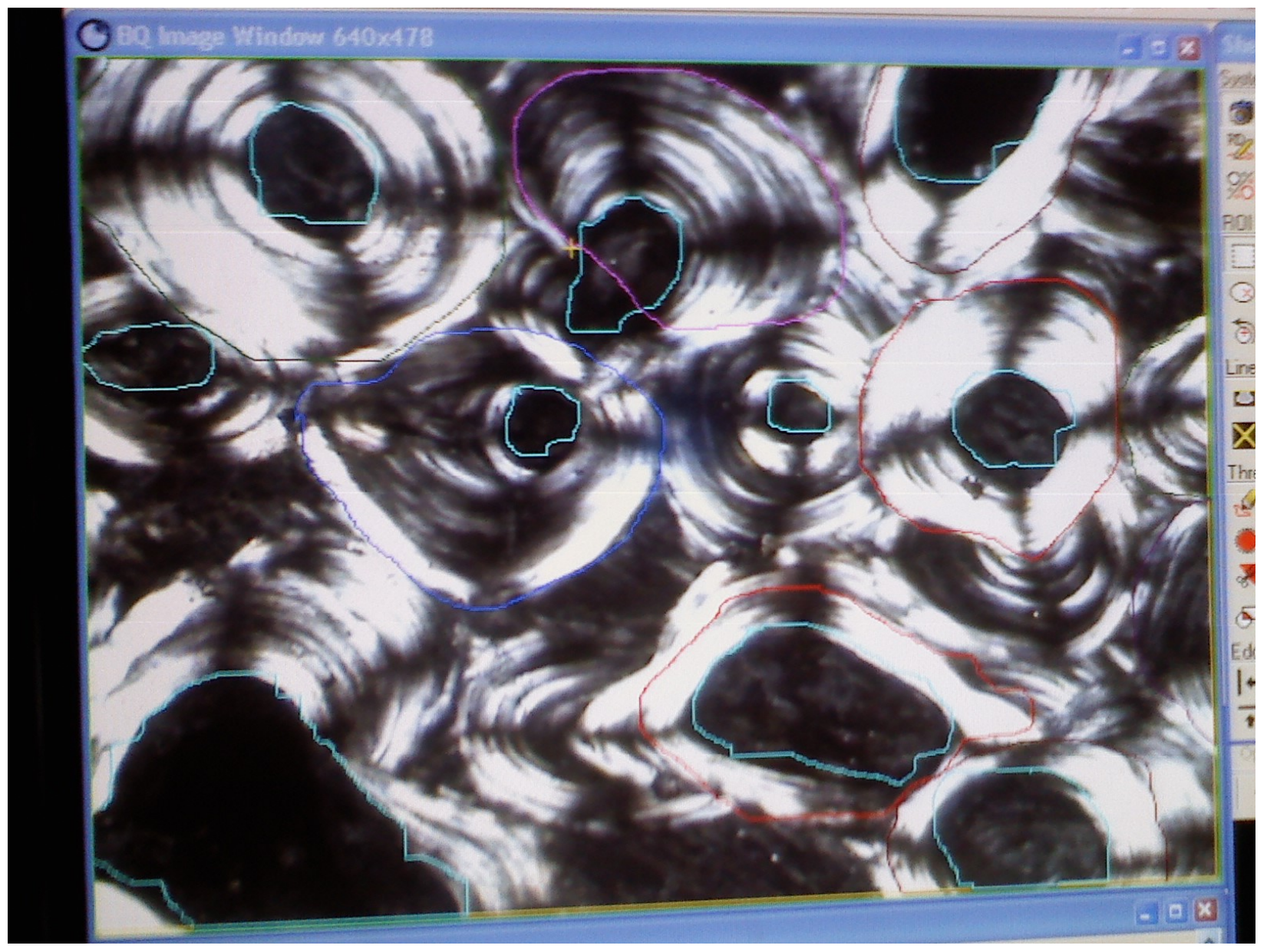

Figure 3.3 Screen shot of BioQuant in mid-tracing of a topo. Notice how each osteon type has its own color scheme, as does porosity. 


\subsection{Microsoft Excel}

In order to ensure the needed accuracy on the calculations, i.e. Volume Fraction and Average Diameter of osteon by type, each section must be isolated from the next. BioQuant unfortunately married the separate data for each section of bone into a large data pool for the entire slide. Since this data was unusable for calculations, it was necessary to use the handwritten notes from the initial recording to separate the data as a whole into two different sets; one for each section of bone. As an example, the calculations for B9N2P1,2 were performed on every data value entered for the topo set. This includes eight topos: B9N2P1,2; A-1, A-2, B-1, B-2, C-1, C-2, D-1, D-2. In order for the calculations to be valid, the volume fractions/average diameters needed to be calculated for B9N2P1 (A-1, A-2, B-1, B-2), separate from B9N2P2 (C-1, C-2, D-1, D2).

In order to carry out these calculations, Microsoft Excel was used. The original area values (in pixels) were separated for each chip set and recorded in its own corresponding column; porosity, hooped, light, dark, alternating. The sum of all the values was taken and then divided by four times the total topo area. The multiplier four was used because the values taken were from four corresponding topos. The decimal number that results is the volume fraction; multiplying it by 100 will result in the per cent of the total area taken up by the particular type of porosity/osteon. Adding up the volume fraction of hooped, light, dark and alternating will result in the total volume fraction. The equation for manually calculating the volume fraction percentage can be summarized as follows. 


$$
\Sigma \text { Entry (Pixel) / (4 (x) Total Area) x } 100=\text { Volume Fraction \% }
$$

The second calculation performed was average diameter for each osteon type. In order to calculate this value, only complete osteons were used. Theoretically, edge osteons could be projected out in order to find the diameter, but for the purpose of this study, to ensure accuracy via BioQuant, only measured complete values were utilized. Luckily, the conversion rate for pixels to microns in BioQuant is 1:1, so all that was necessary is a little manipulation of a basic area equation for a circle Equation 2:

$$
\begin{gathered}
\text { Area }=\pi \times \mathrm{r}^{2} \\
\text { Diameter }=2 \times \mathrm{r} \text { or } \mathrm{r}=\text { diameter } / 2 \\
\text { Therefore, } \\
\text { Area }=\pi \times \mathrm{D}^{2} \times(1 / 4) \text { or } \mathrm{D}=(4 \times \mathrm{A} / \pi)^{\wedge .5}
\end{gathered}
$$

Manipulating these equations gives us a usable solution for finding the diameter of each osteon. Since it was already mentioned that the conversion rate is $1: 1$, all that was needed was to insert the recorded area values for each complete osteon into the final form of equation 4 . Once all of the values were converted for each type, the average of the values is taken. The average diameter of each osteon type is the final calculation needed in order to perform our analysis on Minitab.

\subsection{Minitab}

The Minitab analysis program (Minitab, Inc., Version 15.1.20, State College, PA) was used in order to determine factors that affected $\mathrm{K}_{\mathrm{C}}$, or fracture toughness. Statistical 
regression analyses were completed on all different variations of the collected data in order to determine if certain parameters affected fracture toughness significantly. A sheet of data with the osteon samples' Ultimate Load $(\mathrm{Pa})$, fracture toughness $\left(\mathrm{K}_{\mathrm{C}}\right)$, and a second definition of fracture toughness $\left(\mathrm{K}_{\mathrm{AC}}\right)$ were provided from a previous study so that they may be included on the tests run. Density or porosity can be used as predictors; however not both can be used at the same time because the two parameters are inversely proportional (as one increases, the other decreases). Because of this relationship between porosity and density, a graph was produced with all recorded values of density vs. measured values of porosity to ensure they are indeed inversely proportional. Tests were run using the fracture toughness $\left(\mathrm{K}_{\mathrm{C}}\right)$ as the response, or $\mathrm{Y}$-axis value, and a combination of other parameters as the predictor, or X-axis value. Predictors used were: volume fraction of hooped, light, dark, alternating, total and diameter of hooped, light, dark and alternating. Minitab allows the user to apply one or multiple predictors for each analysis. Regressions were calculated for a combination of all diameters and all volume fractions, and then for each parameter separately in order to determine which had the most effect on fracture toughness. 


\section{Results:}

\subsection{BioQuant / Microsoft Excel}

There are many areas of results from this study that must be addressed since there were many parts to the study. Initially, the results from BioQuant will be presented. Not all of the existing types of osteons were present on each chip of bone; however this is unsurprising. There is variation with no apparent pattern in each chip and/or topo. Overall trends point towards hooped osteons being the least common type. In B9N2A1, B9N2L1, B9N2M2, and B9N2P4 there are zero hooped osteons; the highest incidence of this type is only $6 \%$ volume fractions. Conversely, alternating osteons seem to be the most prevalent throughout the samples tested. Volume fractions range from $16 \%$ up to $33 \%$.

Darkfield osteons have volume fractions ranging from $3 \%$ to $20 \%$, and lightfield osteons range from $5 \%$ to $28 \%$. It appears that darkfield and lightfield have similar incidences throughout osteons. However, a close examination of the results shows that perhaps these types of osteons are more prevalent in different areas of bone. It appears that light osteons are present throughout posterior sections of the bone more frequently than any other section. Dark osteons appear to dominate the anterior regions of the samples tested as well. Porosity appeared to have a higher incidence rate in anterior and lateral samples, and lower in medial and posterior sections.

In regards to average osteon diameter, there does not appear to be any noticeable trends. There are values interspersed low and high in all sections of the samples. Of course, when comparing the number of osteons present in each sample to the size of the osteons, one can draw conclusions. In samples with a low number of osteons, the 
diameters are all relatively large; conversely, in samples with a very high number of osteons, the diameters are all small. After converting all of the osteon diameters from pixels to microns, resultant values were on the order of 50 microns to 400 microns. It does not appear that any certain osteon type has a significantly larger diameter, nor does it appear that any certain type has a significantly smaller diameter.

In regards to densities measured by BioQuant, the values seem directly related to the amount of each type apparent in the sample. For example, density of alternating osteons was consistently higher than the densities of other osteon types. This was due to the fact that there were more alternating osteons per area than any other type. Porosity overshadowed all types of osteons as the highest density within any given chip of bone. There is a large area per chip that is covered by porosity space. Hooped osteon types consistently had the lowest density, most likely because there was the least amount of hooped osteons per area than any other type. Evidence supported this theme for the other two types as well. In topos where lightfield osteons dominated over darkfield osteons, the density of the former was much higher than the latter, and vice versa. As was previously mentioned, charts including all of the pertinent osteon data from each topo set are located in appendix A for further viewing.

The results became more interesting once the separation of data was calculated with Microsoft Excel. It drastically altered the results of Minitab analyses because of the additional data points it offered for calculation. For instance, once separated, hooped osteons were not present in a number of topos. Obviously this changed the volume fraction of samples and average diameter calculated. 
Fracture toughness values used were in between 1.8 -5.5 MPa-N with a mean of 3.28 $\mathrm{MPa}-\mathrm{N}$. With a surface inspection, it appears that the highest fracture toughness values were apparent within the posterior sections of the bone. Load values had a little more variety with values ranging from $1.42-28.01 \mathrm{~N}$ with a mean of 12.56 . Both of these were factors taken into account while running the analysis on Minitab as variable parameters.

\subsection{Minitab Analysis}

Numerous analyses were run in Minitab in order to find the best possible model for expressing the fracture toughness. All combinations of parameters were included so that we might find the best combination of variables to include. While running the analysis, if it appeared that one parameter was decreasing the value of the model, then it was removed so that the validity of the model is increased. In order for the model to be acceptable, the adjusted P-Value's represented all needed to be within the selected confidence level of $95 \%$, i.e. the P-Value needed to be $>0.05$. The best possible model will have the highest R-Sq (adj.) value. Therefore, models were selected and discarded until it appeared the model with the highest $\mathrm{R}-\mathrm{Sq}$ (adj.) value was found. For example, if a model is found to have a $60 \% \mathrm{R}-\mathrm{Sq}$ value, it means that $60 \%$ of the variation within the fracture toughness parameter is explained.

Another thing that was paid special attention to was the regression equation provided with each analysis completed. The regression equation includes all parameters used in the analysis and shows the relationship they have to fracture toughness. A general form of the equation is:

$$
\mathrm{Kc}=\mathrm{C}_{1} \mathrm{X}_{1}+\mathrm{C}_{2} \mathrm{X}_{2}+\ldots \mathrm{C}_{\mathrm{n}} \mathrm{X}_{\mathrm{n}}
$$


where $\mathrm{C}$ can be positive or negative. For example, a regression analysis was run on fracture toughness, $\mathrm{K}_{\mathrm{C}}$, versus porosity, volume fraction hoop, volume fraction light and volume fraction alt. The regression equation supplied for this analysis was:

$\mathrm{KC}\left(\operatorname{Mpa}-\mathrm{m}^{\wedge}(.5)\right)=6.29-5.90$ Porosity $+7.59 \mathrm{VF}$

Hoop - $4.19 \mathrm{VF}$ Light - $3.91 \mathrm{VF}$ Alt

This can be translated as the fracture toughness increases, porosity decreases, volume fraction of hoop increases and the volume fractions of light and alternating decrease.

It is interesting to note that a regression analysis was run using porosity as the only parameter; it accounted for $50 \%$ of the variation of the model by itself only. This is an incredible feat; because of this, porosity was included in every analysis in order to increase the validity of the model.

Initially a simple analysis was run to determine if the numbers recorded from BioQuant were acceptable. The first was a graphing of density versus porosity. The density values were extracted from data gathered in a previous experiment. The two are inversely related by definition; as a bone becomes more porous, it becomes less dense, and as a bone becomes denser, there must be fewer pores. As is shown in Figure 4.1, they are, indeed, inversely related. This is a positive result; it means that our data is in fact valid and can be used to further investigate properties. Beyond this initial investigation, the means of volume fraction for different types were graphed by region, in order to determine if there are, in fact, regional differences. These are viewable in Figures 4.1, 4.2, 4.3, 4.4, 4.5 and 4.6. 


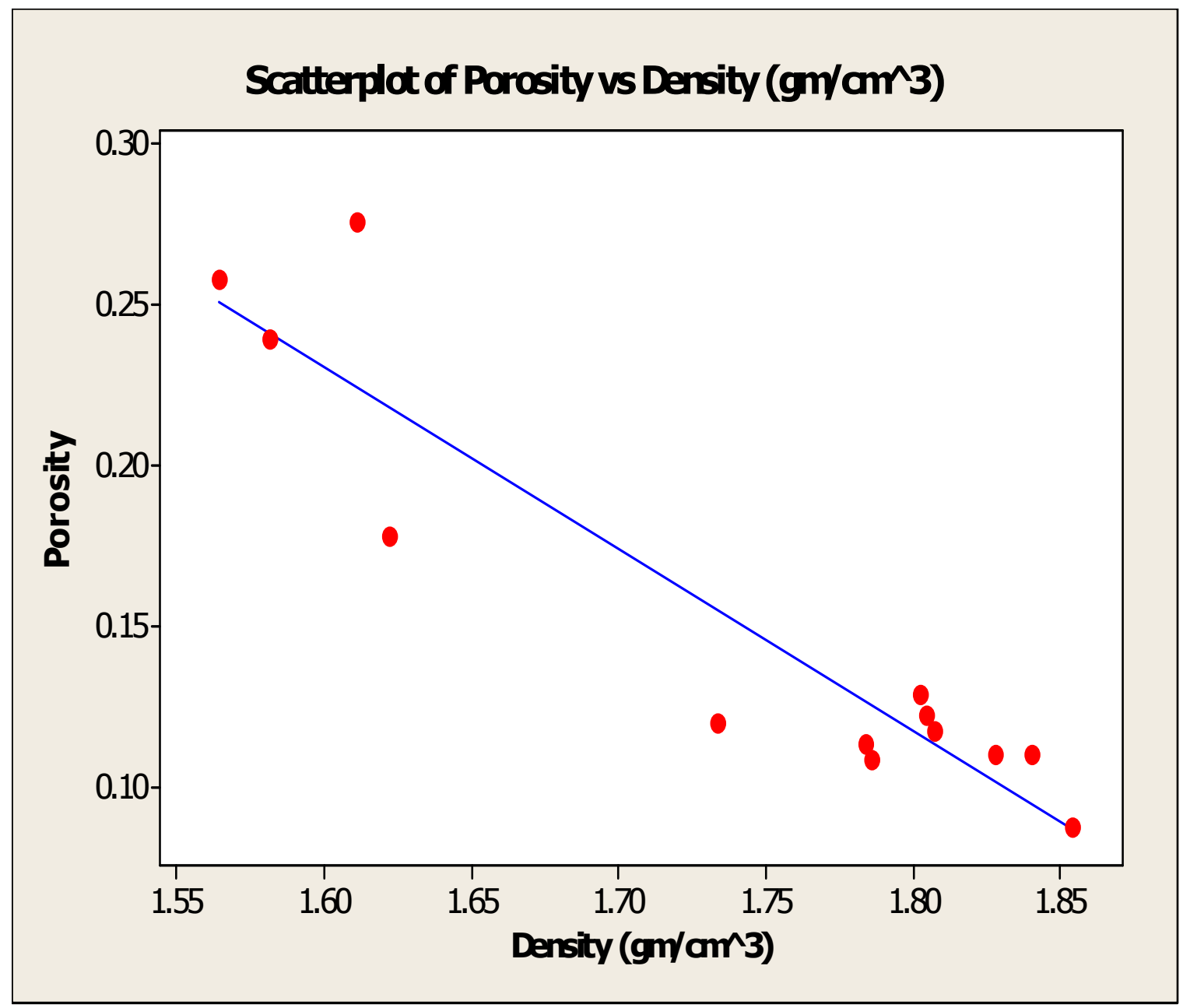

Figure 4.1 Scatterplot of Porosity versus Density. This graph was generated in order to ensure that the two parameters were inversely related. It appears that they are in fact, inversely proportional, so our data is valid. 


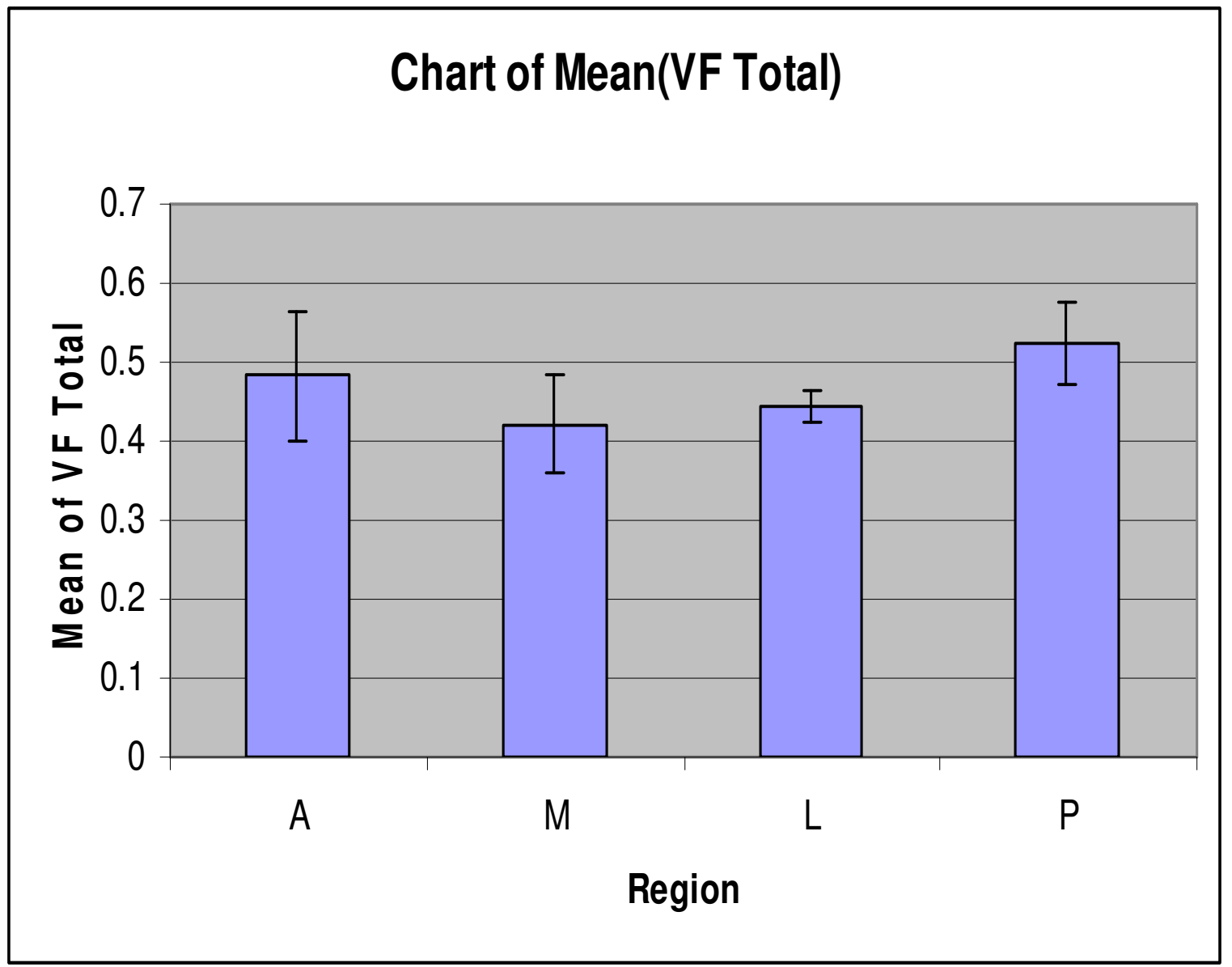

Figure 4.2 Chart of Mean for Volume Fraction Total versus Region. This is a depiction of how concentrated each area was with osteons of any type. 


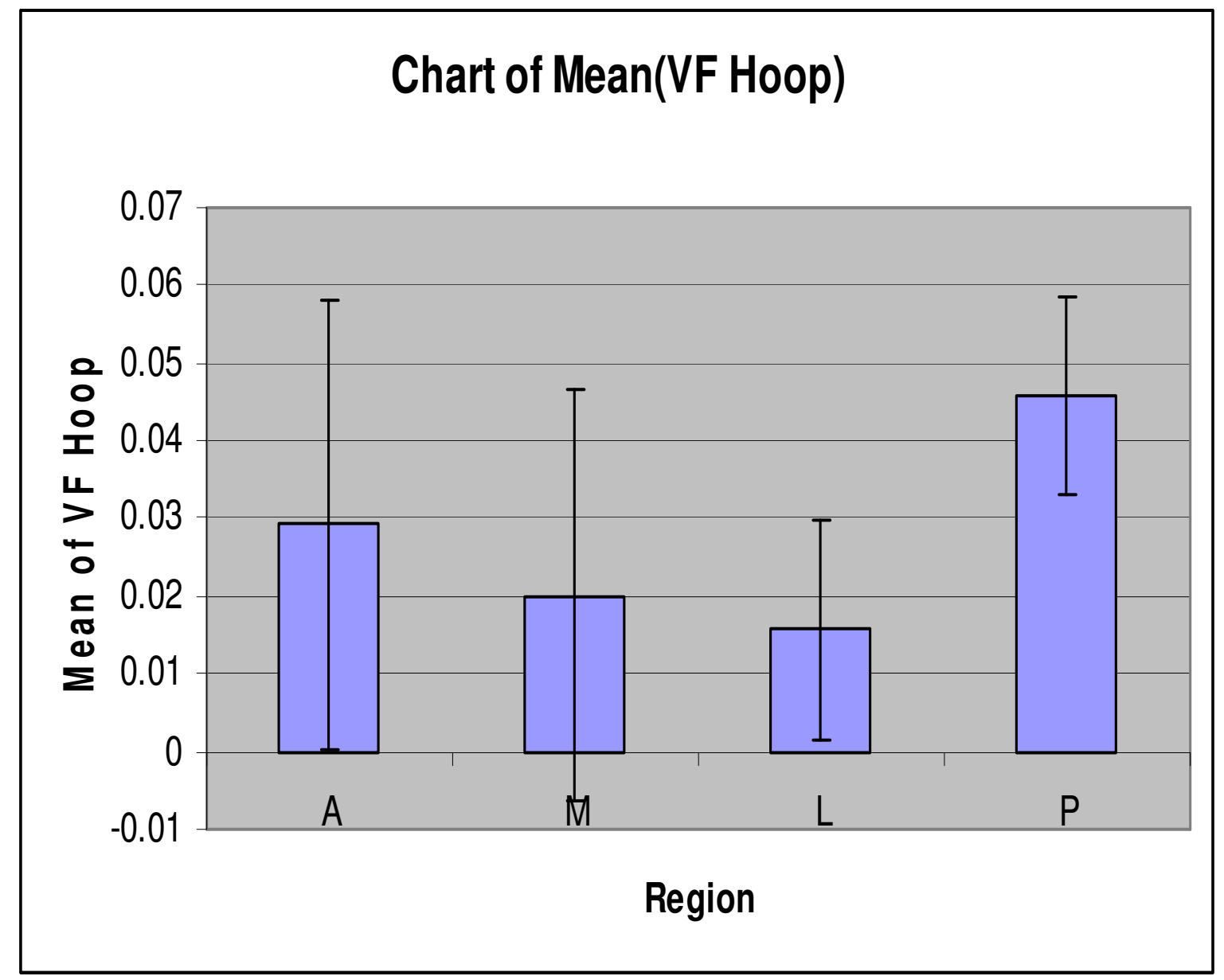

Figure 4.3 Chart of mean for Volume Fraction of Hooped Osteons versus Region. This shows the concentration of Hooped osteons in the posterior and anterior regions and the lack in the lateral and medial regions. 


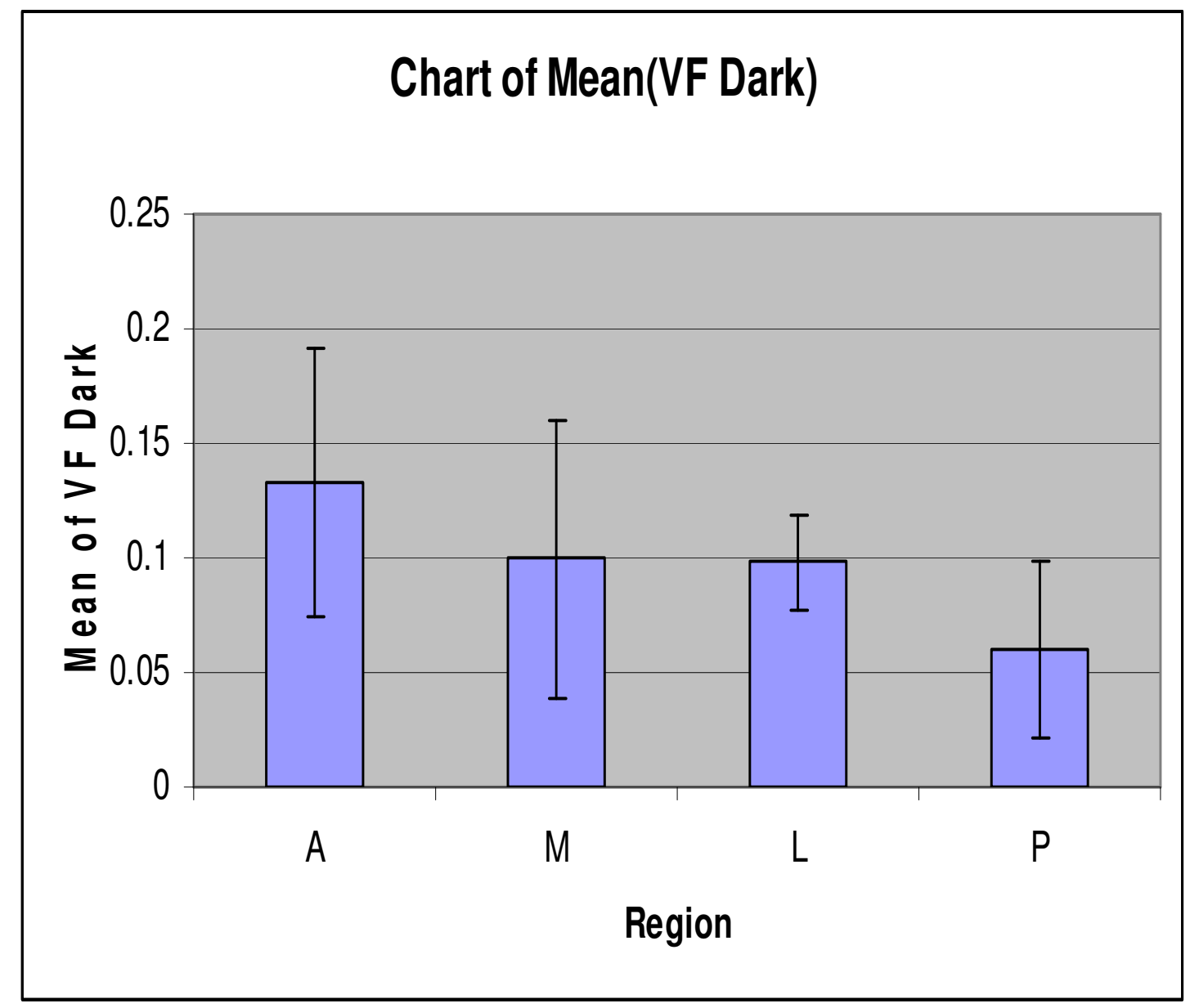

Figure 4.4 Chart of Mean for Volume Fraction of Dark osteons versus Region. This shows the concentration of Darkfield osteons in the anterior region of bone and the decreasing value as it reaches the posterior region. 


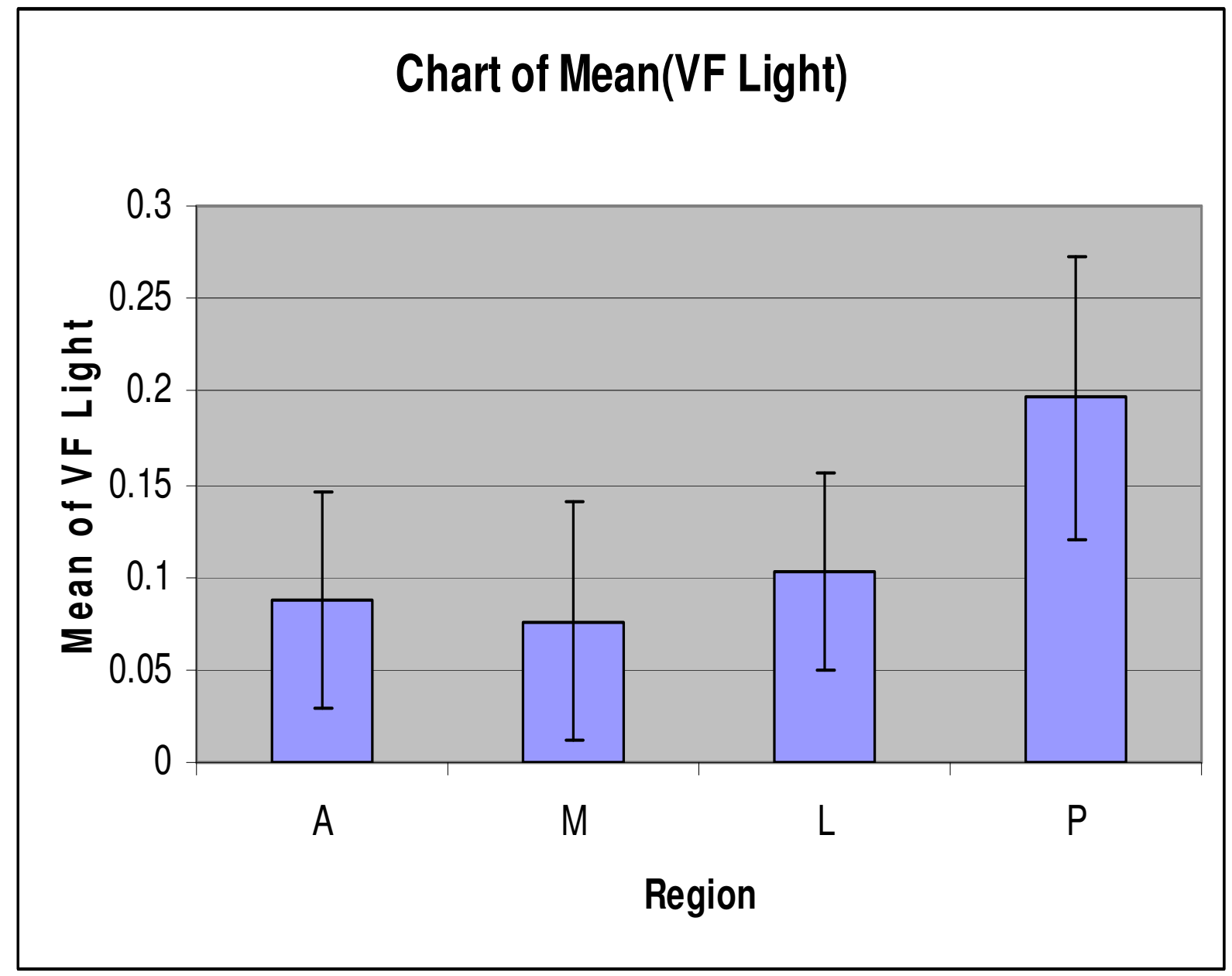

Figure 4.5 Chart of mean for Volume Fraction of Light osteons versus Region. This shows the opposite trend than that of darkfield osteons. Concentration is highest in the posterior region and decreases back to the anterior region. 


\section{Chart of Mean(VF Alt)}

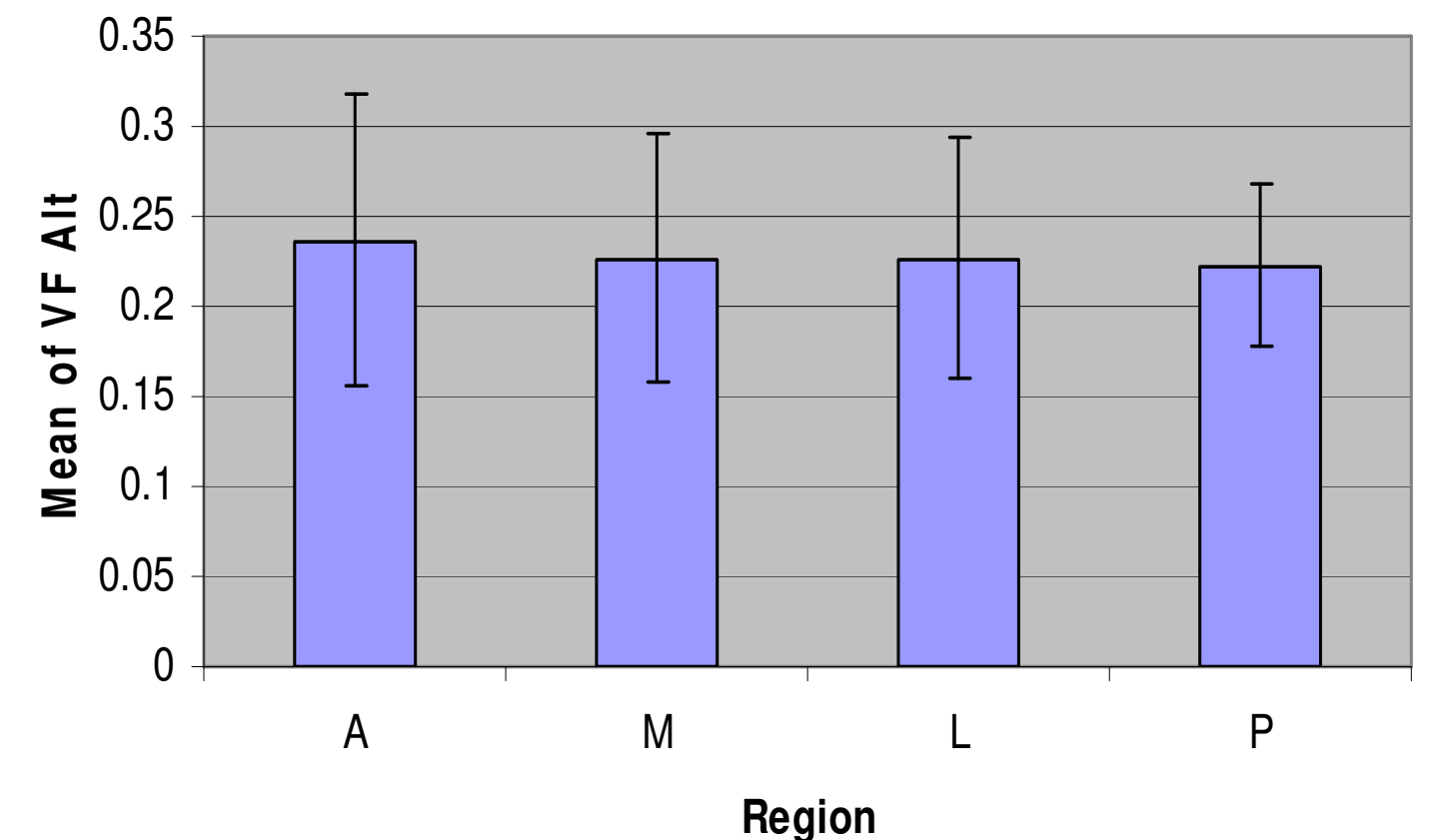

Figure 4.6 Chart of Mean for Volume Fraction of Alternating Osteons versus Region. The concentration of alternating osteons is fairly constant throughout all regions of bone.

As we can gather from these graphs, the amounts of each osteon type present in each region are not constant. In general, there appears to be a higher amount of total volume fraction in the posterior region than any other with a little over half $(0.50)$ of the area being taken up by osteons. Following closely behind are anterior, later and medial ranging from $0.48-0.43$. In this respect, hooped osteons can almost be disqualified based only their insignificant numbers. Even in the posterior region, which had the highest volume fraction of hooped osteons out of the four regions, was less than $5 \%$. In the lateral region, hooped osteons made up a mere $1.5 \%$ of the volume fraction. 
Skipping ahead and moving onto alternating osteons, it appears that they have a fairly constant rate of volume fraction regardless of the region in which they are located $(22-23 \%)$. Now, backing up a couple figures it is seen that darkfield osteons are concentrated in the anterior portion of the bone (13.5\%), moderately interspersed throughout lateral and medial sections $(10 \%)$, and almost nonexistent in posterior sections of the bone (6\%). Conversely, it can be seen in Figure 4.5 that light field osteon volume fractions have an almost opposite pattern. They are concentrated heavily in posterior portions of bone, having a volume fraction around $20 \%$. From there they decrease in lateral sections (10\%), anterior (8\%) and medial (7.5\%). This is an interesting relationship to note. After having produced these graphs relating volume fraction to region, it was then determined the same must be done comparing osteon diameter to region as well. These can be seen in Figures 4.7, 4.8, 4.9, 4.10, 4.11. 


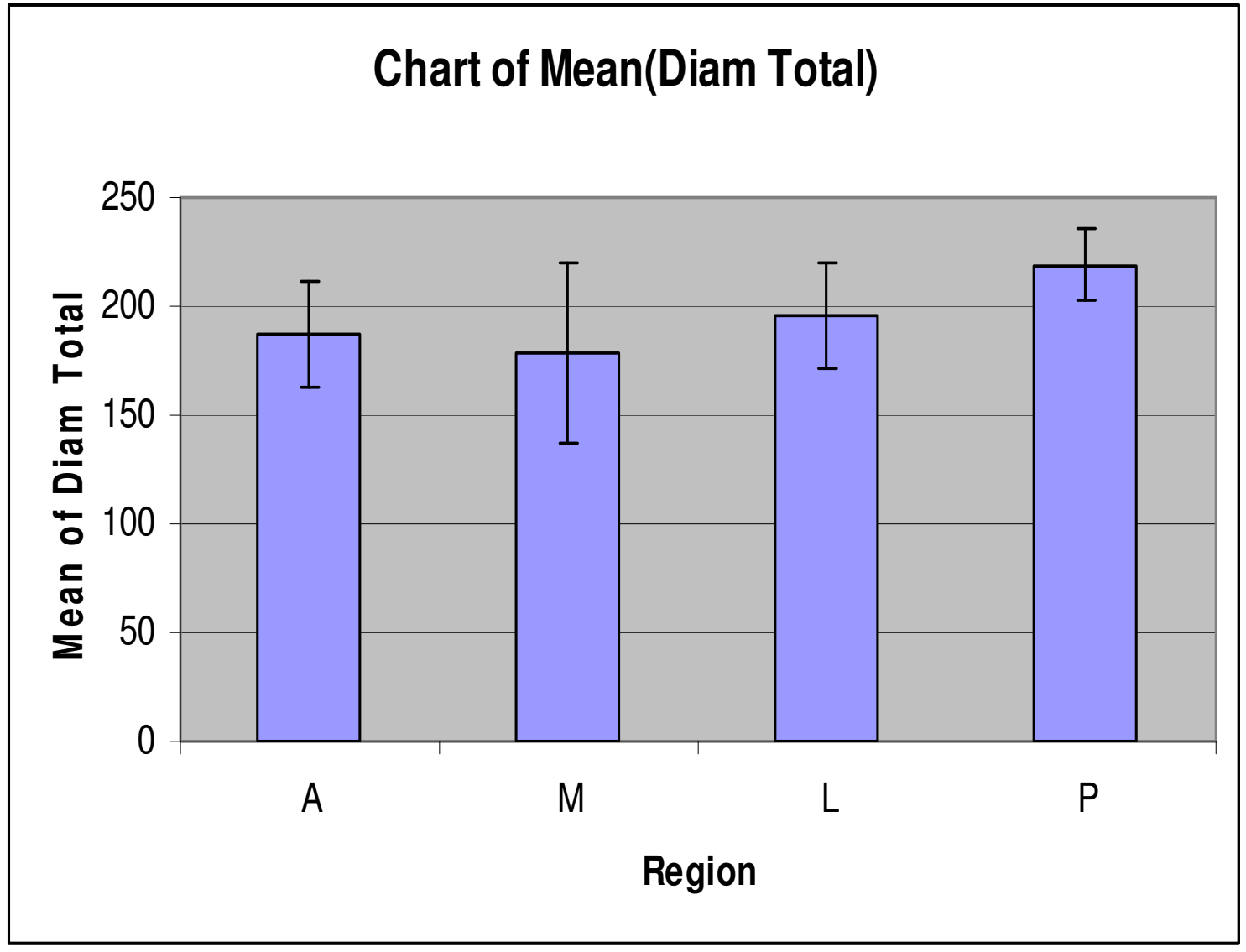

Figure 4.7 Chart of Mean for Average Total Diameter versus Region. There is a fairly constant value for diameter throughout each region. Values range from $175-225$ microns. 


\section{Chart of Mean(Diam Hoop)}

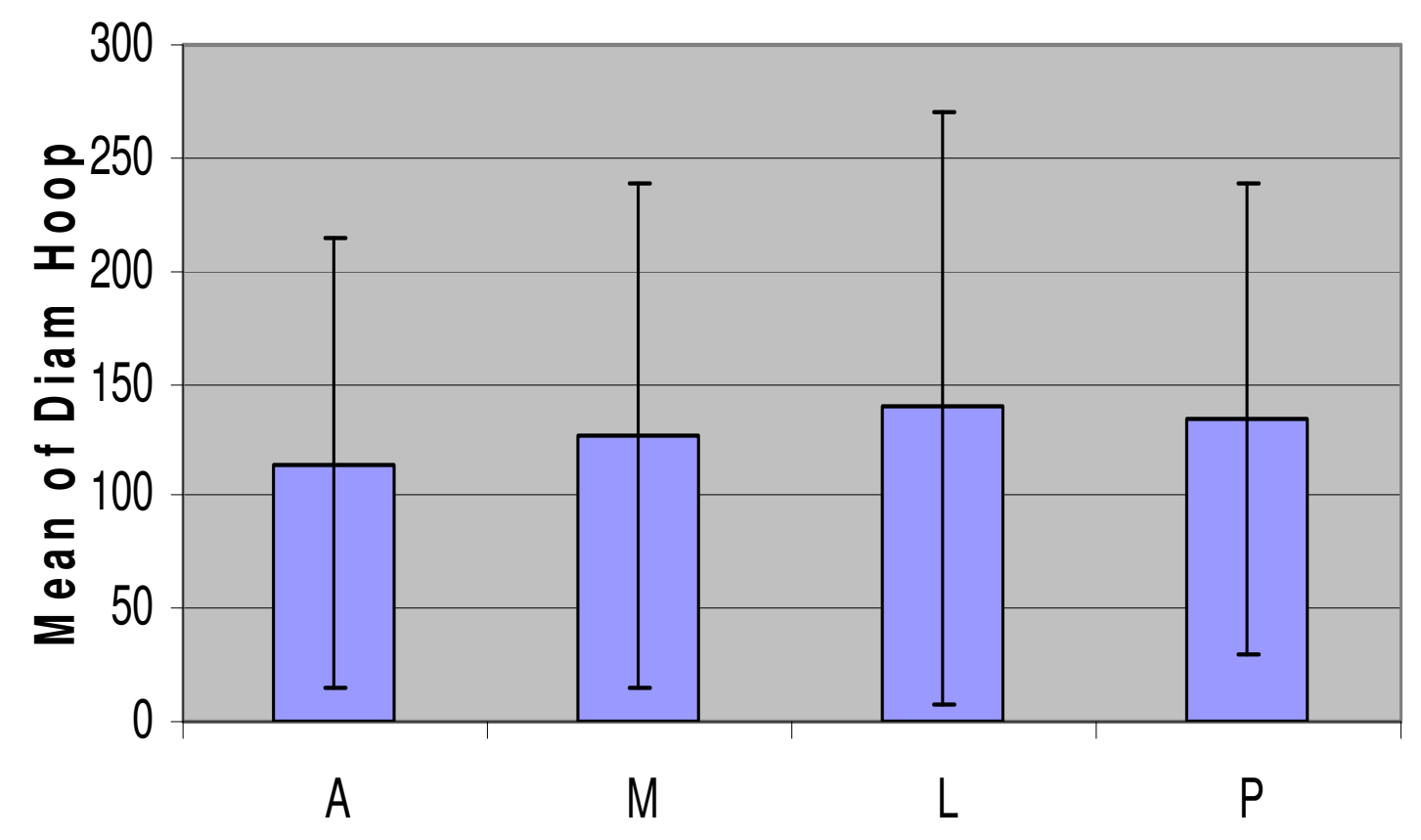

Region

Figure 4.8 Chart of Mean for Average Diameter of Hooped Osteons versus Region.

There is no apparent trend in regions; however hooped osteons are smaller on average then most other osteons. Values range from $115-137$ microns. 


\section{Chart of Mean(Diam Dark)}

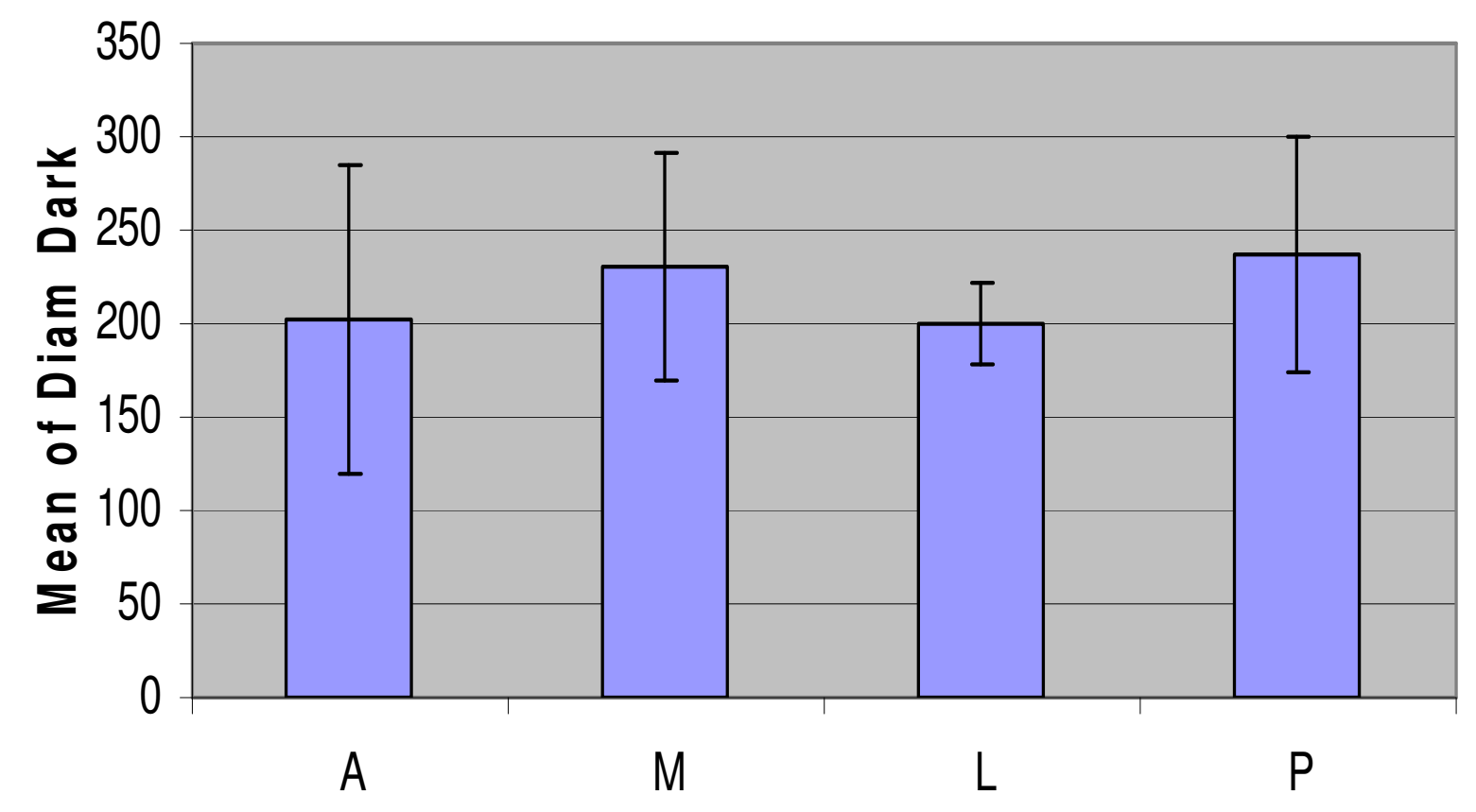

Region

Figure 4.9 Chart of Mean for Average Diameter of Dark Osteons versus Region. There is no apparent trend from region to region; however dark osteons were on average of a larger size than hooped osteons. Values ranged from $200-240$ microns. 


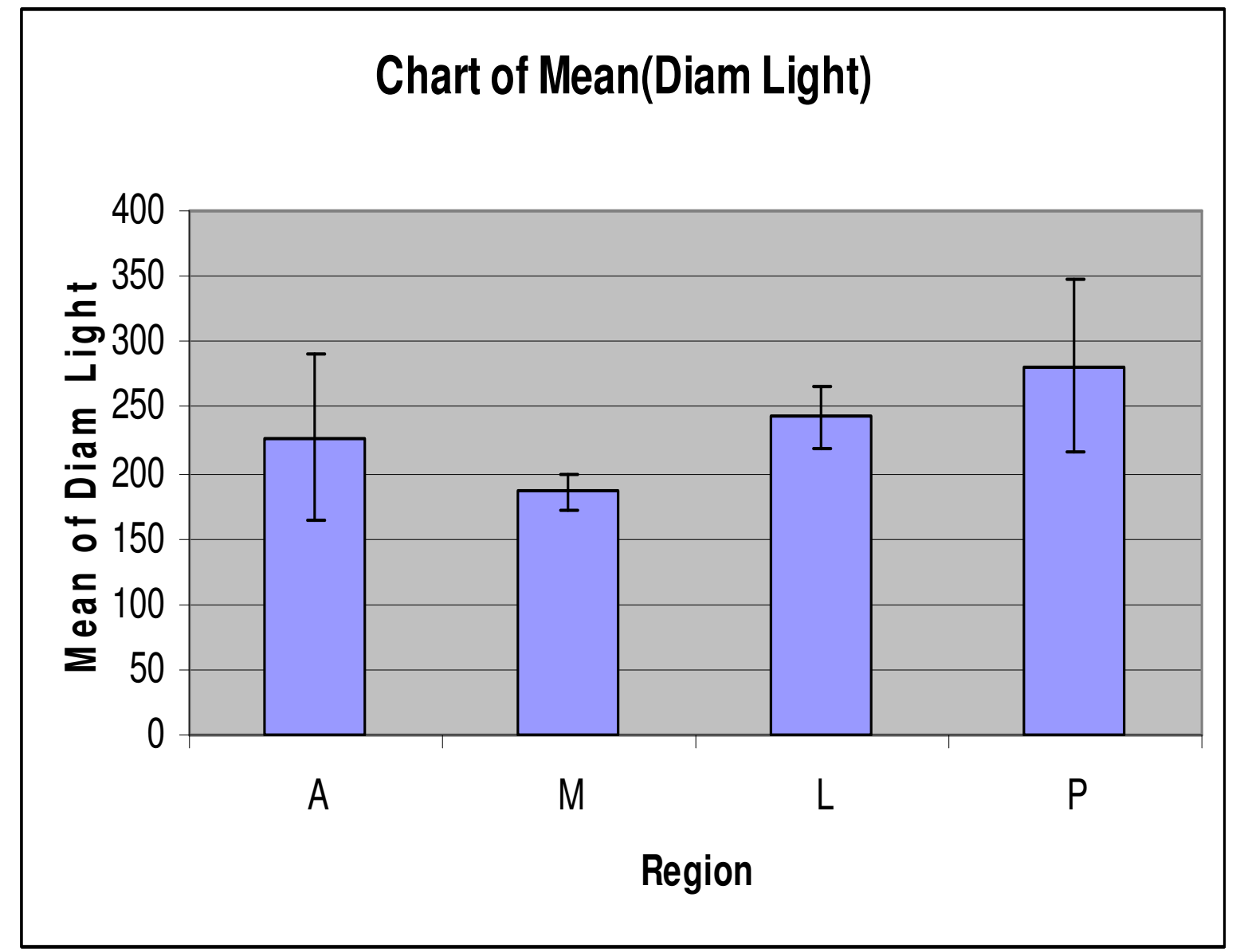

Figure 4.10 Chart of Mean for Diameter of Light Osteons versus Region. Lightfield osteons appeared to be largest in the posterior region, and smallest in the medial region. Values ranged from $190-275$ microns. Lightfield osteons reached the largest observed diameters of all the osteons measured. 


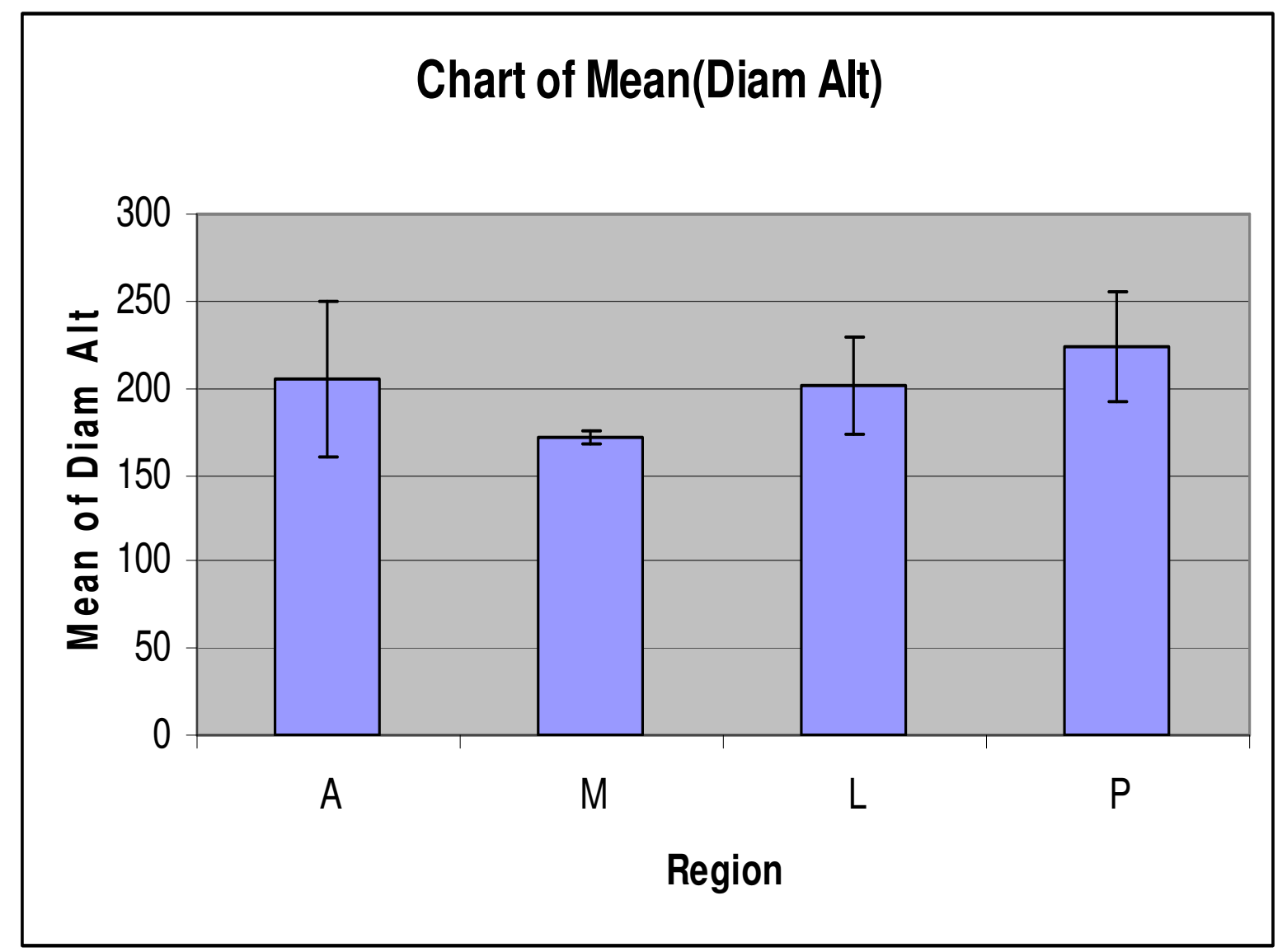

Figure 4.11 Chart of Mean for Average Diameter of Alternating Osteons versus Region. Alternating osteons were of a typical size with other osteons measured and had no apparent trends. Values ranged from 175 - 225 microns.

Just by glancing at these graphs of average diameter for each osteon type versus region, it is clear that there are no clear dominances of larger or smaller osteons by region. There are however, relationships between the sizes of each type in comparison with another. Hooped osteons were consistently smaller than any other type, having diameters ranging from 115 - 135 microns. Alternating osteons were a bit larger than that, ranging from $175-225$ microns. In regards to alternating osteons, it appears that they tended to be larger in posterior sections of the bone than other sections. Dark osteons are a little larger than alternating, having diameter values from $200-230$ 
microns. Interestingly, these darkfield osteons tended to be larger in the posterior section as well, but because the difference was only by a couple microns, this was deemed insignificant. Finally, lightfield osteons were the largest of all ranging from $195-280$ microns; following in the previous trend, light osteons in the posterior section tended to be at least 30 microns larger than lightfield osteons in other sections. All of these factors averaged in together, yielded average osteon diameter sizes ranging from $175-225$ microns with the upper limit once again occurring in the posterior section, and the lower limit occurring in the medial section.

After all these graphs are produced, in order to complete the idea of regional factors within the microstructure of bone, we must view the value of porosity volume fractions versus area. This is seen below in Figure 4.12.

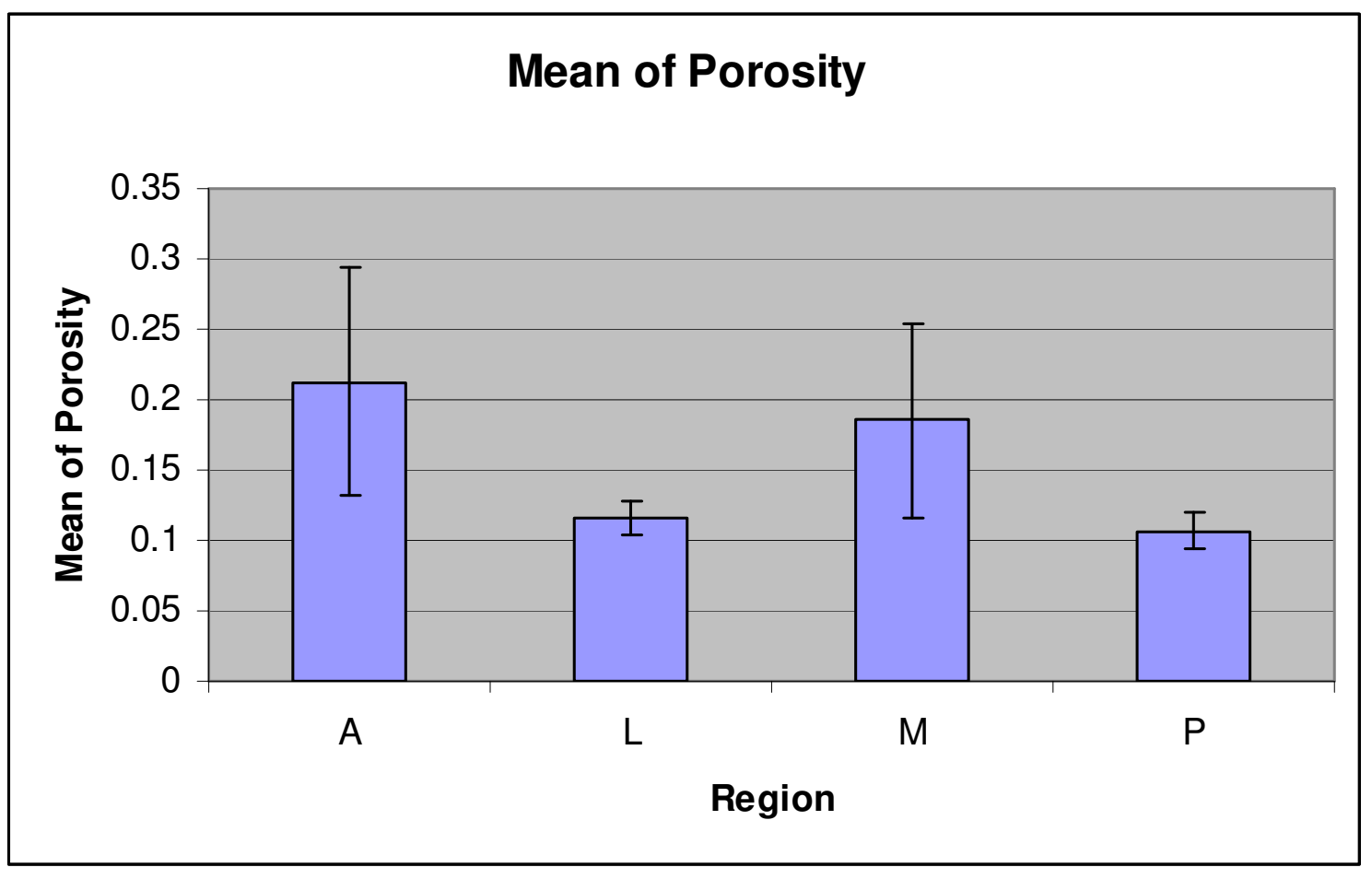

Figure 4.12 Chart of Mean for Porosity versus Region. This chart shows the larger concentrations of porosity in the anterior and lateral regions. In the medial and finally the posterior regions, the porosity reaches its lows, implying that densities are highest in the posterior region. Values range from $9-23 \%$ porosity. 
As is seen from this illustration of porosity volume fraction, the highest percentage of porosity exists in the anterior section of bone $(23 \%)$. The lateral and medial sections are in the middle, with $18 \%$ and $11 \%$ volume fractions respectively. On the lower limit of porosity volume fraction per area are the posterior sections with $9 \%$. This means that there is the most open space in the anterior section, and the least open space in the posterior section of bone. It would also follow that because of this, the density of the anterior region should be the lowest, and the density of the posterior region should be the highest.

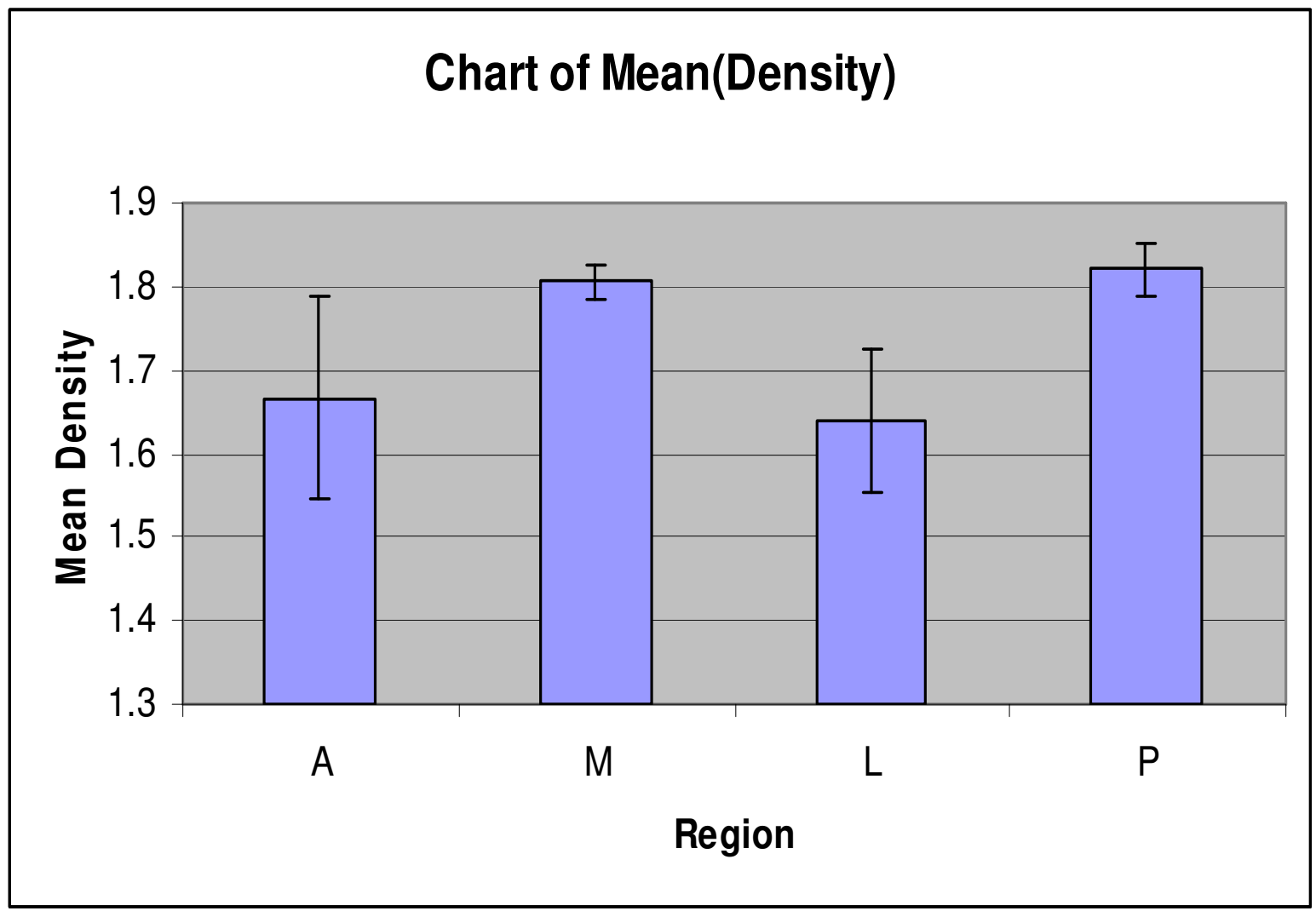

Figure 4.13 Chart of Mean for Density versus Region. Generated in order to determine if certain regions are denser than others. This chart depicts that posterior region is densest and anterior and lateral regions are least dense. 
As we can see from Figure 4.13, this is indeed the case, although the margin of difference is not quite as high as we would expect.

Because the purpose of the study is focused on fracture toughness, a graph was also produced comparing $\mathrm{K}_{\mathrm{C}}$ values versus region as a main effects plot. This, along with an additional main effects plot, for the benefit of porosity is provided in Figure 4.14,

\subsection{5.}

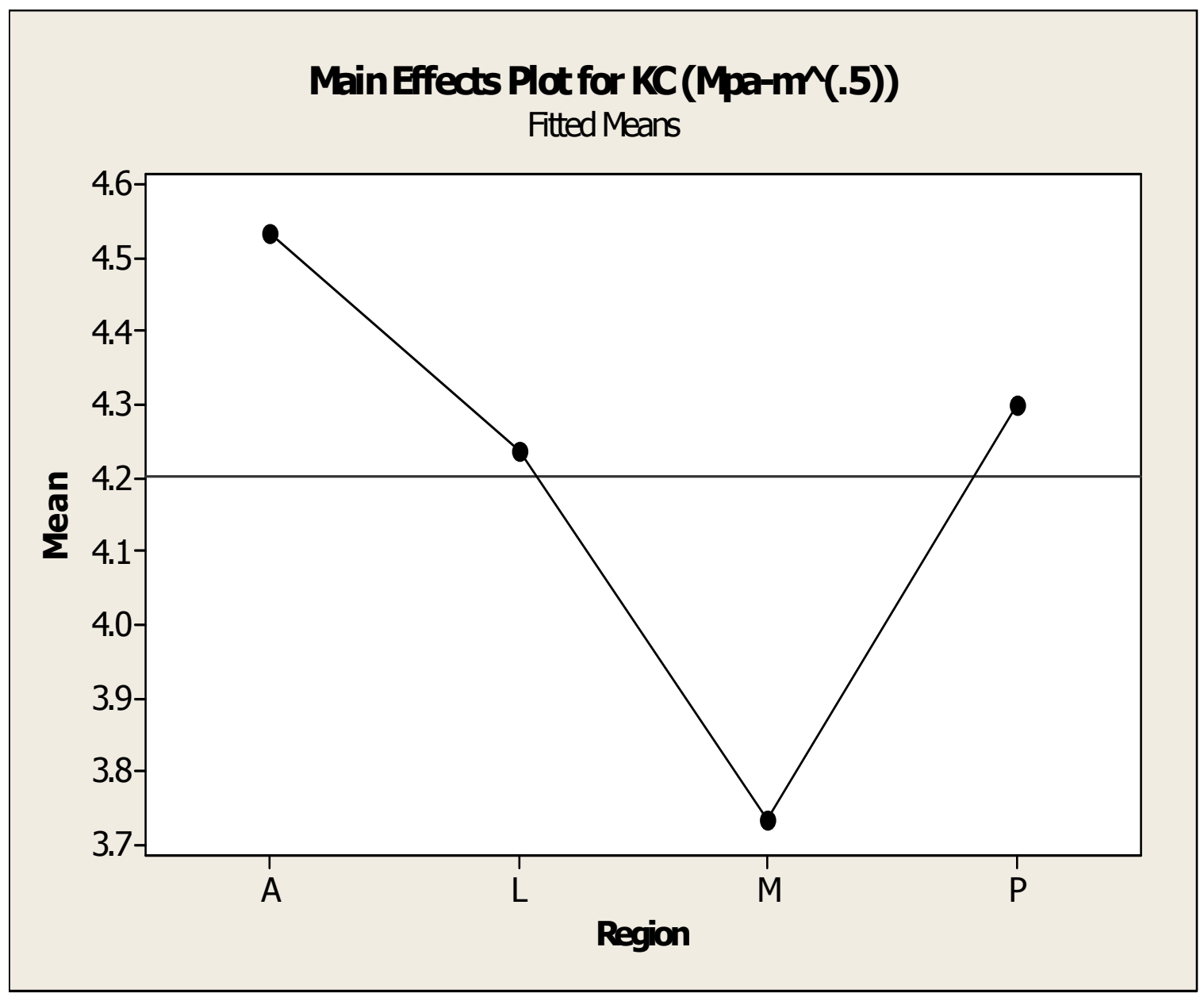

Figure 4.14 Main Effects Plot for Fracture Toughness versus Region. The fracture toughness is highest in the anterior region, decreases through the lateral to the medial region, and then spikes back up in the posterior region. 


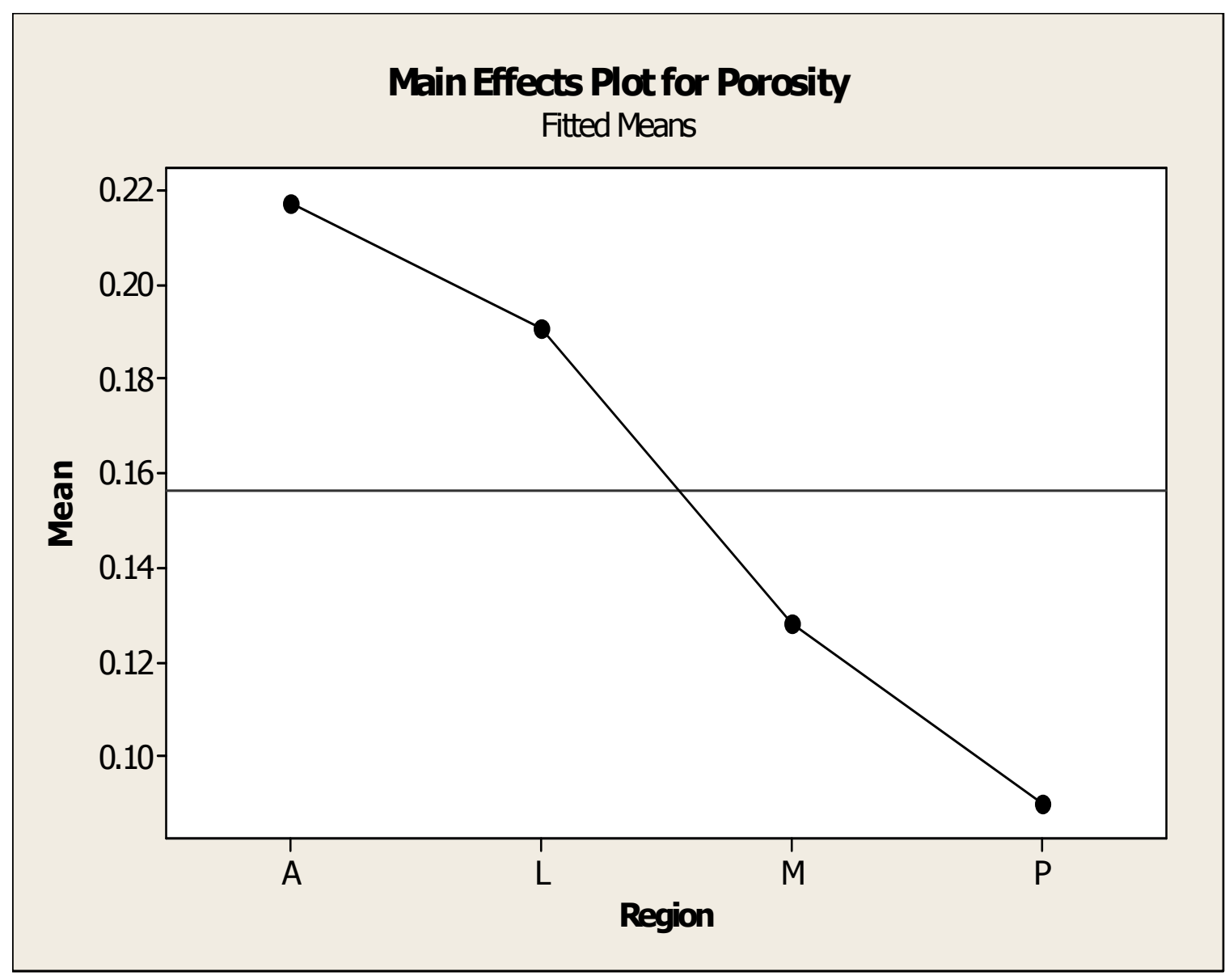

Figure 4.15 Main Effects Plot for Porosity versus Region. Porosity is highest in the anterior region and decreases steadily through the lateral and medial region and is lowest in the posterior region.

Figure 4.15 is very closely related to Figure 4.12 , but provides a better view for showing the trend that porosity has throughout each region. Figure 4.14 illustrates the fracture toughness values by region; unexpectedly, there is a spike upwards in the value when entering the posterior region.

In the search for an ideal model for expressing volume fraction using a regression analysis, it was previously mentioned that porosity was included in every model because of the large amount of variation it accounted for. It appeared that the best possible model that could be generated involved $\mathrm{K}_{\mathrm{C}}$ versus Porosity, VF Hoop, VF Light, VF Alt. The results from Minitab were as follows: 


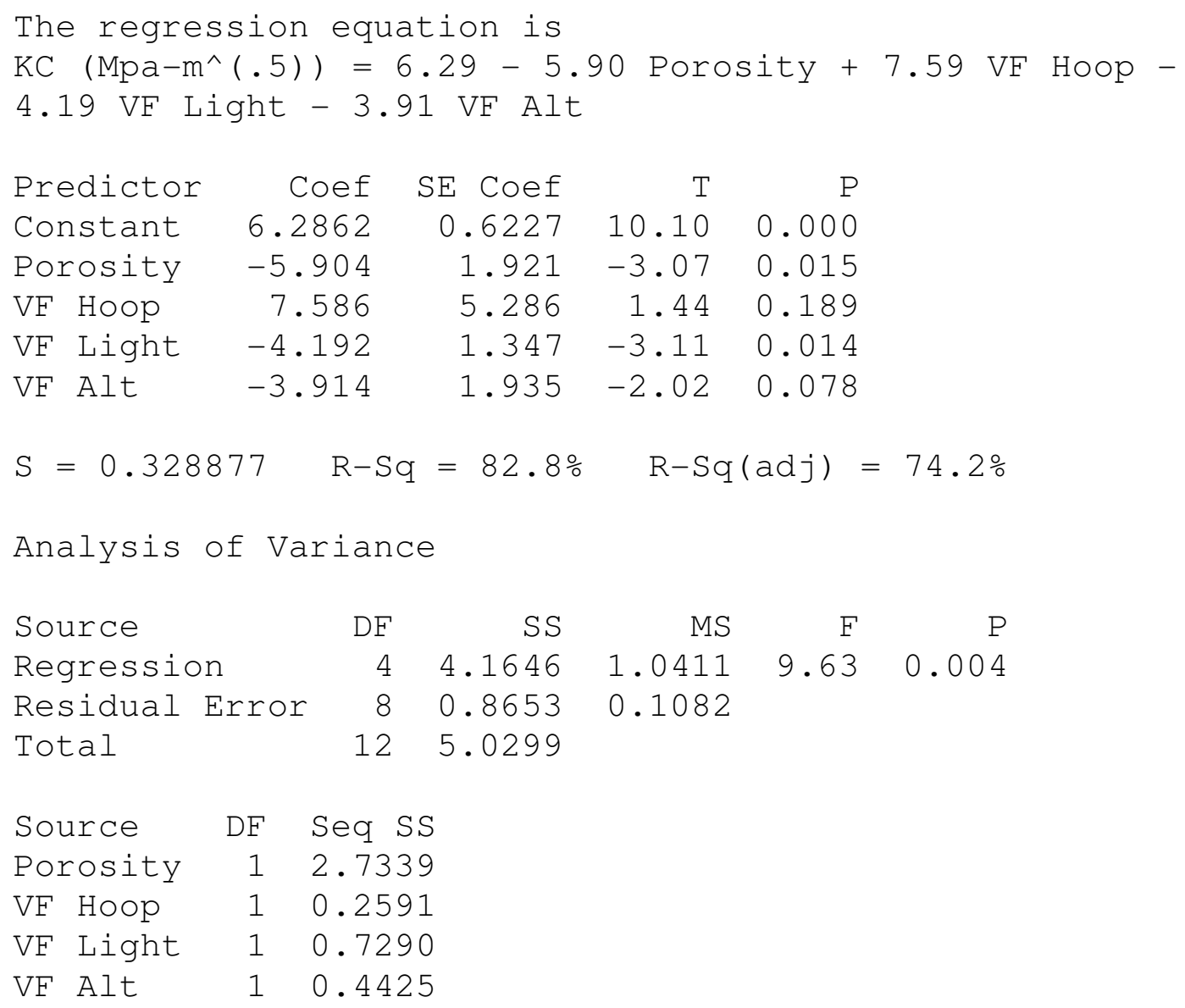

As we can see from this excerpt of analysis, as the fracture toughness increases, porosity, volume fraction of light and volume fraction of alternating all decrease; however the volume fraction of hooped increases. Under the P column, the confidences for each parameter are shown. Porosity and volume fraction of lightfield osteons both have very good confidence levels of .014 and .015 which corresponds to $98.5 \%$ and $98.6 \%$ confidence. Volume fraction of alternating osteons is not quite within our confidence level of .05 , but it is very close and therefore can be counted into our model. Volume fraction of hooped osteons does not have a very high confidence level, and was taken out of the model; however, when the regression is performed without Volume fraction of hooped osteons, the R-sq value decreases from $74.2 \%$ to $71.2 \%$. Because of 
this, and regardless of its unsatisfactory confidence level, it is still included into the model. The R-sq value we achieved of $74.2 \%$ means that about three-quarters of the variance within the model was explained. This is a very reasonable number for a regression analysis, which is why this model has been chosen as the best fit.

Alternatively, and in order to ensure that the best possible combination was chosen, additional models were created using the "General Linear Model" function. This was especially helpful in determining regional differences because it allows a comparison between $\mathrm{K}_{\mathrm{C}}$ and region, while using other parameters are covariates. For the first analysis, the same parameters as in the ideal regression were used. This yielded results as follows:

\section{General Linear Model: KC (Mpa-m^(.5)) versus Region}

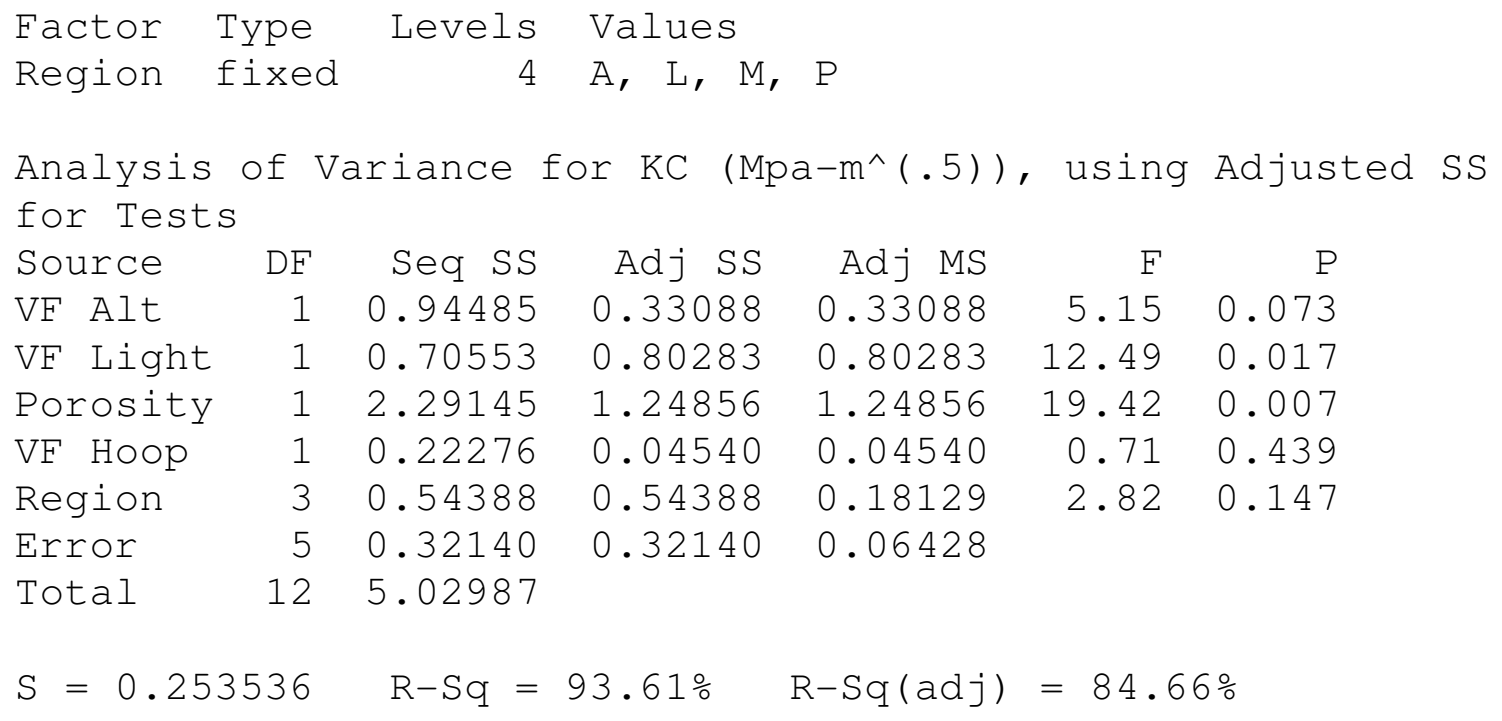

As is apparent, this gave us a very high R-Sq value of almost $85 \%$, which is a very strong model. While viewing the confidence level for each parameter, it appears that there is one in particular that could be decreasing the validity of the model: Volume Fraction of Hooped. With a P value of 0.439 , it appears that eliminating it would perhaps 
increase the $\mathrm{R}-\mathrm{Sq}$ value. Therefore, an additional analysis was run with the same covariates, minus the Volume Fraction of Hooped.

General Linear Model: KC (Mpa-m^(.5)) versus Region

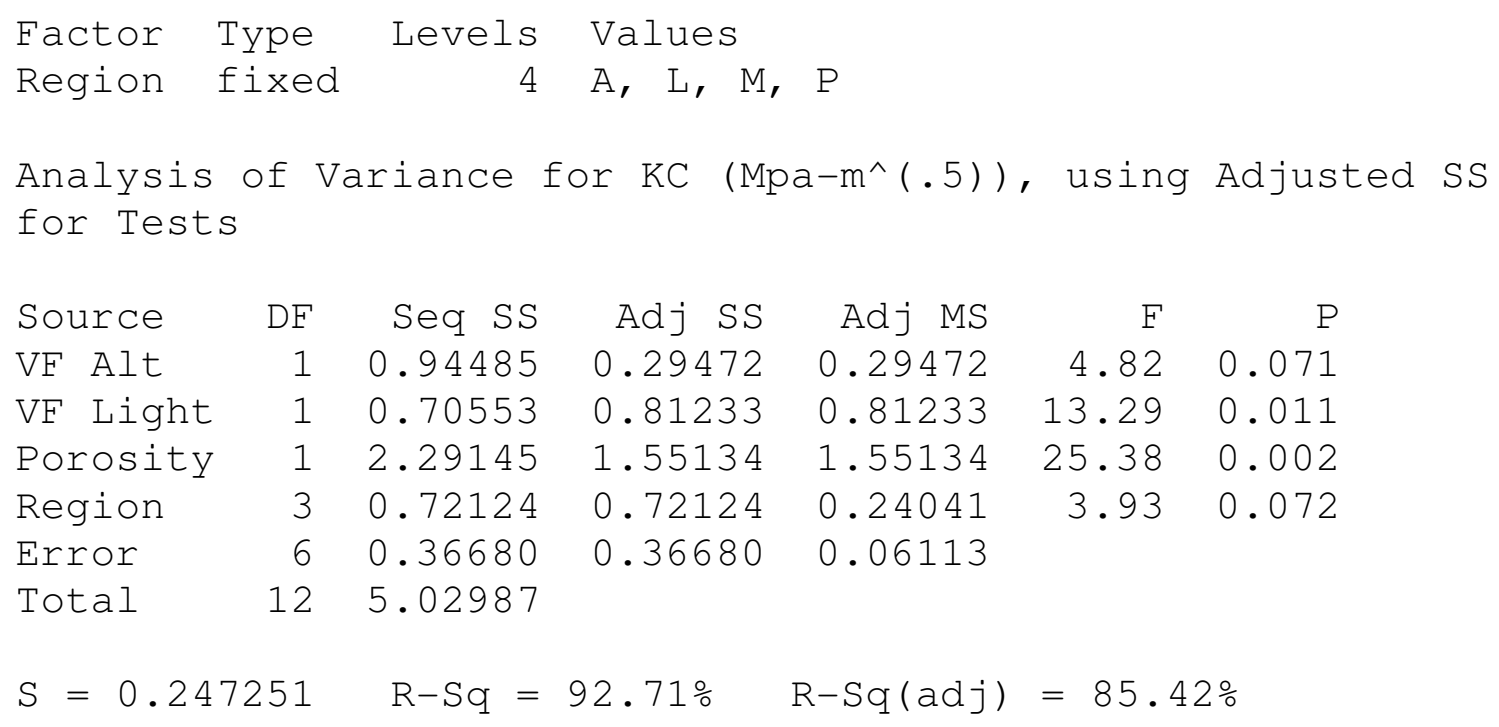

Eliminating the volume fraction of hooped osteons did indeed improve our model to an R-Sq value of $85.42 \%$. It was not by a significant difference that the value was changed; however when the R-Sq value is that high, every percentage point counts. Therefore, it was determined that this is our ideal combination while analyzing using a General Linear Model. As is seen previously, volume fraction of hooped was questionable in both types of models expressed. In the latter model expressed, volume fraction of alternating osteons and region are extremely close to our required confidence level, and so may be included in the model. Volume fractions of light and porosity have extremely good confidence values, well under the limitation of .05 that was set down. Based on all of these models, we can determine that volume fraction of alternating osteons, volume fraction of light osteons, porosity and region all have a large effect on the fracture toughness; volume fraction of hooped osteons has a middling effect on fracture toughness, but not near the significance of the previously mentioned parameters. 


\section{Discussion}

Numerous studies over the past century have been performed on osteonal bone in order to determine all manner of things: tensile and compressive strengths; bending, elastic modulus, fracture properties; orientation of microstructure fibers; and the purpose of each osteon type. (3-12) There were three main objectives that this experiment intended to cover; they all had to be completed in a particular order, because the first step was necessary for the second and third.

The first objective of this study was to quantify the microstructure of cortical bone using polarized light. This was completed and documented on samples from human cortical bone taken from a test subject's tibia. The results were analyzed for any trends that might be apparent with a surface examination. There were conjectures as to the presence of some patterns or trends; however closer examination was needed in order to firm the beliefs. So, in order to do this, the data collected was correlated with fracture toughness data from another experiment. These two sets of data, in conjunction, were submitted to a further analysis using the Minitab program in order to determine differences in microstructure, and to determine which factors most affected the fracture toughness of the cortical bone.

There were three hypotheses set down when this experiment was begun in anticipation of the results, the first of which was: regional differences will be present in the microstructure of osteonal bone. While examining the results of the quantification of the microstructure of the samples, it is clear there are regional differences. Alternating osteons were present with a fairly constant volume fraction, regularly taking up $20-25 \%$ of each sample area for each region. Hooped osteons were also constant from region to 
region taking up an almost insignificant volume fraction of $1-5 \%$ per sample area. The regional difference then becomes apparent when comparing light and dark osteons. The ranges of the volume fraction are closely similar, at $7-18 \%$ throughout samples as seen in Figures 4.4 and 4.5; however, the proportion of each type per region is apparently inversely related. Darkfield osteons dominate the anterior region and are least present in the posterior region. Conversely, lightfield osteons dominate the posterior region and are least apparent in the anterior region. Based only on this result, we can surmise that there are regional differences in osteonal bone.

As a human walks, different parts of the tibial bone are subject to different stresses. The posterior region of the tibia is subject to tensile stresses as a human walks; simultaneously, the anterior region of the tibia is subject to compressive stresses. It is the conjecture of this study, that different osteon types are present in differing regions of bone for fatigue and stress reasons. Lightfield osteons are composed of lamellae upon lamellae all oriented in the longitudinal direction. For this reason, they are most beneficial where the stresses are tensile. Darkfield osteons are composed of lamellae upon lamellae all oriented in the transverse direction. These are most beneficial where the stresses are compressive. Nothing in human biology or mechanics is by chance, the concentration of these particular types of osteons are something that the human body has done on purpose in order to make the structure of each human most durable.

As we can see from Figure 4.14, porosity is the most concentrated in the anterior regions and decrease over the lateral and medial sections, and is the least concentrated in the posterior region. This is an acceptable result and it can be reasoned that because of this, the fracture toughness should follow a similar course. However, when we view 
Figure 4.15 , we can see that $\mathrm{K}_{\mathrm{C}}$ begins on a course similar to this, having the highest value in the anterior region and decreasing again over the lateral and medial regions. From this point, we would expect that fracture toughness would reach its low point in the posterior region, similar to the porosity; however $\mathrm{K}_{\mathrm{C}}$ spikes at this point and increases back to a point almost at the maximum fracture toughness value in the anterior region. We might ask, "Why does this occur?"

The anterior and posterior regions are most exposed to stresses during everyday strain of bone. This means that these areas of bone are fatigued more regularly than the lateral and medial regions of bone. Based on these facts, it makes sense that the fracture toughness values are highest in the anterior and posterior regions. This opinion agrees with M.G. Ascenzi et al.'s study (2003) in which they concluded that the observed orientation differences suggest that the dark lamella is more resistant to axial tension and bending than the bright lamella at an equal degree of calcification. The question of whether the two lamellar types differ in terms of elementary component densities remains unresolved; however the differences observed in the two types of lamellar specimens suggest that they serve distinctly different mechanical and possibly biological functions.

It is the opinion of this author that the lightfield osteons increased concentration in the posterior region has something to do with the increased fracture toughness in that region. It appears that the darkfield osteon and lightfield osteon each have distinct characteristics. Perhaps as the bone is subjected to different stresses it pushes out one kind of osteon and induces the tissue to remodel into the other type of osteon. Since there are an overwhelming amount of lightfield osteons in the posterior region, it stands to reason that this region is most subject to tensile stresses. Comparatively, because of the 
large amount of darkfield osteons in the anterior region, it would also imply the highest compressive forces in this region.

Now, contemplate the human tibia and picture the bone during a typical strain cycle (i.e. walking a step). As the foot touches the ground, heel first, not much of the body's weight is focused on the side with contact to the ground. The body continues to move forward as the entire foot is in contact with the ground and the other foot begins to lift in the air heel first. At this point, the side of the body with the foot departing the ground has all the pressure centered in the ball of the foot. In this position the body's weight is focused over the anterior end of the body and, likewise the anterior region of the bones. With all of this weight pushing down on the anterior surface of the bone it compresses. This compression then results in a tension in the posterior region. As this foot completely leaves the ground, the subject's weight is completely held up by the one foot still in contact with the ground. The same forces are in effect in this position, now in the other leg. So, it is the opinion of this author that the body's natural cycle of strain denotes where certain osteon types are focused. As was mentioned earlier, nothing the human body does is by accident. The orientation of osteons is designed in order to be most beneficial to the body.

In regards to the last two hypotheses made at the beginning of this study, there was significant proof supporting their ideas. They were as follows: that the volume fracture of osteons will affect the fracture toughness and that specific osteon types will affect the fracture toughness as well. For proof for these conjectures, we turn to the Minitab analysis preformed. Once again referring to the ideal model generated to express the fracture toughness, we can clearly see that not only the volume fraction of osteons 
affect the fracture toughness, but specific osteon types as well. It stands to reason that as these osteon structures within bone increase or decrease in frequency it would affect the toughness of the bone. Presenting the regression equation for the ideal model for fracture toughness: $\mathrm{KC}\left(\operatorname{Mpa}-\mathrm{m}^{\wedge}(.5)\right)=6.29-5.90$ Porosity $+7.59 \mathrm{VF}$ Hoop - 4.19 VF Light - 3.91 VF Alt, we can see that the volume fractions of hooped, lightfield, and alternating osteons all affect the fracture toughness in a major way. From the Minitab analysis we remember that the parameter that has the most affect on fracture toughness is porosity. Thinking about this, logic agrees that as the porosity increases, there is more open space within the bone and less material to resist the propagation of a crack, hence less fracture toughness. Based on this result, we can surmise that the results obtained in this study are in fact pertinent and accurate.

With the conclusion of this discussion, we can see that all three objectives were completed, and in doing so, proof was supplied for all three hypotheses made at the beginning of this study and it appears that they were all sound and correct. 


\section{Limitations}

As in any experiment, there are limitations to the validity of the study. In this case, all the samples tested were procured from the same source. Although all of the logic surrounding the hypotheses made is sound and reasonable, there is a chance that the patterns detected in this study would not be apparent in a different test subject. Of course there is always the chance that the equipment used was not calibrated to specifications, although limitations such as these are not likely and therefore are discounted. Additionally, as in any experiment, there is the potential for human error. The tracings performed in BioQuant were all manually done; at times it was difficult to maintain accuracy while keeping a steady pointer on the line being traced. This can create errors in the data if not cautious. 


\section{Conclusions}

In regards to conclusions made from this study, it was determined that there are regional differences in human bones based on stress and strain patterns. Darkfield osteons are present in areas where compressive strains are present, and lightfield osteons are present where tensile stresses are present. Based on this, anterior regions contain darkfield osteons and are subject to the most compressive stresses; posterior regions contain lightfield osteons and are subject to tensile stresses. Both of these osteon types are in place because their fiber orientation makes them most apt for handling those respective stresses. It was determined that the volume fraction of osteons affects the fracture toughness of a sample because the osteons are structural units designed to add stability to a sample. It was also decided that specific types of osteons affect the fracture toughness, some more than others. The degree to which each type affected the $\mathrm{K}_{\mathrm{C}}$ value was highlighted by the Minitab analysis results. Porosity is an extremely good predictor for fracture toughness, since it is inversely related to density and the value for $\mathrm{K}_{\mathrm{C}}$. There was strong evidence that the differences in microstructure were present by region; however further investigation would be needed into this matter in order to completely determine the reason for the differences in osteon concentration per region. 
Appendix A: BioQuant Data Tables 


\begin{tabular}{|lll|l|}
\hline & & & \\
& A & & B $9 \mathrm{~N} 2 \mathrm{A3}$ \\
& B & \\
\hline
\end{tabular}

B9N2A3 - A1

B9N2A3-A2

\begin{tabular}{|l|l|l|}
\hline Array Heading & Array Type & Value \\
\hline A1 & Total Volume & 539900.62 \\
\hline A2 & Hooped Edge & 28220.55 \\
\hline A4 & Darkfield Edge & 24805.37 \\
\hline & & 26926.98 \\
\hline A5 & Alternating Edge & 44970.40 \\
\hline & & 6044.98 \\
\hline A6 & Porosity & 26585.81 \\
\hline & & 3578.65 \\
\hline & & 3003.83 \\
\hline & & 1133.66 \\
\hline & & 18619.13 \\
\hline & & 2290.41 \\
\hline & & 5248.04 \\
\hline & & 8077.74 \\
\hline & & 76911.75 \\
\hline A9 & Darkfield Central & 19930.48 \\
\hline A10 & $\begin{array}{l}\text { Alternating } \\
\text { Central }\end{array}$ & 15346.10 \\
\hline & & 10532.51 \\
\hline
\end{tabular}

\begin{tabular}{|l|l|l|}
\hline Array Heading & Array Type & Value \\
\hline A1 & Total Volume & 539900.62 \\
\hline A5 & Alternating Edge & 11502.69 \\
\hline & & 9358.87 \\
\hline A6 & Porosity & 26183.35 \\
\hline & & 1633.85 \\
\hline & & 7383.86 \\
\hline & & 8111.850 \\
\hline & & 8031.54 \\
\hline & & 1374.42 \\
\hline & & 172.36 \\
\hline & & 26218.89 \\
\hline A8 & Lightfield Central & 24250.98 \\
\hline A9 & Darkfield Central & 7876.95 \\
\hline A10 & Alternating Central & 32627.24 \\
\hline & & 36471.54 \\
\hline & & 35626.62 \\
\hline
\end{tabular}

*Note: There are two Topos recorded per chip of bone. "1" signifies the top topo, "2" signifies the bottom.

*Note: From this point forward, "Total Volume" can be considered a constant value, unless otherwise noted.

*Note: The "Array Heading" was a parameter label used in the program BioQuant to classify types of osteons. 


\begin{tabular}{|ll|l|}
\hline A & & \\
& B & B 9 H 2 A3 \\
& & \\
\hline
\end{tabular}

B9N2A3-B1

\begin{tabular}{|l|l|l|}
\hline Array Heading & Array Type & Value \\
\hline A3 & Lightfield Edge & 9960.35 \\
\hline & & 3249.04 \\
\hline A4 & Darkfield Edge & 15617.08 \\
\hline & & 11378.31 \\
\hline & & 41751.56 \\
\hline A5 & & 30329.39 \\
\hline & & 38.20 \\
\hline & Porosity & 8959.07 \\
\hline A6 & & 2405.91 \\
\hline & & 6825.03 \\
\hline & & 596.15 \\
\hline & & 1110.15 \\
\hline & & 350.05 \\
\hline & & 4193.46 \\
\hline & & 2677.77 \\
\hline & & 8124.82 \\
\hline & & 1282.03 \\
\hline & & 51313.89 \\
\hline & & 834.25 \\
\hline A7 & & 20310.73 \\
\hline A10 & Alternating Central & 25979.89 \\
\hline & & 14826.36 \\
\hline & & 3687.93 \\
\hline & & 14155.59 \\
\hline
\end{tabular}

B9N2A3-B2

\begin{tabular}{|l|l|l|}
\hline Array Heading & Array Type & Value \\
\hline A3 & Lightfield Edge & 20146.37 \\
\hline & & 17114.11 \\
\hline A4 & Darkfield Edge & 18619.13 \\
\hline A5 & Alternating Edge & 15153.31 \\
\hline & & 31979.56 \\
\hline & & 16413.12 \\
\hline & & 13785.99 \\
\hline & Porosity & 61578.98 \\
\hline A6 & & 3290.80 \\
\hline & & 4586.15 \\
\hline & & 4145.48 \\
\hline & & 4705.20 \\
\hline & & 30404.35 \\
\hline & & 15189.74 \\
\hline & & 22291.07 \\
\hline & & 2667.11 \\
\hline & & 325.95 \\
\hline & & 536.62 \\
\hline A9 & Darkfield Central & 26674.66 \\
\hline A10 & & 43122.43 \\
\hline & & 46423.00 \\
\hline
\end{tabular}




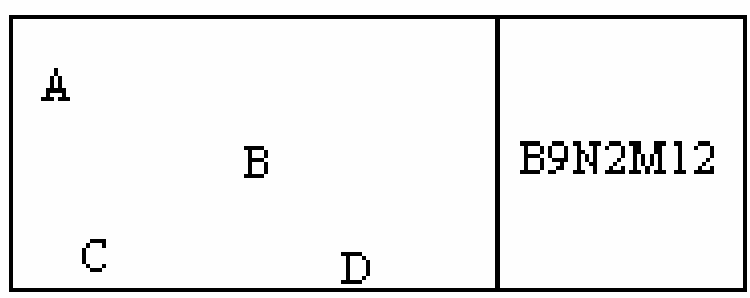

B9N2M1,2-A1

B9N2M1,2-A2

\begin{tabular}{|c|c|c|}
\hline Array Heading & Array Type & Value \\
\hline A3 & Lightfield Edge & 20293.85 \\
\hline \multirow[t]{2}{*}{ A4 } & Darkfield Edge & 4564.83 \\
\hline & & 8000.44 \\
\hline \multirow[t]{3}{*}{ A5 } & Alternating Edge & 13058.36 \\
\hline & & 14342.16 \\
\hline & & 8622.35 \\
\hline \multirow[t]{12}{*}{ A6 } & Porosity & 1970.57 \\
\hline & & 1639.18 \\
\hline & & 623.69 \\
\hline & & 3051.81 \\
\hline & & 28937.53 \\
\hline & & 1813.32 \\
\hline & & 701.87 \\
\hline & & 6289.30 \\
\hline & & 4387.14 \\
\hline & & 3025.15 \\
\hline & & 7745.46 \\
\hline & & 180.35 \\
\hline A7 & Hooped Central & 30351.93 \\
\hline A8 & Lightfield Central & 19111.33 \\
\hline \multirow[t]{5}{*}{ A10 } & Alternating Central & 15700.59 \\
\hline & & 10162.92 \\
\hline & & 26425.89 \\
\hline & & 21914.37 \\
\hline & & 7440.72 \\
\hline
\end{tabular}

\begin{tabular}{|l|l|l|}
\hline Array Heading & Array Type & Value \\
\hline A3 & Lightfield Edge & 6837.47 \\
\hline & & 17734.24 \\
\hline A5 & Alternating Edge & 19401.85 \\
\hline & & 1417.57 \\
\hline & & 10014.55 \\
\hline & & 3228.61 \\
\hline & & 6126.71 \\
\hline A6 & Porosity & 36934.41 \\
\hline & & 2464.55 \\
\hline & & 12717.19 \\
\hline & & 6311.51 \\
\hline & & 448.66 \\
\hline & & 202.57 \\
\hline & & 3945.58 \\
\hline & & 2946.08 \\
\hline & & 673.44 \\
\hline & & 419.35 \\
\hline & & 770.28 \\
\hline A8 & & 28396.46 \\
\hline A9 & Lightfield Central & 74874.55 \\
\hline A10 & Darkfield Central & 33499.69 \\
\hline & Alternating Central & \\
\hline & & \\
\hline & & \\
\hline & & \\
\hline & & \\
\hline & & \\
\hline & & \\
\hline & & \\
\hline & & \\
\hline & & \\
\hline & & \\
\hline & & \\
\hline & & \\
\hline & & \\
\hline
\end{tabular}




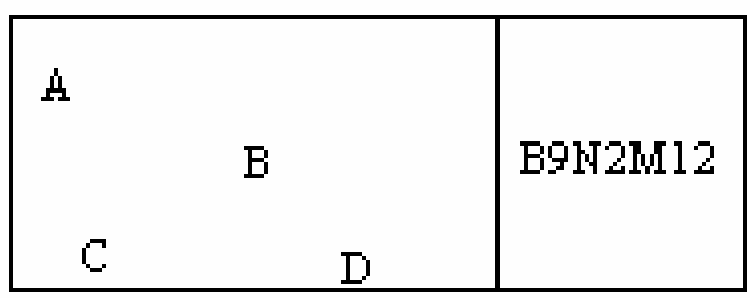

B9N2M1,2-B1

B9N2M1,2-B2

\begin{tabular}{|c|c|c|}
\hline Array Heading & Array Type & Value \\
\hline \multirow[t]{2}{*}{ A4 } & Darkfield Edge & 16607.69 \\
\hline & & 12447.11 \\
\hline \multirow[t]{6}{*}{ A5 } & Alternating Edge & 15838.30 \\
\hline & & 6394.14 \\
\hline & & 7175.08 \\
\hline & & 11462.71 \\
\hline & & 5368.87 \\
\hline & & 17911.93 \\
\hline \multirow[t]{12}{*}{ A6 } & Porosity & 977.29 \\
\hline & & 4281.41 \\
\hline & & 4930.87 \\
\hline & & 2752.40 \\
\hline & & 4500.86 \\
\hline & & 1831.08 \\
\hline & & 2239.77 \\
\hline & & 976.40 \\
\hline & & 3142.43 \\
\hline & & 1214.50 \\
\hline & & 5619.41 \\
\hline & & 350.94 \\
\hline \multirow[t]{2}{*}{ A7 } & Hooped Central & 37327.11 \\
\hline & & 39646.84 \\
\hline \multirow[t]{2}{*}{ A9 } & Darkfield Central & 42728.85 \\
\hline & & 96900.99 \\
\hline A10 & Alternating Central & 14807.70 \\
\hline
\end{tabular}

\begin{tabular}{|l|l|l|}
\hline Array Type & Array Heading & Value \\
\hline A3 & Lightfield Edge & 11648.40 \\
\hline A4 & Darkfield Edge & 28495.97 \\
\hline A5 & Alternating Edge & 21269.36 \\
\hline & & 13451.94 \\
\hline & & 8801.82 \\
\hline & & 29074.35 \\
\hline & & 7386.53 \\
\hline A6 & Porosity & 1042.15 \\
\hline & & 2103.84 \\
\hline & & 1165.64 \\
\hline & & 4206.78 \\
\hline & & 2957.63 \\
\hline & & 1860.40 \\
\hline & & 8052.86 \\
\hline & & 1242.05 \\
\hline & & 7661.06 \\
\hline & & 12120.16 \\
\hline & & 29937.03 \\
\hline A10 & Alternating Central & 22567.38 \\
\hline & & 66378.35 \\
\hline & & 42042.97 \\
\hline & &
\end{tabular}




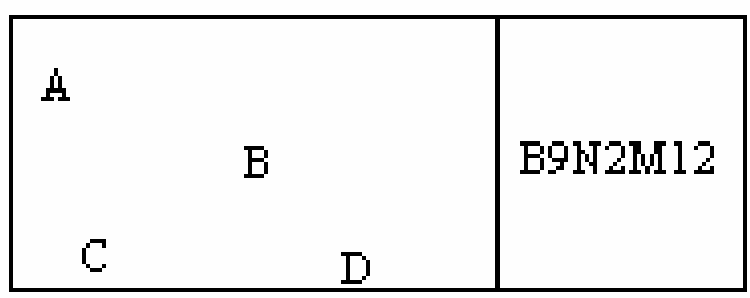

B9N2M1,2-C1

B9N2M1,2-C2

\begin{tabular}{|c|c|c|}
\hline Array Heading & Array Type & Value \\
\hline A4 & Darkfield Edge & 18101.17 \\
\hline \multirow[t]{5}{*}{ A5 } & Alternating Edge & 9785.33 \\
\hline & & 5642.51 \\
\hline & & 9695.59 \\
\hline & & 5876.17 \\
\hline & & 69073.89 \\
\hline \multirow[t]{10}{*}{ A6 } & Porosity & 1815.09 \\
\hline & & 8769.84 \\
\hline & & 28047.30 \\
\hline & & 15921.81 \\
\hline & & 9224.72 \\
\hline & & 30589.14 \\
\hline & & 3501.36 \\
\hline & & 1090.12 \\
\hline & & 3564.44 \\
\hline & & 718.75 \\
\hline \multirow[t]{2}{*}{ A9 } & Darkfield Central & 12693.21 \\
\hline & & 64708.08 \\
\hline \multirow[t]{3}{*}{ A10 } & Alternating Central & 22538.06 \\
\hline & & 48754.28 \\
\hline & & 20856.23 \\
\hline
\end{tabular}

\begin{tabular}{|l|l|l|}
\hline Array Heading & Array Type & Value \\
\hline A4 & Darkfield Edge & 35014.49 \\
\hline & & 14418.57 \\
\hline & & 31060.91 \\
\hline & & 20697.20 \\
\hline A6 & & 36527.51 \\
\hline & & 9246.93 \\
\hline & & 4695.43 \\
\hline & & 4181.91 \\
\hline & & 5049.03 \\
\hline & & 3592.87 \\
\hline & & 871.56 \\
\hline & & 2177.58 \\
\hline & & 5347.55 \\
\hline & & 3239.27 \\
\hline & & 305.62 \\
\hline A10 & & 30298.62 \\
\hline & & 25540.11 \\
\hline & & 24446.24 \\
\hline & & 19157.53 \\
\hline & & 29116.99 \\
\hline
\end{tabular}




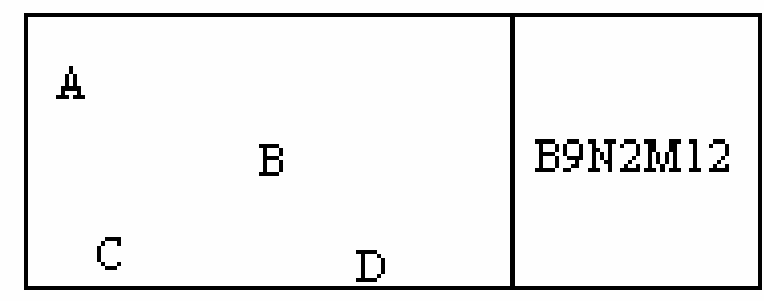

B9N2M1,2-D1

B9N2M1,2-D2

\begin{tabular}{|c|c|c|}
\hline Array Heading & Array Type & Value \\
\hline A3 & Lightfield Edge & 13280.47 \\
\hline A4 & Darkfield Edge & 16363.37 \\
\hline A5 & Alternating Edge & 13068.13 \\
\hline \multirow[t]{15}{*}{ A6 } & Porosity & 227.44 \\
\hline & & 1036.81 \\
\hline & & 1576.10 \\
\hline & & 1617.86 \\
\hline & & 507.30 \\
\hline & & 3305.90 \\
\hline & & 1921.71 \\
\hline & & 2135.82 \\
\hline & & 1563.66 \\
\hline & & 8215.45 \\
\hline & & 353.60 \\
\hline & & 756.95 \\
\hline & & 6224.44 \\
\hline & & 3010.05 \\
\hline & & 2179.35 \\
\hline \multirow[t]{2}{*}{ A9 } & Darkfield Central & 8936.86 \\
\hline & & 27623.52 \\
\hline \multirow[t]{7}{*}{ A10 } & Alternating Central & 10424.12 \\
\hline & & 26873.67 \\
\hline & & 32463.76 \\
\hline & & 13497.25 \\
\hline & & 38056.52 \\
\hline & & 12077.51 \\
\hline & & 10369.92 \\
\hline
\end{tabular}

\begin{tabular}{|l|l|l|}
\hline Array Heading & Array Type & Value \\
\hline A3 & Lightfield Edge & 11648.40 \\
\hline & & 13280.47 \\
\hline A4 & Darkfield Edge & 14174.24 \\
\hline & & 29061.91 \\
\hline A5 & Alternating Edge & 31753.89 \\
\hline & & 26694.20 \\
\hline & & 23598.86 \\
\hline A6 & Porosity & 1250.93 \\
\hline & & 6391.47 \\
\hline & & 4340.94 \\
\hline & & 5146.76 \\
\hline & & 4582.60 \\
\hline & & 4647.45 \\
\hline & & 453.11 \\
\hline & & 263.87 \\
\hline & & 2879.45 \\
\hline & & 29347.99 \\
\hline & & 7016.05 \\
\hline A8 & & 26847.90 \\
\hline A10 & Lightfield Central & 25104.78 \\
\hline & & 24896.88 \\
\hline & & 32413.12 \\
\hline
\end{tabular}




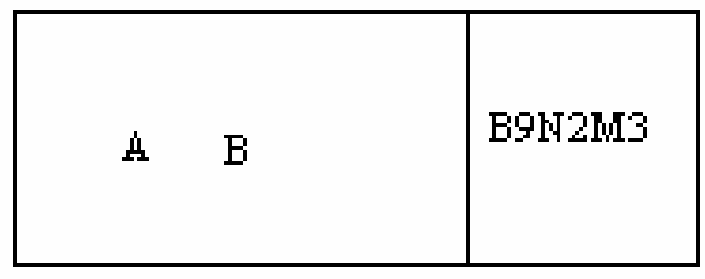

B9N2M3-A1

\begin{tabular}{|l|l|l|}
\hline Array Heading & Array Type & Value \\
\hline A3 & Lightfield Edge & 26178.02 \\
\hline & & 20859.79 \\
\hline & & 15465.15 \\
\hline A4 & Darkfield Edge & 22945.86 \\
\hline A5 & Alternating Edge & 10233.10 \\
\hline A6 & Porosity & 1615.19 \\
\hline & & 34493.86 \\
\hline & & 538.40 \\
\hline & & 3741.24 \\
\hline & & 96469.08 \\
\hline & & 4483.98 \\
\hline A8 & & 65708.47 \\
\hline A10 & Lightfield Central & 43646.61 \\
\hline
\end{tabular}

B9N2M3-A2

\begin{tabular}{|c|c|c|}
\hline Array Heading & Array Type & Value \\
\hline \multirow[t]{3}{*}{ A3 } & Lightfield Edge & 20859.79 \\
\hline & & 15765.15 \\
\hline & & 798.71 \\
\hline \multirow[t]{4}{*}{ A5 } & Alternating Edge & 10233.10 \\
\hline & & 3946.47 \\
\hline & & 11395.19 \\
\hline & & 15142.65 \\
\hline \multirow[t]{10}{*}{ A6 } & Porosity & 6787.72 \\
\hline & & 5694.04 \\
\hline & & 2436.11 \\
\hline & & 1143.43 \\
\hline & & 246.99 \\
\hline & & 3263.26 \\
\hline & & 1165.64 \\
\hline & & 1422.40 \\
\hline & & 2373.92 \\
\hline & & 1288.24 \\
\hline \multirow[t]{2}{*}{ A8 } & Lightfield Central & 34934.53 \\
\hline & & 32791.60 \\
\hline \multirow[t]{2}{*}{ A10 } & Alternating Central & 21823.75 \\
\hline & & 35134.43 \\
\hline
\end{tabular}




\begin{tabular}{|c|c|c|}
\hline A & B & $\mathrm{B} 9 \mathrm{~N} 2 \mathrm{M} 3$ \\
\hline
\end{tabular}

B9N2M3-B1

\begin{tabular}{|l|l|l|}
\hline Array Heading & Array Type & Value \\
\hline A3 & Lightfield Edge & 4536.40 \\
\hline A5 & Alternating Edge & 27459.15 \\
\hline A6 & Porosity & 2014.10 \\
\hline & & 1134.54 \\
\hline & & 5643.40 \\
\hline & & 3192.18 \\
\hline & & 918.65 \\
\hline & & 284.30 \\
\hline & & 1584.98 \\
\hline & & 2285.08 \\
\hline & & 1341.55 \\
\hline & & 238.10 \\
\hline & & 476.21 \\
\hline & & 531.29 \\
\hline A7 & & 22164.91 \\
\hline A8 & Lightfield Central & 24057.30 \\
\hline & & 13371.09 \\
\hline A10 & Alternating Central & 10138.93 \\
\hline & & 8236.77 \\
\hline & & 28169.91 \\
\hline & & 9714.25 \\
\hline & & 20517.74 \\
\hline
\end{tabular}

B9N2M3-B2

\begin{tabular}{|l|l|l|}
\hline Array Heading & Array Type & Value \\
\hline A3 & Lightfield Edge & 28564.38 \\
\hline & & 6052.08 \\
\hline & & 14599.81 \\
\hline A5 & Alternating Edge & 34753.28 \\
\hline & & 15279.47 \\
\hline & & 6456.33 \\
\hline A6 & Porosity & 19768.78 \\
\hline & & 4085.96 \\
\hline & & 4590.59 \\
\hline & & 1316.67 \\
\hline & & 5067.69 \\
\hline & & 1497.92 \\
\hline & & 5406.18 \\
\hline & & 434.45 \\
\hline & & 44.42 \\
\hline & & 1561.00 \\
\hline & & 11452.05 \\
\hline & & 3141.54 \\
\hline A8 & & 1687.16 \\
\hline A9 & Lightfield Central & 27723.91 \\
\hline A10 & Darkfield Central & 36698.09 \\
\hline & Alternating Central & 33931.47 \\
\hline
\end{tabular}




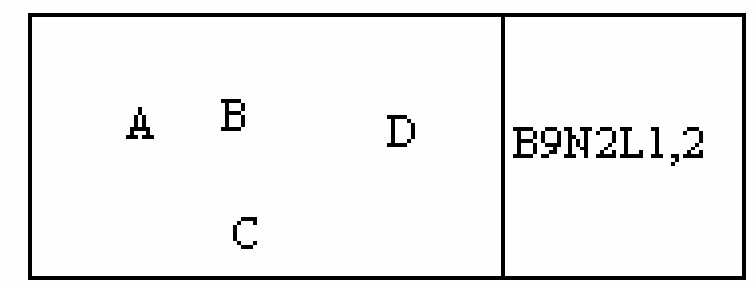

B9N2L1,2-A1

B9N2L1,2-A2

\begin{tabular}{|l|l|l|}
\hline Array Heading & Array Type & Value \\
\hline A1 & Total Volume & 474939.33 \\
\hline A4 & Darkfield Edge & 16580.15 \\
\hline & & 8490.86 \\
\hline & & 3759.90 \\
\hline A5 & Alternating Edge & 21906.38 \\
\hline & & 10794.28 \\
\hline & & 11782.55 \\
\hline & & 9896.38 \\
\hline A6 & Porosity & 1661.39 \\
\hline & & 2105.61 \\
\hline & & 5130.77 \\
\hline & & 843.13 \\
\hline & & 3698.57 \\
\hline & & 980.84 \\
\hline & & 17960.79 \\
\hline & & 65402.84 \\
\hline A10 & & 53954.35 \\
\hline & Alternating Central & 62950.74 \\
\hline
\end{tabular}

\begin{tabular}{|c|c|c|}
\hline Array Heading & Array Type & Value \\
\hline A1 & Total Volume & 477953.82 \\
\hline \multirow[t]{7}{*}{ A5 } & Alternating Edge & 23220.39 \\
\hline & & 28780.27 \\
\hline & & 11460.93 \\
\hline & & 6265.31 \\
\hline & & 13332.00 \\
\hline & & 24703.20 \\
\hline & & 34158.91 \\
\hline \multirow[t]{11}{*}{ A6 } & Porosity & 5451.50 \\
\hline & & 3252.60 \\
\hline & & 10310.40 \\
\hline & & 12028.65 \\
\hline & & 25659.17 \\
\hline & & 11319.67 \\
\hline & & 6071.63 \\
\hline & & 947.97 \\
\hline & & 2650.23 \\
\hline & & 4858.01 \\
\hline & & 6870.34 \\
\hline A9 & Darkfield Central & 27864.28 \\
\hline \multirow[t]{4}{*}{ A10 } & Alternating Central & 79815.60 \\
\hline & & 24395.80 \\
\hline & & 12292.52 \\
\hline & & 29063.68 \\
\hline
\end{tabular}

*Note: This chip of bone was not of the same dimensions as previous specimens; therefore a new Total Volume value was required to maintain accuracy. 


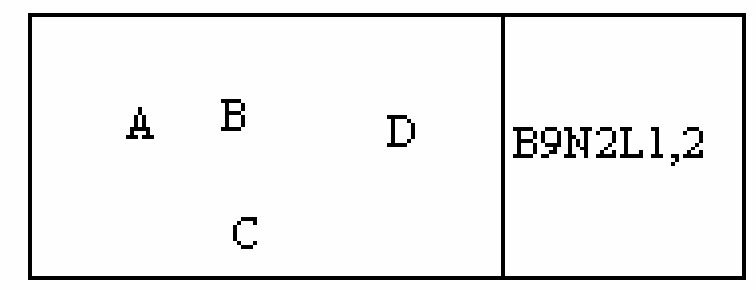

B9N2L1,2-B1

B9N2L1,2-B2

\begin{tabular}{|l|l|l|}
\hline Array Heading & Array Type & Value \\
\hline A1 & Total Volume & 522922.44 \\
\hline A3 & Lightfield Edge & 4528.40 \\
\hline & & 34290.40 \\
\hline & & 15777.89 \\
\hline A5 & Alternating Edge & 17004.83 \\
\hline A6 & & 23078.23 \\
\hline & Porosity & 824.48 \\
\hline & & 3762.56 \\
\hline & & 7029.37 \\
\hline & & 295.85 \\
\hline & & 2979.84 \\
\hline & & 9114.55 \\
\hline & & 9633.40 \\
\hline & & 18322.39 \\
\hline A8 & & 89300.22 \\
\hline A9 & & 56978.61 \\
\hline & Lightfield Central & 17844.41 \\
\hline
\end{tabular}

\begin{tabular}{|l|l|l|}
\hline Array Heading & Array Type & Value \\
\hline A1 & Total Volume & 524056.10 \\
\hline A5 & Alternating Edge & 52906.87 \\
\hline & & 40363.81 \\
\hline A6 & Porosity & 20088.62 \\
\hline & & 4031.76 \\
\hline & & 20508.85 \\
\hline & & 700.09 \\
\hline & & 7245.26 \\
\hline & & 16351.82 \\
\hline & & 12822.03 \\
\hline & & 14340.38 \\
\hline & & 32455.77 \\
\hline A9 & & 25046.14 \\
\hline & Darkfield Central & 51844.29 \\
\hline A10 & & 43810.09 \\
\hline
\end{tabular}




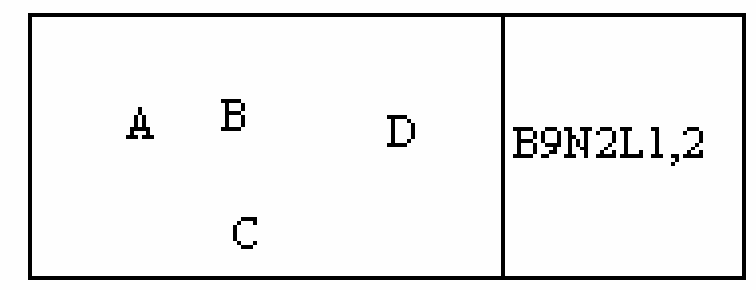

B9N2L1,2-C1

B9N2L1,2-C2

\begin{tabular}{|l|l|l|}
\hline Array Heading & Array Type & Value \\
\hline A1 & Total Volume & 461256.40 \\
\hline A4 & Darkfield Edge & 30137.81 \\
\hline A5 & Alternating Edge & 17141.65 \\
\hline & & 33230.49 \\
\hline A6 & Porosity & 5731.36 \\
\hline & & 7171.52 \\
\hline & & 10892.33 \\
\hline & & 8103.50 \\
\hline & & 498.42 \\
\hline & & 3133.54 \\
\hline & & 1505.91 \\
\hline & & 1448.16 \\
\hline & & 5977.45 \\
\hline & & 5271.14 \\
\hline & & 1436.71 \\
\hline A8 & & 45094.78 \\
\hline A9 & Lightfield Central & 20515.07 \\
\hline A10 & Darkfield Central & 39374.97 \\
\hline & Alternating Central & 39016.93 \\
\hline & & 11176.63 \\
\hline
\end{tabular}

\begin{tabular}{|l|l|l|}
\hline Array Heading & Array Type & Value \\
\hline A1 & Total Volume & 443928.17 \\
\hline A4 & Darkfield Edge & 5424.84 \\
\hline A5 & Alternating Edge & 36067.29 \\
\hline A6 & Porosity & 26309.51 \\
\hline & & 22539.84 \\
\hline & & 9995.89 \\
\hline & & 4719.42 \\
\hline & & 53274.69 \\
\hline A8 & Lightfield Central & 56531.72 \\
\hline A9 & Darkfield Central & 17983.89 \\
\hline A10 & Alternating Central & 56821.36 \\
\hline & & 72572.59 \\
\hline
\end{tabular}




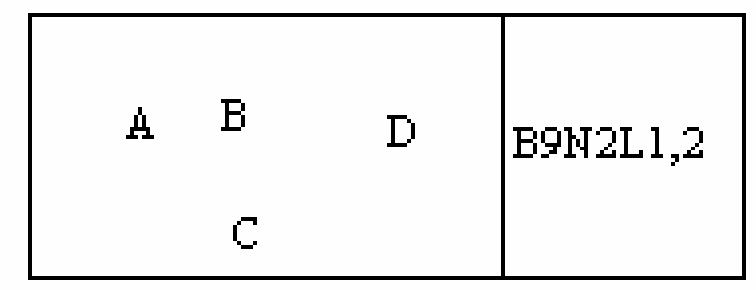

B9N2L1,2-D1

B9N2L1,2-D2

\begin{tabular}{|l|l|l|}
\hline Array Heading & Array Type & Value \\
\hline A1 & Total Volume & 524056.10 \\
\hline A3 & Lightfield Edge & 13517.68 \\
\hline & & 5144.09 \\
\hline A5 & Alternating Edge & 21929.48 \\
\hline & & 6498.08 \\
\hline A6 & Porosity & 20627.90 \\
\hline & & 2742.63 \\
\hline & & 1107.89 \\
\hline & & 8536.17 \\
\hline & & 10622.22 \\
\hline & & 15403.85 \\
\hline & & 9189.18 \\
\hline & & 4461.77 \\
\hline & & 1936.81 \\
\hline & & 11377.42 \\
\hline A7 & & 53452.37 \\
\hline A8 & Hooped Central & 26913.65 \\
\hline & Lightfield Central & 32384.69 \\
\hline A10 & & 25077.23 \\
\hline & Alternating Central & 33359.31 \\
\hline & &
\end{tabular}

\begin{tabular}{|l|l|l|}
\hline Array Heading & Array Type & Value \\
\hline A1 & Total Volume & 524056.10 \\
\hline A4 & Darkfield Edge & 14490.53 \\
\hline & & 15447.38 \\
\hline & & 72768.94 \\
\hline & & 12654.12 \\
\hline A5 & Alternating Edge & 10278.41 \\
\hline & & 15090.23 \\
\hline A6 & Porosity & 730.30 \\
\hline & & 3423.18 \\
\hline & & 2074.52 \\
\hline & & 1293.58 \\
\hline & & 14242.65 \\
\hline & & 2054.08 \\
\hline & & 19666.61 \\
\hline & & 23677.93 \\
\hline & & 25682.27 \\
\hline A9 & & 40935.97 \\
\hline A10 & Darkfield Central & 26002.99 \\
\hline
\end{tabular}




\begin{tabular}{|l|l|}
\hline A B & B9H2L3 \\
\hline
\end{tabular}

B9N2L3-A1

\begin{tabular}{|l|l|l|}
\hline Array Heading & Array Type & Value \\
\hline A1 & Total Volume & 524056.10 \\
\hline A3 & Lightfield Edge & 15841.85 \\
\hline A4 & Darkfield Edge & 3958.02 \\
\hline A5 & Alternating Edge & 25693.81 \\
\hline & & 19922.48 \\
\hline & & 14343.05 \\
\hline A6 & Porosity & 13889.05 \\
\hline & & 432.67 \\
\hline & & 1472.15 \\
\hline & & 6019.21 \\
\hline & & 3494.25 \\
\hline & & 18739.96 \\
\hline & & 2655294 \\
\hline & & 5234.71 \\
\hline & & 4899.77 \\
\hline & & 2163.36 \\
\hline A8 & Lightfield Central & 58748.39 \\
\hline & & 65411.73 \\
\hline A10 & Alternating Central & 35641.73 \\
\hline & & 18684.88 \\
\hline
\end{tabular}

B9N2L3-A2

\begin{tabular}{|l|l|l|}
\hline Array Heading & Array Type & Value \\
\hline A1 & Total Volume & 524056.10 \\
\hline A3 & Lightfield Edge & 6088.55 \\
\hline & & 30351.04 \\
\hline & & 3362.76 \\
\hline A4 & Darkfield Edge & 15649.95 \\
\hline A5 & Alternating Edge & 13909.49 \\
\hline A6 & Porosity & 2523.18 \\
\hline & & 3992.67 \\
\hline & & 3839.86 \\
\hline & & 957.74 \\
\hline & & 2449.44 \\
\hline & & 632.57 \\
\hline & & 6468.76 \\
\hline & & 5370.65 \\
\hline & & 491.31 \\
\hline & & 2613.80 \\
\hline & & 5859.29 \\
\hline & & 311.84 \\
\hline A8 & & 33762.67 \\
\hline A9 & Lightfield Central & 50667.10 \\
\hline A10 & Darkfield Central & 38478.53 \\
\hline & Alternating Central & 33782.21 \\
\hline & & 19551.11 \\
\hline & & 6613.58 \\
\hline
\end{tabular}




\begin{tabular}{|l|l|}
\hline A B & B9H2L3 \\
\hline
\end{tabular}

B9N2L3-B1

\begin{tabular}{|l|l|l|}
\hline Array Heading & Array Type & Value \\
\hline A1 & Total Volume & 522922.44 \\
\hline A2 & Hooped Edge & 9995.89 \\
\hline A3 & Lightfield Edge & 11564.33 \\
\hline & & 15353.21 \\
\hline A4 & Darkfield Edge & 38585.14 \\
\hline & & 9426.40 \\
\hline A5 & Alternating Edge & 14896.53 \\
\hline & & 25128.76 \\
\hline A6 & Porosity & 24187.90 \\
\hline & & 3480.93 \\
\hline & & 9470.82 \\
\hline & & 8995.50 \\
\hline & & 10329.06 \\
\hline & & 49369.08 \\
\hline & & 4927.31 \\
\hline & & 2851.91 \\
\hline & & 3230.38 \\
\hline A8 & & 53717.13 \\
\hline A10 & Lightfield Edge \\
\hline & Alternating Central & 16245.21 \\
\hline
\end{tabular}

B9N2L3-B2

\begin{tabular}{|c|c|c|}
\hline Array Heading & Array Type & Value \\
\hline A1 & Total Volume & 522922.44 \\
\hline A2 & Hooped Edge & 12304.96 \\
\hline \multirow[t]{3}{*}{ A3 } & Lightfield Edge & 7552.67 \\
\hline & & 5702.93 \\
\hline & & 5397.30 \\
\hline \multirow[t]{3}{*}{$\mathrm{A} 4$} & Darkfield Edge & 17807.98 \\
\hline & & 8569.94 \\
\hline & & 6291.08 \\
\hline \multirow[t]{12}{*}{ A6 } & Porosity & 338.50 \\
\hline & & 8778.72 \\
\hline & & 2795.93 \\
\hline & & 2038.98 \\
\hline & & 1188.74 \\
\hline & & 856.46 \\
\hline & & 1239.38 \\
\hline & & 381.14 \\
\hline & & 1848.85 \\
\hline & & 771.17 \\
\hline & & 208.78 \\
\hline & & 34.51 \\
\hline A7 & Hooped Central & 19169.97 \\
\hline A8 & Lightfield Central & 15792.10 \\
\hline \multirow[t]{2}{*}{ A9 } & Darkfield Central & 29976.12 \\
\hline & & 38725.72 \\
\hline \multirow[t]{2}{*}{ A10 } & Alternating Central & 30829.02 \\
\hline & & 15203.06 \\
\hline
\end{tabular}




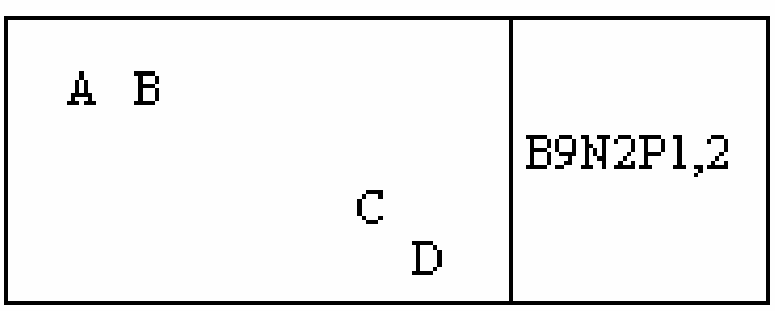

B9N2P1,2-A1

\begin{tabular}{|l|l|l|}
\hline Array Heading & Array Type & Value \\
\hline A1 & Total Volume & 770486.07 \\
\hline A3 & Lightfield Edge & 56494.91 \\
\hline & & 49095.89 \\
\hline & & 23193.56 \\
\hline & Darkfield Edge & 52950.42 \\
\hline A4 & & 19552.10 \\
\hline & Alternating Edge & 12067.59 \\
\hline A5 & & 10236.66 \\
\hline & Porosity & 1382.32 \\
\hline A6 & & 2229.02 \\
\hline & & 12904.59 \\
\hline & & 829.34 \\
\hline & & 6341.29 \\
\hline & & 422.33 \\
\hline & & 1896.01 \\
\hline & & 2592.66 \\
\hline & & 3882.61 \\
\hline & & 13061.53 \\
\hline & & 6775.10 \\
\hline & & 32033.09 \\
\hline & & 11816.24 \\
\hline A10 & & 27789.40 \\
\hline & & 31582.69 \\
\hline & & 47034.01 \\
\hline & & 72170.79 \\
\hline & &
\end{tabular}

B9N2P1,2-A2

\begin{tabular}{|l|l|l|}
\hline Array Heading & Array Type & Value \\
\hline A1 & Total Volume & 770486.07 \\
\hline A3 & Lightfield Edge & 31307.10 \\
\hline & & 32090.51 \\
\hline A4 & Darkfield Edge & 12881.63 \\
\hline A5 & Alternating Edge & 11672.06 \\
\hline & & 79116.86 \\
\hline A6 & Porosity & 12750.21 \\
\hline & & 9074.30 \\
\hline & & 5141.93 \\
\hline & & 45495.26 \\
\hline & & 8690.25 \\
\hline & & 3060.92 \\
\hline & & 2301.75 \\
\hline & & 8020.39 \\
\hline & & 23645.23 \\
\hline & & 15914.47 \\
\hline A7 & Hooped Central & 56500.02 \\
\hline A8 & Lightfield Central & 50277.38 \\
\hline & & 49978.82 \\
\hline A9 & Darkfield Central & 50966.38 \\
\hline
\end{tabular}




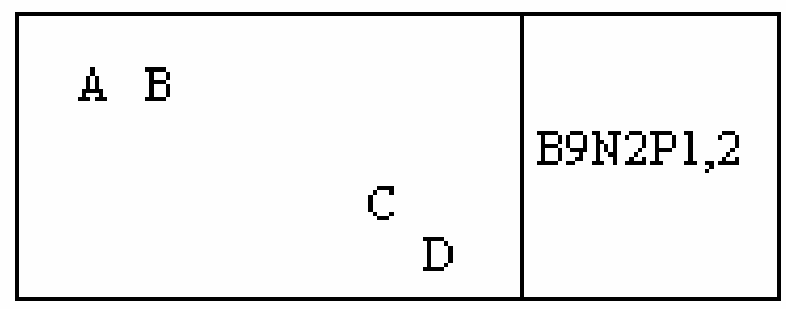

B9N2P1,2-B1

\begin{tabular}{|l|l|l|}
\hline Array Heading & Array Type & Value \\
\hline A1 & Total Volume & 772114.14 \\
\hline A2 & Hooped Edge & 23746.03 \\
\hline A4 & Darkfield Edge & 28979.83 \\
\hline & & 8450.83 \\
\hline A5 & Alternating Edge & 12017.83 \\
\hline A6 & Porosity & 2044.01 \\
\hline & & 1228.70 \\
\hline & & 816.58 \\
\hline & & 1162.36 \\
\hline & & 805.10 \\
\hline & & 2944.81 \\
\hline & & 2370.65 \\
\hline & & 2763.63 \\
\hline & & 1830.94 \\
\hline & & 2458.69 \\
\hline A7 & & 474.64 \\
\hline A8 & Hooped Central & 32038.20 \\
\hline A9 & Lightfield Central & 15585.29 \\
\hline A10 & Darkfield Central & 19557.21 \\
\hline & Alternating Central & 25274.58 \\
\hline & & 72895.51 \\
\hline & & 31108.05 \\
\hline & & 18199.63 \\
\hline & & 26023.54 \\
\hline & & 23374.74 \\
\hline & &
\end{tabular}

B9N2P1,2-B2

\begin{tabular}{|l|l|l|}
\hline Array Heading & Array Type & Value \\
\hline A1 & Total Volume & 772114.14 \\
\hline A3 & Lightfield Edge & 47983.29 \\
\hline & & 4059.96 \\
\hline & & 62578.47 \\
\hline & & 34168.97 \\
\hline A4 & Darkfield Edge & 51355.53 \\
\hline A5 & Alternating Edge & 13827.08 \\
\hline & & 9511.94 \\
\hline A6 & Porosity & 1518.34 \\
\hline & & 3374.79 \\
\hline & & 2064.43 \\
\hline & & 12040.80 \\
\hline & & 10001.89 \\
\hline & & 9893.44 \\
\hline & & 51213.90 \\
\hline & & 10457.39 \\
\hline A7 & Hooped Central & 42692.08 \\
\hline A9 & Darkfield Central & 57375.29 \\
\hline
\end{tabular}

*Note: From this point forward, Total Volume can again be considered a constant value. 


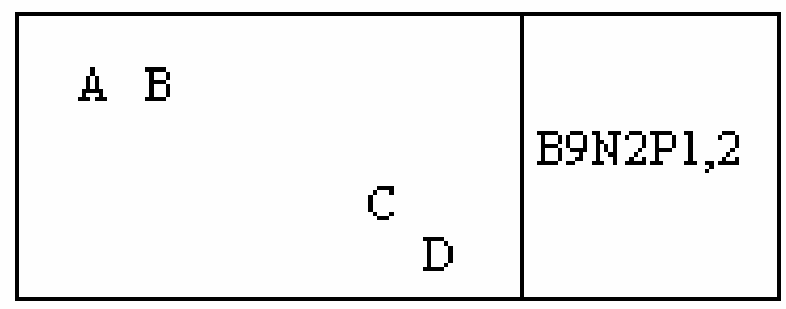

B9N2P1,2-C1

\begin{tabular}{|l|l|l|}
\hline Array Heading & Array Type & Value \\
\hline A2 & Hooped Edge & 26724.01 \\
\hline & & 25140.61 \\
\hline A3 & Lightfield Edge & 74186.73 \\
\hline & & 39113.14 \\
\hline A4 & Darkfield Edge & 3345.45 \\
\hline A5 & Alternating Edge & 49501.63 \\
\hline & & 61037.16 \\
\hline A6 & Porosity & 4783.40 \\
\hline & & 2147.36 \\
\hline & & 308.74 \\
\hline & & 654.54 \\
\hline & & 664.75 \\
\hline & & 4997.75 \\
\hline & & 672.41 \\
\hline & & 21918.92 \\
\hline & & 1996.81 \\
\hline & & 9791.36 \\
\hline & & 5688.02 \\
\hline & & 779.58 \\
\hline & & 3247.20 \\
\hline & & 214.35 \\
\hline A8 & Lightfield Central & 37266.89 \\
\hline & & 40401.81 \\
\hline & & 67211.31 \\
\hline A9 & Darkfield Central & 6342.57 \\
\hline A10 & Alternating Central & 12782.10 \\
\hline & & 13585.93 \\
\hline & &
\end{tabular}

B9N2P1,2-C2

\begin{tabular}{|l|l|l|}
\hline $\begin{array}{l}\text { *Array } \\
\text { Heading }\end{array}$ & Array Type & Value \\
\hline A2 & Hooped Edge & 86453.37 \\
\hline A3 & Lightfield Edge & 8452.93 \\
\hline & & 39249.66 \\
\hline & & 180051.85 \\
\hline A4 & Darkfield Edge & 22190.69 \\
\hline A6 & Porosity & 2959.96 \\
\hline & & 60128.71 \\
\hline & & 50101.31 \\
\hline & & 3774.15 \\
\hline & & 1920.25 \\
\hline & & 6874.62 \\
\hline A8 & & 146477.46 \\
\hline
\end{tabular}




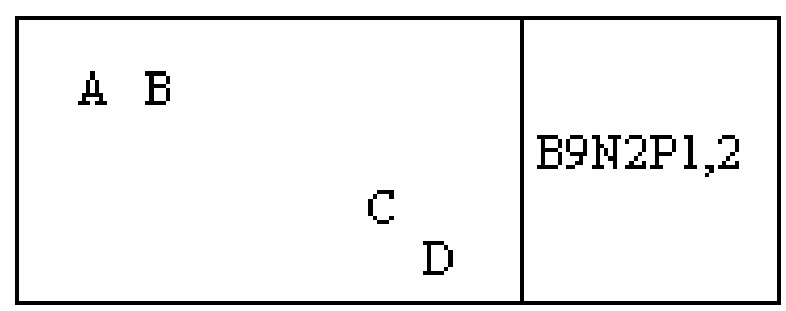

B9N2P1,2-D1

\begin{tabular}{|l|l|l|}
\hline Array Heading & Array Type & Value \\
\hline A3 & Lightfield Edge & 4193.93 \\
\hline & & 15586.56 \\
\hline & & 8548.62 \\
\hline A4 & Darkfield Edge & 9931.71 \\
\hline A5 & Alternating Edge & 98381.89 \\
\hline & & 40909.62 \\
\hline & & 45663.68 \\
\hline & Porosity & 9472.38 \\
\hline A6 & & 11876.21 \\
\hline & & 14734.25 \\
\hline & & 2176.71 \\
\hline & & 15188.48 \\
\hline & & 6896.31 \\
\hline & & 3728.22 \\
\hline & & 951.83 \\
\hline & & 447.85 \\
\hline & & 201.59 \\
\hline & & 635.41 \\
\hline & & 715.29 \\
\hline A8 & & 78449.56 \\
\hline A9 & Lightfield Central & 47506.10 \\
\hline A10 & Darkfield Central & 51629.30 \\
\hline & Alternating Central & 54250.58 \\
\hline & &
\end{tabular}

B9N2P1,2-D2

\begin{tabular}{|l|l|l|}
\hline Array Heading & Array Type & Value \\
\hline A2 & Hooped Edge & 7364.57 \\
\hline A3 & Lightfield Edge & 34171.52 \\
\hline & & 47478.03 \\
\hline & & 38401.18 \\
\hline A5 & Alternating Edge & 45658.58 \\
\hline & & 19989.74 \\
\hline A6 & Porosity & 15663.12 \\
\hline & & 6935.87 \\
\hline & & 11848.14 \\
\hline & & 31490.83 \\
\hline & & 21987.82 \\
\hline & & 1564.27 \\
\hline & & 837.00 \\
\hline & & 7617.21 \\
\hline & & 20974.75 \\
\hline & & 243.70 \\
\hline A7 & & 9001.57 \\
\hline A10 & Hooped Central & 22373.15 \\
\hline & & 119939.73 \\
\hline
\end{tabular}




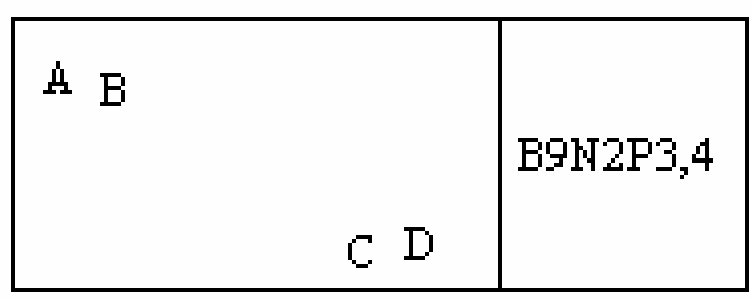

B9N2P3,4-A1

\begin{tabular}{|l|l|l|}
\hline Array Heading & Array Type & Value \\
\hline A2 & Hooped Edge & 78880.82 \\
\hline A3 & Lightfield Edge & 10776.37 \\
\hline A4 & Darkfield Edge & 34849.03 \\
\hline A5 & Alternating Edge & 9924.06 \\
\hline & & 17296.29 \\
\hline & & 13588.48 \\
\hline & & 18970.29 \\
\hline A6 & Porosity & 8012.74 \\
\hline & & 5111.31 \\
\hline & & 49463.72 \\
\hline & & 74234.76 \\
\hline & & 2500.79 \\
\hline & & 4202.86 \\
\hline & & 357.26 \\
\hline & & 14725.32 \\
\hline & & 654.54 \\
\hline & & 4699.19 \\
\hline & & 4445.28 \\
\hline & & 3397.76 \\
\hline A7 & & 27697.00 \\
\hline A10 & Hooped Central & 34877.00 \\
\hline & Alternating Central & 31960.37 \\
\hline & & 18078.42 \\
\hline & &
\end{tabular}

B9N2P3,4-A2

\begin{tabular}{|l|l|l|}
\hline Array Heading & Array Type & Value \\
\hline A3 & Lightfield Edge & 16484.81 \\
\hline A4 & Darkfield Edge & 9547.66 \\
\hline A5 & Alternating Edge & 27281.59 \\
\hline & & 53055.05 \\
\hline & & 18481.61 \\
\hline & & 15503.63 \\
\hline & & 803.98 \\
\hline A6 & Porosity & 3934.92 \\
\hline & & 2482.93 \\
\hline & & 3104.30 \\
\hline & & 5673.99 \\
\hline & & 1476.23 \\
\hline & & 4691.54 \\
\hline & & 769.38 \\
\hline & & 256.46 \\
\hline & & 990.11 \\
\hline & & 575.44 \\
\hline & & 281.91 \\
\hline & & 616.27 \\
\hline A9 & & 86177.77 \\
\hline & & 3413.15 \\
\hline A10 & & 26768.67 \\
\hline & Alternating Central & 30865.63 \\
\hline & & 29284.77 \\
\hline & & 31771.53 \\
\hline & & 28834.38 \\
\hline & &
\end{tabular}




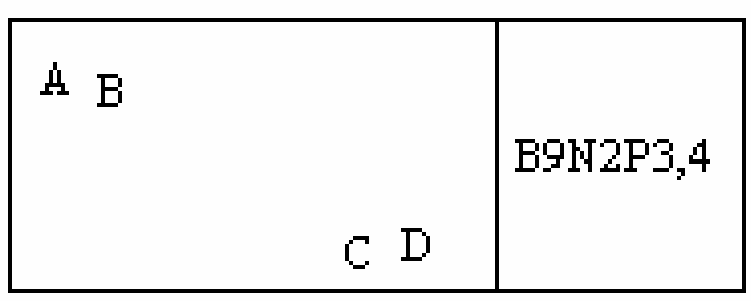

B9N2P3,4-B1

\begin{tabular}{|c|c|c|}
\hline Array Heading & Array Type & Value \\
\hline A3 & Lightfield Edge & 12724.69 \\
\hline \multirow[t]{2}{*}{ A4 } & Darkfield Edge & 36852.22 \\
\hline & & 23313.50 \\
\hline \multirow[t]{3}{*}{ A5 } & Alternating Edge & 12640.48 \\
\hline & & 8831.88 \\
\hline & & 17888.31 \\
\hline \multirow[t]{13}{*}{ A6 } & Porosity & 2486.76 \\
\hline & & 777.03 \\
\hline & & 942.90 \\
\hline & & 1209.57 \\
\hline & & 79.11 \\
\hline & & 1519.61 \\
\hline & & 4197.76 \\
\hline & & 2243.06 \\
\hline & & 913.55 \\
\hline & & 1813.07 \\
\hline & & 3140.02 \\
\hline & & 278.15 \\
\hline & & 1157.25 \\
\hline A7 & Hooped Central & 31622.25 \\
\hline A8 & Lightfield Central & 9192.96 \\
\hline A9 & Darkfield Central & 65602.38 \\
\hline \multirow[t]{4}{*}{ A10 } & Alternating Central & 30073.45 \\
\hline & & 64345.61 \\
\hline & & 21399.63 \\
\hline & & 18305.54 \\
\hline
\end{tabular}

B9N2P3,4-B2

\begin{tabular}{|l|l|l|}
\hline Array Heading & Array Type & Value \\
\hline A2 & Hooped Edge & 33929.10 \\
\hline A4 & Darkfield Edge & 32326.55 \\
\hline & & 15706.50 \\
\hline A5 & Alternating Edge & 28760.37 \\
\hline & & 33795.13 \\
\hline & Porosity & 13194.22 \\
\hline A6 & & 1073.04 \\
\hline & & 3353.10 \\
\hline & & 2647.28 \\
\hline & & 11483.22 \\
\hline & & 2884.84 \\
\hline & & 4903.34 \\
\hline & & 7595.51 \\
\hline & & 2192.02 \\
\hline & & 3769.05 \\
\hline & & 5778.93 \\
\hline & Lightfield Central & 4597.12 \\
\hline A8 & & 57127.25 \\
\hline & & 68946.17 \\
\hline & & 16955.62 \\
\hline & Alternating Central & 49456.97 \\
\hline A10
\end{tabular}




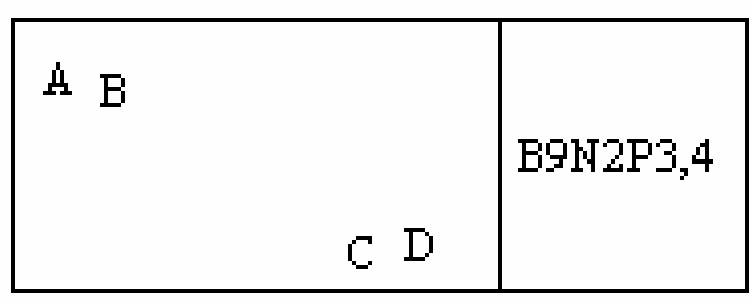

B9N2P3,4-C1

\begin{tabular}{|l|l|l|}
\hline Array Heading & Array Type & Value \\
\hline A2 & Hooped Edge & 26222.58 \\
\hline A3 & Lightfield Edge & 17367.74 \\
\hline & & 79405.22 \\
\hline & & 33448.08 \\
\hline & & 21696.91 \\
\hline A5 & Alternating Edge & 13503.00 \\
\hline A6 & Porosity & 68466.81 \\
\hline & & 4368.73 \\
\hline & & 5075.59 \\
\hline & & 12700.45 \\
\hline & & 1291.22 \\
\hline & & 71247.03 \\
\hline A8 & & 121415.96 \\
\hline A10 & Lightfield Central & 27670.24 \\
\hline & Alternating Central & 2767 \\
\hline
\end{tabular}

B0N2P3,4-C2

\begin{tabular}{|l|l|l|}
\hline Array Heading & Array Type & Value \\
\hline A5 & Alternating Edge & 72968.23 \\
\hline & & 49204.34 \\
\hline & & 22998.35 \\
\hline & & 24359.75 \\
\hline & & 2426.79 \\
\hline & & 50096.20 \\
\hline A6 & & 3291.86 \\
\hline & & 9739.77 \\
\hline & & 21195.48 \\
\hline & & 20845.88 \\
\hline & & 5731.40 \\
\hline & & 2311.96 \\
\hline & & 509.09 \\
\hline & & 2650.07 \\
\hline & & 12519.27 \\
\hline & & 2766.18 \\
\hline A8 & & 38944.72 \\
\hline A9 & Lightfield Central & 80697.72 \\
\hline A10 & Darkfield Central & 57939.25 \\
\hline & Alternating Central & 71916.88 \\
\hline & &
\end{tabular}




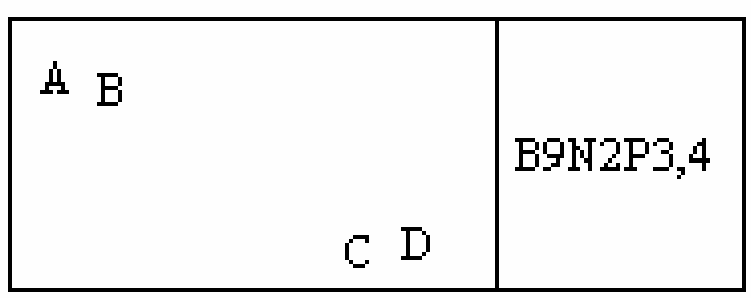

B9N2P3,4-D1

\begin{tabular}{|l|l|l|}
\hline Array Heading & Array Type & Value \\
\hline A3 & Lightfield Edge & 22657.68 \\
\hline & & 25367.72 \\
\hline & & 7502.37 \\
\hline & & 12933.94 \\
\hline A5 & Alternating Edge & 43924.61 \\
\hline & & 49115.03 \\
\hline A6 & Porosity & 5958.10 \\
\hline & & 2777.66 \\
\hline & & 10838.89 \\
\hline & & 40813.93 \\
\hline & & 9286.10 \\
\hline & & 2299.20 \\
\hline & & 4053.58 \\
\hline A8 & Lightfield Central & 110654.90 \\
\hline & & 177784.55 \\
\hline A10 & Alternating Central & 55768.92 \\
\hline
\end{tabular}

B9N2P3,4-D2

\begin{tabular}{|l|l|l|}
\hline Array Heading & Array Type & Value \\
\hline A2 & Hooped Edge & 56272.90 \\
\hline A3 & Lightfield Edge & 66389.62 \\
\hline A5 & Alternating Edge & 49416.14 \\
\hline & & 5733.96 \\
\hline & & 54347.55 \\
\hline & & 139739.36 \\
\hline A6 & Porosity & 12840.80 \\
\hline & & 8910.98 \\
\hline & & 8722.15 \\
\hline & & 11279.08 \\
\hline & & 14111.61 \\
\hline & & 4584.36 \\
\hline & & 1748.00 \\
\hline A10 & & 28519.23 \\
\hline & Alternating Central & 77644.46 \\
\hline & &
\end{tabular}




\begin{tabular}{|lll|l|}
\hline A $^{\mathrm{B}}$ & & & \\
& & & B9H2A 2,2 \\
& C & & \\
& & D & \\
\hline
\end{tabular}

B9N2A1,2-A1

\begin{tabular}{|l|l|l|}
\hline Array Heading & Array Type & Value \\
\hline A3 & Lightfield Edge & 5753.10 \\
\hline A4 & Darkfield Edge & 33254.14 \\
\hline A5 & Alternating Edge & 43327.48 \\
\hline & & 12182.43 \\
\hline & & 10926.93 \\
\hline A6 & Porosity & 23076.18 \\
\hline & & 4367.45 \\
\hline & & 10983.07 \\
\hline & & 83902.82 \\
\hline & & 2808.29 \\
\hline & & 6110.35 \\
\hline & & 18993.25 \\
\hline & & 2166.50 \\
\hline & & 42565.76 \\
\hline A9 & & 94298.96 \\
\hline A10 & Darkfield Central & 95813.47 \\
\hline & Alternating Central & \\
\hline
\end{tabular}

B9N2A1,2-A2

\begin{tabular}{|l|l|l|}
\hline Array Heading & Array Type & Value \\
\hline A4 & Darkfield Edge & 80885.28 \\
\hline A5 & Alternating Edge & 22891.17 \\
\hline & & 23427.05 \\
\hline & & 48210.40 \\
\hline & & 76332.82 \\
\hline & Porosity & 13990.39 \\
\hline A6 & & 6544.16 \\
\hline & & 7413.06 \\
\hline & & 29816.83 \\
\hline & & 33791.30 \\
\hline & & 12782.10 \\
\hline & & 1268.26 \\
\hline & & 11432.19 \\
\hline & & 4025.51 \\
\hline & & 28003.76 \\
\hline & & 25518.28 \\
\hline & & 24751.45 \\
\hline & & 27968.03 \\
\hline A9 & & 13287.37 \\
\hline & & 63192.18 \\
\hline A10 & Alternating Central & 98208.36 \\
\hline
\end{tabular}




\begin{tabular}{|lll|l|}
\hline A $^{\mathrm{B}}$ & & & \\
& & & B9H2A 2,2 \\
& C & & \\
& & D & \\
\hline
\end{tabular}

B9N2A1,2-B1

\begin{tabular}{|l|l|l|}
\hline Array Heading & Array Type & Value \\
\hline A3 & Lightfield Edge & 154292.43 \\
\hline A4 & Darkfield Edge & 41038.49 \\
\hline & & 89630.39 \\
\hline A5 & Alternating Edge & 30527.51 \\
\hline & & 10061.86 \\
\hline & & 22269.80 \\
\hline A6 & Porosity & 3114.51 \\
\hline & & 31717.94 \\
\hline & & 26509.66 \\
\hline & & 93698.01 \\
\hline & & 118199.38 \\
\hline & & 347.05 \\
\hline A8 & Lightfield Central & 86726.41 \\
\hline & & 52374.99 \\
\hline A10 & Alternating Central & 3313.55 \\
\hline
\end{tabular}

B9N2A1,2-B2

\begin{tabular}{|l|l|l|}
\hline Array Heading & Array Type & Value \\
\hline A3 & Lightfield Edge & 18753.38 \\
\hline & & 31730.20 \\
\hline & & 20621.32 \\
\hline & & 38205.96 \\
\hline A4 & Darkfield Edge & 12717.03 \\
\hline & & 36741.21 \\
\hline A5 & Alternating Edge & 73445.43 \\
\hline A6 & Porosity & 15131.06 \\
\hline & & 12053.56 \\
\hline & & 6753.41 \\
\hline & & 17913.83 \\
\hline & & 2568.41 \\
\hline & & 95597.84 \\
\hline & & 19335.20 \\
\hline A8 & & 70555.48 \\
\hline A9 & Lightfield Central & \\
\hline & Darkfield Central & 142196.77 \\
\hline
\end{tabular}




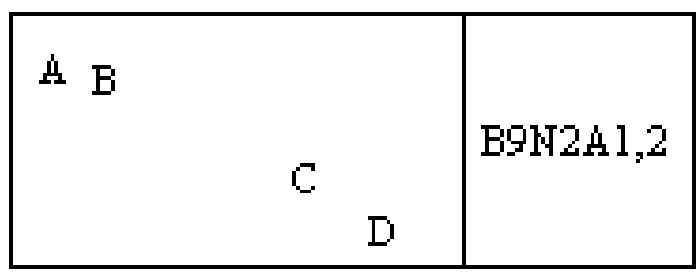

B9N2A1,2-C1

\begin{tabular}{|l|l|l|}
\hline Array Heading & Array Type & Value \\
\hline A2 & Hooped Edge & 41237.53 \\
\hline A3 & Lightfield Edge & 17921.49 \\
\hline A5 & Alternating Edge & 44706.74 \\
\hline & & 9703.32 \\
\hline & & 12007.52 \\
\hline & & 41237.53 \\
\hline A6 & Porosity & 7487.06 \\
\hline & & 5971.28 \\
\hline & & 3964.26 \\
\hline & & 2829.98 \\
\hline & & 155.66 \\
\hline & & 1190.43 \\
\hline & & 103489.37 \\
\hline & & 31000.88 \\
\hline A9 & Darkfield Central & 40782.03 \\
\hline A10 & Alternating Central & 35252.22 \\
\hline
\end{tabular}

B9N2A1,2-C2

\begin{tabular}{|c|c|c|}
\hline Array Heading & Array Type & Value \\
\hline $\mathrm{A} 2$ & Hooped Edge & 49302.59 \\
\hline \multirow[t]{3}{*}{$\mathrm{A} 4$} & Darkfield Edge & 7347.99 \\
\hline & & 19219.99 \\
\hline & & 14452.28 \\
\hline \multirow[t]{4}{*}{ A5 } & Alternating Edge & 6642.41 \\
\hline & & 2641.14 \\
\hline & & 25839.81 \\
\hline & & 8429.96 \\
\hline \multirow[t]{12}{*}{$\mathrm{A} 6$} & Porosity & 10604.12 \\
\hline & & 15455.14 \\
\hline & & 1376.71 \\
\hline & & 123.76 \\
\hline & & 3086.44 \\
\hline & & 2241.78 \\
\hline & & 1446.89 \\
\hline & & 2509.72 \\
\hline & & 696.65 \\
\hline & & 2480.38 \\
\hline & & 3271.44 \\
\hline & & 19612.07 \\
\hline \multirow[t]{3}{*}{ A9 } & Darkfield Central & 6259.63 \\
\hline & & 9725.02 \\
\hline & & 35498.47 \\
\hline \multirow[t]{4}{*}{ A10 } & Alternating Central & 30054.15 \\
\hline & & 22596.43 \\
\hline & & 45265.59 \\
\hline & & 36762.90 \\
\hline
\end{tabular}




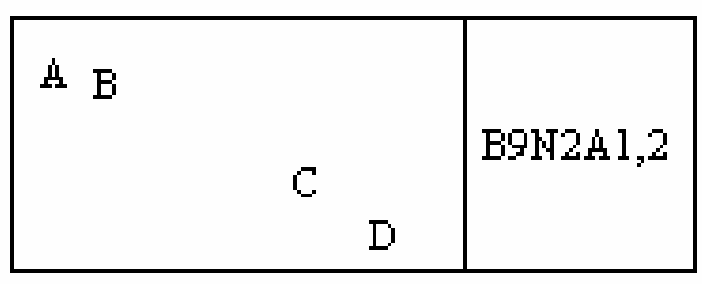

B9N2A1,2-D1

\begin{tabular}{|l|l|l|}
\hline Array Heading & Array Type & Value \\
\hline A3 & Lightfield Edge & 53703.21 \\
\hline A4 & Darkfield Edge & 21907.44 \\
\hline & & 30472.65 \\
\hline A5 & Alternating Edge & 23613.34 \\
\hline & & 16486.08 \\
\hline A6 & Porosity & 19761.35 \\
\hline & & 12466.95 \\
\hline & & 6458.68 \\
\hline & & 839.55 \\
\hline & & 18842.70 \\
\hline & & 230.94 \\
\hline & & 244.98 \\
\hline & & 36124.95 \\
\hline & & 8034.43 \\
\hline A7 & Hooped Central & 53444.20 \\
\hline A8 & Lightfield Central & 66366.66 \\
\hline & & 29071.70 \\
\hline A10 & Alternating Central & 10160.10 \\
\hline & & 7564.89 \\
\hline & & 66773.67 \\
\hline
\end{tabular}

B9N2A1,2-D2

\begin{tabular}{|c|c|c|}
\hline Array Heading & Array Type & Value \\
\hline $\mathrm{A} 2$ & Hooped Edge & 25496.59 \\
\hline A4 & Darkfield Edge & 44998.93 \\
\hline \multirow[t]{4}{*}{ A5 } & Alternating Edge & 33076.79 \\
\hline & & 8061.22 \\
\hline & & 20649.39 \\
\hline & & 8650.70 \\
\hline \multirow[t]{14}{*}{ A6 } & Porosity & 21912.54 \\
\hline & & 3845.60 \\
\hline & & 1115.15 \\
\hline & & 4034.44 \\
\hline & & 1982.77 \\
\hline & & 4366.18 \\
\hline & & 960.76 \\
\hline & & 1910.04 \\
\hline & & 692.82 \\
\hline & & 5138.10 \\
\hline & & 2977.98 \\
\hline & & 956.94 \\
\hline & & 2622.00 \\
\hline & & 999.04 \\
\hline A7 & Hooped Central & 8626.45 \\
\hline A8 & Lightfield Central & 16017.82 \\
\hline A9 & Darkfield Central & 22203.45 \\
\hline \multirow[t]{3}{*}{ A10 } & Alternating Central & 31711.56 \\
\hline & & 25922.74 \\
\hline & & 14642.39 \\
\hline
\end{tabular}




\section{Appendix B: Calculations}

\begin{tabular}{|l|l|l|l|l|l|l|}
\hline $\begin{array}{l}\text { Array } \\
\text { Heading }\end{array}$ & Array Type & B9N2A1 & B9N2A2 & B9N2A3 & B9N2M1 & B9N2M2 \\
\hline P26 & $\begin{array}{l}\text { Density of } \\
\text { Porosity }\end{array}$ & 12.46 & 12.46 & 23.46 & 24.61 & 24.61 \\
\hline P25 & $\begin{array}{l}\text { Density of } \\
\text { Hooped }\end{array}$ & .81 & .81 & 1.23 & .79 & .79 \\
\hline P23 & $\begin{array}{l}\text { Density of } \\
\text { Lightfield }\end{array}$ & 2.27 & 2.27 & 3.09 & 2.12 & 2.12 \\
\hline P22 & $\begin{array}{l}\text { Density of } \\
\text { Darkfield }\end{array}$ & 3.40 & 3.40 & 5.56 & 5.29 & 5.29 \\
\hline P21 & $\begin{array}{l}\text { Density of } \\
\text { Alternating }\end{array}$ & 6.63 & 6.63 & 14.20 & 14.82 & 14.82 \\
\hline P5 & $\begin{array}{l}\text { Volume of } \\
\text { Central }\end{array}$ & 1369007.03 & 1369007.03 & 377843.01 & 1168373.82 & 1168373.82 \\
\hline P6 & $\begin{array}{l}\text { Volume of } \\
\text { Edge }\end{array}$ & 1509043.68 & 1509043.68 & 467898.41 & 747100.09 & 747100.09 \\
\hline P7 & VF Total & .54 & .39 & .52 & .45 & .46 \\
\hline P8 & VF Hooped & 0.0 & .06 & .03 & .05 & 0.0 \\
\hline P9 & VF Light & .16 & .06 & .05 & .05 & .03 \\
\hline P10 & VF Dark & .20 & .08 & .12 & .13 & .14 \\
\hline P11 & $\begin{array}{l}\text { VF } \\
\text { Alternating }\end{array}$ & .19 & .19 & .33 & .22 & .30 \\
\hline P12 & VF Porosity & .28 & .12 & .24 & .11 & .13 \\
\hline P13 & $\begin{array}{l}\text { Average } \\
\text { Diameter } \\
\text { Hooped }\end{array}$ & 0 & 182.83 & 160.81 & 213.09 & 0 \\
\hline P14 & $\begin{array}{l}\text { Average } \\
\text { Diameter } \\
\text { Lightfield }\end{array}$ & 296.75 & 208.63 & 175.72 & 173.07 & 184.89 \\
\hline P15 & $\begin{array}{l}\text { Average } \\
\text { Diameter } \\
\text { Darkfield }\end{array}$ & 296.43 & 161.83 & 147.91 & 297.75 & 177.09 \\
\hline $\begin{array}{l}\text { Diameter } \\
\text { Alternating }\end{array}$ & 255.95 & 186.92 & 171.58 & 173.84 & 174.28 \\
\hline
\end{tabular}




\begin{tabular}{|l|l|l|l|l|l|l|}
\hline $\begin{array}{l}\text { Array } \\
\text { Heading }\end{array}$ & Array Type & B9N2M3 & B9N2L1 & B9N2L2 & B9N2L3 & B9N2P1 \\
\hline P26 & Density of Porosity & 18.54 & 18.72 & 18.72 & 21.97 & 13.28 \\
\hline P25 & Density of Hooped & .46 & .25 & .25 & 1.43 & 1.46 \\
\hline P23 & Density of Lightfield & 6.49 & 2.53 & 2.53 & 6.69 & 4.70 \\
\hline P22 & Density of Darkfield & .93 & 4.05 & 4.05 & 4.78 & 2.27 \\
\hline P21 & Density of Alternating & 8.81 & 9.11 & 9.11 & 7.16 & 5.18 \\
\hline P5 & Volume of Central & 468763.75 & 1029180.33 & 1029180.33 & 580600.26 & 1469455.90 \\
\hline P6 & Volume of Edge & 291554.61 & 819502.98 & 819502.98 & 337615.13 & 1738930.17 \\
\hline P7 & VF Total & .35 & .43 & .46 & .44 & .47 \\
\hline P8 & VF Hooped & .01 & 0 & .03 & .02 & .05 \\
\hline P9 & VF Light & .15 & .06 & .16 & .16 & .17 \\
\hline P10 & VF Dark & .03 & .08 & .10 & .10 & .09 \\
\hline P11 & VF Alternating & .16 & .23 & .23 & .16 & .17 \\
\hline P12 & VF Porosity & .11 & .26 & .18 & .12 & .11 \\
\hline P13 & $\begin{array}{l}\text { Average Diameter } \\
\text { Hooped }\end{array}$ & 167.99 & 0.0 & 260.88 & 156.23 & 234.44 \\
\hline P14 & $\begin{array}{l}\text { Average Diameter } \\
\text { Lightfield }\end{array}$ & 199.64 & 269.35 & 224.02 & 234.55 & 215.38 \\
\hline P15 & $\begin{array}{l}\text { Average Diameter } \\
\text { Darkfield }\end{array}$ & 216.16 & 193.65 & 180.41 & 223.42 & 227.61 \\
\hline P16 & $\begin{array}{l}\text { Average Diameter } \\
\text { Alternating }\end{array}$ & 166.67 & 221.97 & 213.22 & 169.62 & 204.45 \\
\hline
\end{tabular}




\begin{tabular}{|l|l|l|l|l|}
\hline $\begin{array}{l}\text { Array } \\
\text { Heading }\end{array}$ & Array Type & B9N2P2 & B9N2P3 & B9N2P4 \\
\hline P26 & Density of Porosity & 13.28 & 12.95 & 12.95 \\
\hline P25 & Density of Hooped & 1.46 & .97 & .97 \\
\hline P23 & Density of Lightfield & 4.70 & 3.89 & 3.89 \\
\hline P22 & Density of Darkfield & 2.27 & 1.62 & 1.62 \\
\hline P21 & $\begin{array}{l}\text { Density of } \\
\text { Alternating }\end{array}$ & 5.18 & 7.61 & 7.61 \\
\hline P5 & Volume of Central & 1469455.90 & 1766737.44 & 1766737.44 \\
\hline P6 & Volume of Edge & 1738930.17 & 1549737.67 & 1549737.67 \\
\hline P7 & VF Total & .57 & .49 & .57 \\
\hline P8 & VF Hooped & .05 & .06 & .03 \\
\hline P9 & VF Light & .28 & .11 & .24 \\
\hline P10 & VF Dark & .03 & .10 & .03 \\
\hline P11 & VF Alternating & .21 & .23 & .28 \\
\hline P12 & VF Porosity & .12 & .09 & .11 \\
\hline P13 & $\begin{array}{l}\text { Average Diameter } \\
\text { Hooped }\end{array}$ & 107.76 & 194.22 & 0 \\
\hline P14 & $\begin{array}{l}\text { Average Diameter } \\
\text { Lightfield }\end{array}$ & 297.01 & 246.26 & 366.75 \\
\hline P15 & $\begin{array}{l}\text { Average Diameter } \\
\text { Darkfield }\end{array}$ & 167.90 & 228.73 & 320.54 \\
\hline P16 & $\begin{array}{l}\text { Average Diameter } \\
\text { Alternating }\end{array}$ & 222.98 & 198.73 & 268.56 \\
\hline
\end{tabular}




\section{Literature Cited}

1. Alto A., Pope M.H. (1979) On the fracture toughness of equine metacarpi. J. Biomechanics 12, 415-421.

2. Arrdizzoni A., 2001. Osteocyte lacunar size - lamellar thickness relationships in human secondary osteons. Bone 28, No. 2, 215-219.

3. Ascenzi A., Baschieri P., Benvenuti A., 1990. The bending properties of single osteons. Journal of Biomechanics, 23, No. 8, 763-771.

4. Ascenzi A., Benvenuti A., 1977. Evidence of a state of initial stress in osteonic lamellae. Journal of Biomechanics, 10, 447-453.

5. Ascenzi A., Benvenuti A., Bonucci E., 1982. The tensile properties of single osteonic lamellae: Technical problems and preliminary results. Journal of Biomechanics, 15, No. 1, 29-37.

6. Ascenzi A., Bonucci E., 1967. The tensile properties of single osteons. Anat. Rec. $158,375-385$.

7. Ascenzi A. Bonucci E., 1968. The compressive properties of single osteons. Anat. Rec., 161, 377-392.

8. Ascenzi A., Bonucci E., Bocciarelli D.S., 1965. An electron microscope study of osteon calcification. Journal of Ultrastructure Research 12, No. 3, 287-303.

9. Ascenzi A., Bonucci E., Simkin A., 1973. An approach to the mechanical properties of single osteonic lamellae. Journal of Biomechanics 6, No. 3, 227235.

10. Ascenzi M.G., Ascenzi A., Benvenuti A, Burghammer M., Panzavolta S., Bigi A., 2003. Structural differences between "dark" and "bright" isolated human osteonic lamellae. Journal of Structural Biology 141, 22-33.

11. Ascenzi M.G., Comite M.D., Mitov P., Kabo J.M., 2007. Hysteretic pinching of human secondary osteons subjected to torsion. Journal of Biomechanics 40, 2619-2627.

12. Ascenzi M.G., Gill J., Lomovtsev A, 2008. Orientation of collagen at the osteocyte lacunae in human secondary osteons. Journal of Biomechanics 41, 3426-3435. 
13. Barth, R.W., Williams, J.L. and Kaplan, F.S. (1993) Osteon morphometry in females and femoral neck fractures. Clin. Orthop. Rel. Res. (283), 178-186.

14. Behiri, J.C., Bonfield,. W., 1989. Orientation dependence of the fracture mechanics of cortical bone. Journal of Biomechanics 22, 863-872.

15. Boyce TM, Fybrie DP, Radin EL, Schaffler MB. Damage and strain mode associations in human compact bone bending fatigue. J Orthopaedic Res 1998;16:322-9

16. Britz H.M., Thomas C.D.L., Clement J.G., Cooper D.M.L., 2009. The relation of femoral osteon geometry to age, sex, height and weight. Bone 45, 77-83.

17. Corondan, G. and Haworth, W.L. (1986) A fractographic study of human long bone. J. Biomechanics 19, 207-218.

18. Currey, J.D., 1964. Three analogies to explain the mechanical properties of bone. Bioheology 2, 1-10.

19. Giraud-Guille, M.M., 1988. Twisted plywood architecture of collagen fibrils in human compact bone osteons. Calcif. Tissue Int. 42, 167-180

20. Giraud-Guille, M.M., Besseau, L., Martin, R., 2003. Liquid crystalline assemblies of collagen in bone and in vitro systems. Journal of Biomechanics 36, 1571-1579.

21. Hofmann R., Heyroth F., Meinhard H., Franzel W., Raum K., 2006. Assessment of composition and anisotropic elastic properties of secondary osteon lamellae. Journal of Biomechanics 39, 2282-2294.

22. Lee T.C., O'Brien F.J., Taylor D., 2000. The nature of fatigue damage in bone. International Journal of Fatigue 22, 847-853.

23. Marotti, G., 1996. The structure of bone tissues and the cellular control of their deposition. Ital. J. Anat. Embryol. 101, 25-79

24. Martin R.B. 2000. Does osteocyte formation cause the nonlinear refilling of osteons. Bone 26, No 1 71-78.

25. Martin R.B., Burr D.B., Sharkey N.A.. Skeletal Tissue Mechanics. SpringerVerlag New York, Inc., 2004.

26. Martin RB, Gibson VA, Stover SM, Gibeling JC, Griffin LV. Osteon structure in the equine third metacarpus. Bone 1996;19:165-71. 
27. McCarthy, I.D., Yang, L, 1992. A distributed model of exchange processes within the osteon. Journal of Biomechanics, Vol. 25, No. 4; 441-450.

28. Najafi A.R., Arshi A.R., Eslami M.R., Fariborz S., Moeinzadeh M.H., 2007. Micromechanics fracture in osteonal cortical bone: A study of the interactions between microcrack propagation, microstructure and the material properties. Journal of Biomechanics 40, 2788-2795.

29. Nalla R.K., Kruzic J.J., Kinney J.H., Ritchie R.O., 2005. Mechanistic aspects of fracture and R-curve behavior in human cortical bone. Biomaterials 26, 217-231.

30. Norman T.L., Nivargikar S.V., Burr D.B., 1996. Resistance to crack growth in human cortical bone is greater in shear than in tension. Journal of Biomechanics, 29, No. 8, 1023-1031.

31. Norman T.L., Wang, Z., 1997. Microdamage of human cortical bone: incidence and morphology in long bones. Bone 20, 375-379.

32. O'Brien, F.J., Taylor, D., Lee, T.C., 2005. The effect of bone microstructure on the initiation and growth of microcracks. Journal of Orthopaedic Research 23, 475-480.

33. van Oers, R.F.M., Ruimerman R., van Rietbergen B., Hilbers P.A.J., Huiskes R., 2008. Relating osteon diameter to strain. Bone 43, 476-482.

34. Prendergast, P.J., Huiskes, R., 1996. Microdamage and osteocyte-lacuna strain in bone: a microstructural finite element analysis. Journal of Biomechanical Engineering 118, 240-246.

35. Rho J.Y., Tsui T.Y., and Pharr G.M. Elastic properties of osteon and trabecular bone measured by nanoindentation. $11^{\text {th }}$ Conference of the ESB, 7/8-11/1998, Toulouse, France.

36. Rodan GA, Rodan S. The cells of bone. In: riggs BL, Melton III LJ, editors. Osteoporosis: etiology, diagnosis and management. $2^{\text {nd }}$ ed. Philadelphia: Lippincott-Raven, 1995.

37. Schaffler, M.B., Jepsen K. J., 2000. Fatigue and repair in bone. International Journal of Fatigue 22, 839-846.

38. Schaffler, M.B., Pitchford, W.C., Choi, K., Riddle, J.M., 1994. Examination of compact bone Microdamage using back-scattered electron microscopy. Bone 15 (5), 483-488. 
39. Skedros J.G., Mendenhall S.D., Kiser C.J., Winet H., 2009. Interpreting cortical bone adaptation and load history by quantifying osteon morphotypes in circularly polarized light images. Bone 44, 392-403.

40. Ural A., Vashishth D., 2007. Anisotropy of age-related toughness loss in human cortical bone: A finite element study. Journal of Biomechanics 40, 1606-1614.

41. Ziv, V., Wagner, H.D., Weiner, S., 1996. Microstructure-microhardness relations in parallel-fibered and lamellar bone. Bone 18, 417-428.

42. Zysset P.K., Guo X.E., Hoffler C.E., Moore K.E., Goldstein S.A., 1999. Elastic modulus and hardness of cortical and trabecular bone lamellae measured by nanoindentation in the human femur. Journal of Biomechanics 32, 1005-1012. 